Florida International University FIU Digital Commons

\title{
Airborne Laser Quantification of Florida Shoreline and Beach Volume Change Caused by Hurricanes
}

William Robertson

Florida International University, wrober01@fiu.edu

DOI: $10.25148 /$ etd.FI08081541

Follow this and additional works at: https://digitalcommons.fiu.edu/etd

\section{Recommended Citation}

Robertson, William, "Airborne Laser Quantification of Florida Shoreline and Beach Volume Change Caused by Hurricanes" (2007). FIU Electronic Theses and Dissertations. 35.

https://digitalcommons.fiu.edu/etd/35 


\section{FLORIDA INTERNATIONAL UNIVERSITY}

Miami, Florida

\section{AIRBORNE LASER QUANTIFICATION OF FLORIDA SHORELINE AND BEACH VOLUME CHANGE CAUSED BY HURRICANES}

A dissertation submitted in partial fulfillment of the requirements for the degree of DOCTOR OF PHILOSOPHY in GEOSCIENCES

by

William Robertson V 
To: Interim Dean Mark Szuchman

College of Arts and Sciences

This dissertation, written by William Robertson V, and entitled Airborne Laser Quantification of Florida Shoreline and Beach Volume Change Caused by Hurricanes, having been approved in respect to style and intellectual content, is referred to you for judgment.

We have read this dissertation and recommend that it be approved.

\section{Grenville Draper}

Stephen Leatherman

Keqi Zhang, Co-Major Professor

Dean Whitman, Co-Major Professor

Date of Defense: March 8, 2007

The dissertation of William Robertson V is approved.

Interim Dean Mark Szuchman

College of Arts and Sciences

Dean George Walker

University Graduate School

Florida International University, 2007 
(C) Copyright 2007 by William Robertson V

All rights reserved. 


\section{DEDICATION}

I dedicate this dissertation to my dad. His persistent and not-so-subtle method of persuasion has been the primary motivator to get me to where I am today. 


\section{ACKNOWLEDGMENTS}

I would like to thank my committee members Dean Whitman, Keqi Zhang, Stephen Leatherman, and Grenville Draper. Each committee member spent a significant amount of time trying to shape me as a scientist, and it will be my goal to proudly represent them in the years to come. I would also like to thank Charlie Finkl, Abby Sallenger, Jeff Lillycrop, Ramesh Shrestha, Michael Sartori, and Bud Howard. Dr. Fink1 provided many helpful reviews and mapped the geology used in Chapter 4. Dr. Sallenger provided an extensive review of Chapter 3, and his team at USGS provided the EAARL data. Dr. Lillycrop and his team at the U.S. Army Corps of Engineers collected and provided the CHARTS airborne laser data. Dr. Shrestha and Mr. Sartori at the University

of Florida provided the ALSM and GPS groundtruth data. Mr. Howard of Palm Beach County provided the LADS data.

I would also like to thank my wife. Carolyn has endured many years in south Florida, most of which were made difficult due to my lengthy education process. I look forward to making that up to her for the rest of my life. 


\title{
ABSTRACT OF THE DISSERTATION \\ AIRBORNE LASER QUANTIFICATION OF FLORIDA SHORELINE AND BEACH VOLUME CHANGE CAUSED BY HURRICANES
}

\author{
by \\ William Robertson V \\ Florida International University, 2007 \\ Miami, Florida

\section{Professor Dean Whitman, Co-Major Professor \\ Professor Keqi Zhang, Co-Major Professor}

This dissertation combines three separate studies that measure coastal change using airborne laser data. The initial study develops a method for measuring subaerial and subaqueous volume change incrementally alongshore, and compares those measurements to shoreline change in order to quantify their relationship in Palm Beach County, Florida. A poor correlation $\left(\mathrm{R}^{2}=0.39\right)$ was found between shoreline and volume change before the hurricane season in the northern section of Palm Beach County because of beach nourishment and inlet dynamics. However, a relatively high $\mathrm{R}^{2}$ value of 0.78 in the southern section of Palm Beach County was found due to little disturbance from tidal inlets and coastal engineering projects. The shoreline and volume change caused by the 2004 hurricane season was poorly correlated with $\mathrm{R}^{2}$ values of 0.02 and 0.42 for the north and south sections, respectively. The second study uses airborne laser data to investigate if there is a significant relationship between shoreline migration before and after Hurricane Ivan near Panama City, Florida. In addition, the relationship between shoreline change and subaerial volume was quantified and a new method for quantifying 
subaqueous sediment change was developed. No significant spatial relationship was found between shoreline migration before and after the hurricane. Utilization of a single coefficient to represent all relationships between shoreline and subaerial volume change was found to be problematic due to the spatial variability in the linear relationship. Differences in bathymetric data show only a small portion of sediment was transported beyond the active zone and most sediment remained within the active zone despite the occurrence of a hurricane. The third study uses airborne laser bathymetry to measure the offshore limit of change, and compares that location with calculated depth of closures and subaqueous geomorphology. There appears to be strong geologic control of the depth of closure in Broward and Miami-Dade Counties. North of Hillsboro Inlet, hydrodynamics control the geomorphology which in turn indicates the location of the depth of closure. 


\section{TABLE OF CONTENTS}

CHAPTER

PAGE

1. Introduction 1

2. Shoreline and Beach Volume Change Before and After the 2004 Hurricane Season, Palm Beach County, Florida.........................................................6

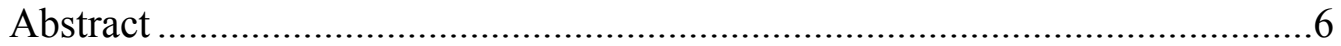

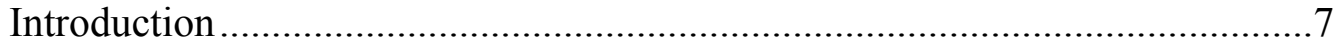

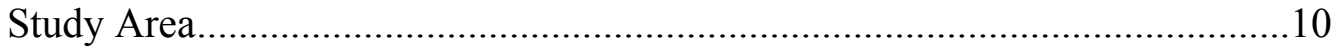

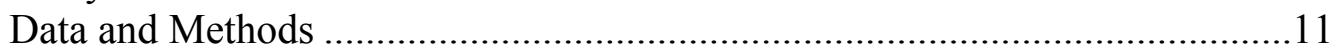

Airborne laser data ......................................................................... 11

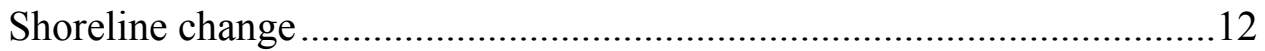

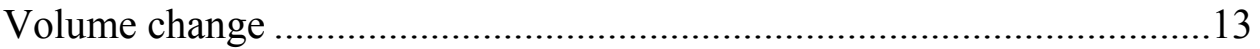

Beach Change Before and After 2004 Hurricane Season .................................14

Relationship Between Shoreline and Volume Change .................................16

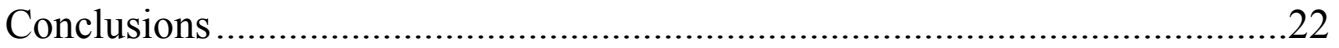

3. Hurricane-Induced Beach Change Derived from Airborne Laser Measurements near Panama City, Florida...................................................................................2 24

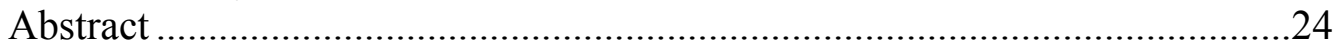

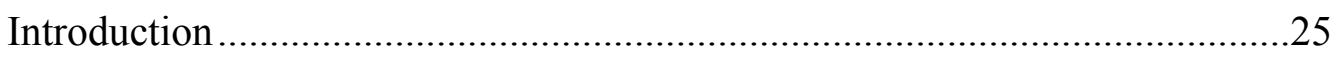

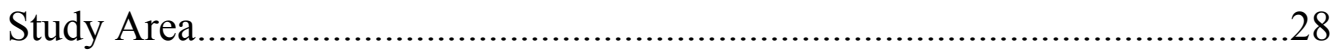

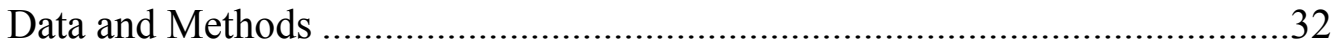

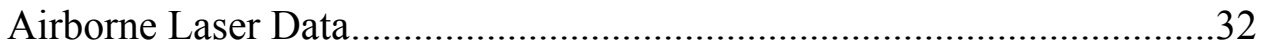

Shoreline and Beach Width Change .......................................................35

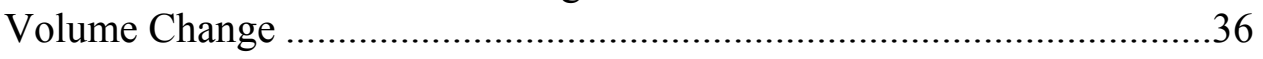

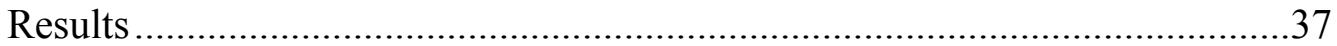

Shoreline Migration, Beach Width Change, and Subaerial Beach

Volume Change ............................................................................39

Relationship Between Beach Width and Subaerial Volume.....................42

Active Zone Sediment Movement ......................................................43

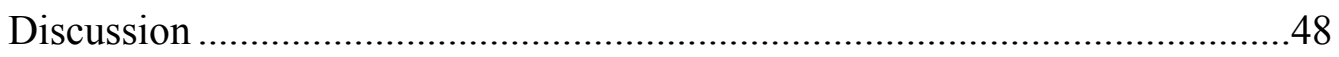

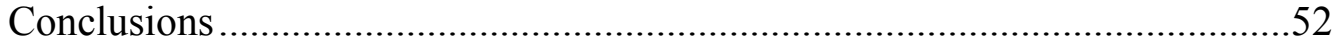

4. Hurricane-Induced Depth of Closure Derived from Airborne Laser

Bathymetry, Southeast Florida......................................................................54

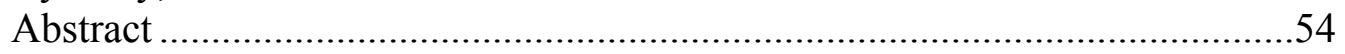

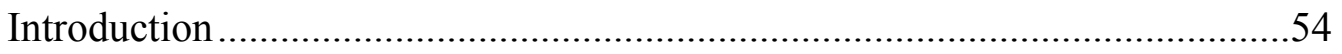

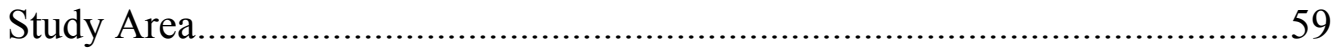

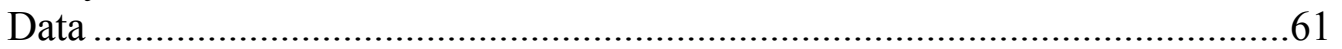

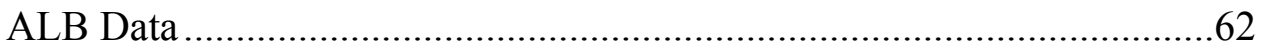

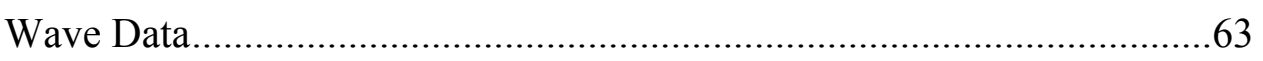

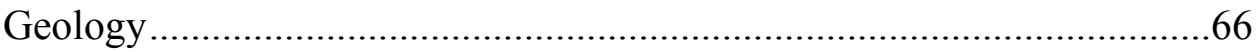

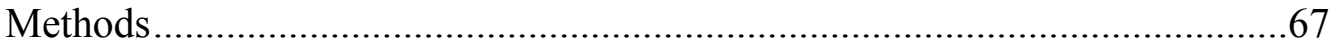


The LOC Contour ..........................................................................6 67

Metric Mapping and DOC Extraction.................................................69

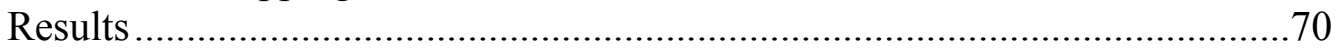

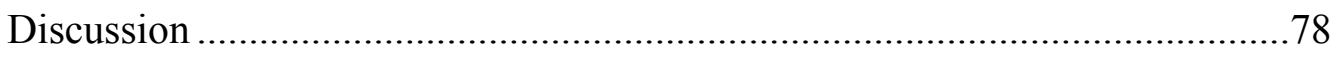

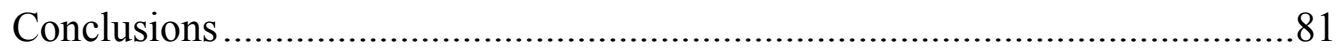

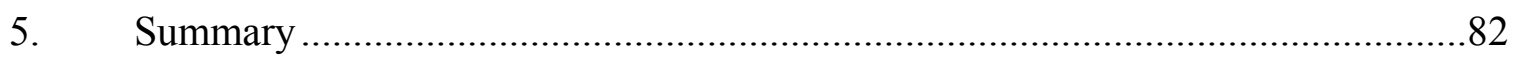

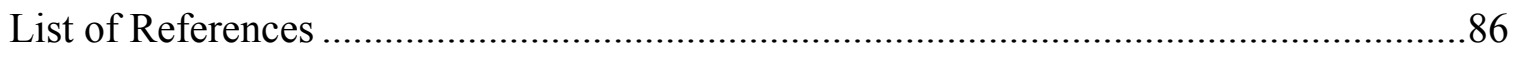

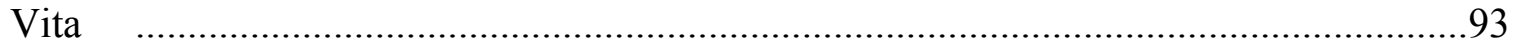




\section{LIST OF TABLES}

TABLE

PAGE

2-1. Shoreline and volume change before and after the 2004 hurricane season. 13

3-1. Panama City shoreline (S), beach width (W), and subaerial volume (V) change for four periods in 2004. First numeric column represents mean change, SD represents standard deviation.

3-2. Correlation coefficients for changes in shoreline position (S), beach width (W), and subaerial volume $(\mathrm{V})$ for respective time intervals

3-3. Active zone volume change for all bins (top) and excluding bins containing borrow pits (bottom) between May and December, 2004.

4-1. Coefficients used to calculate the DOC. A is from Hallermeier (1977), B and C are from Birkemeier (1985), D and E are from Nicholls (1998). A, B, D and E use Equation 4-1. C uses Equation 4-2

4-2. Measured DOC values split by inlets, from north to south. Distance along coastline is the location of data on Figures 4-3, 4-5, and 4-6. LOC Dist. is the distance from the shoreline to the LOC. DOC is the depth, in meters.

4-3. Vertical difference between measured and calculated DOC, in meters. Source of A-E same as Table 4-1 and Figure 4-3. Filtered data were smoothed by a 5 point (500 $\mathrm{m})$ moving average.

4-4. Horizontal difference in meters between the LOC and landward boundaries of hard ground (left) or hard ground and diabathic (right). Values are split by inlets,

from north to south. Refer to Table 4-2 for location.

4-5. Vertical difference in meters between the DOC and landward boundaries of hard ground (left) or hard ground and diabathic (right). Values are split by inlets, from north to south. Refer to Table 4-2 for location. 


\section{LIST OF FIGURES}

FIGURE

PAGE

2-1. Study area with hurricane tracks and extent of airborne laser data. 10

2-2. Volume change due to the 2004 hurricane season for the area surrounding Transect 175 .

2-3. Shoreline and volume change along entire study area. North to south is from left to right. The interval between two adjacent transects is $100 \mathrm{~m}$. LWI is the location of Lake Worth Inlet. S. LWI is the location of South Lake Worth Inlet. Vertical lines are locations of transects in Figure 2-4. Data were filtered by a 5 point moving average for clarity.

2-4. Perpendicular profiles cut from before and after LIDAR data. Horizontal line represents the MHHW datum.

2-5. Plot of shoreline change against volume change to show degree of correlation before the 2004 hurricane season. North represents transects north of Transect 305. South represents transects south of Transect 305.

2-6. Plot of shoreline change against volume change to show degree of correlation after the 2004 hurricane season. North represents transects north of Transect 305. South represents transects south of Transect 305.

3-1. Map of the study area near Panama City, Florida showing locations of beach transects, track of Hurricane Ivan, and location of NOAA offshore wave buoy 42039.

3-2. Map of Hurricane Ivan wind speeds with storm track, location of NOAA offshore wave buoy 42039, and Transect A to B displayed in Figure 3-3. Wind data courtesy of NOAA's Hurricane Research Division.

3-3. FEMA surveyed high water marks for Transect A to B in Figure 3-2. The study area is between the asterisks.

3-4. Significant wave height and wave direction for NOAA buoy 42039 offshore of Panama City during 2004 with timeline showing when airborne laser data were collected and their proximity to Hurricane Ivan. Middle plot represents significant wave height. Upper plot is wave direction, with north at the top of the page. Dates of airborne laser data collections are vertical lines. CHARTS data collection dates were provided in ranges, thus the median date was chosen.

3-5. Simplified beach profile showing the active and subaerial zones defined in this study. Not to scale, as active zone is significantly wider than subaerial zone. 
3-6. Evolution of beach width over time for Panama City beaches. Top to bottom are the five sequential data sets from Figure 3-4, starting with the May 5, 2004 CHARTS data. Distance along shoreline is from west to east. Horizontal lines are average beach width for the respective date.

3-7. Evolution of subaerial volume over time for Panama City beaches in 2004. Top to bottom are the five sequential data sets from Figure 3-4, starting with the May CHARTS data. Distance along shoreline is from west to east. Horizontal lines are average subaerial volume for the respective date.

3-8. (a) Alongshore shoreline, (b) beach width, and (c) subaerial volume change calculated over four time periods in 2004. Lines correspond to the time intervals defined in Results: dashed line (summer, 5/4 to $8 / 27$ ), medium line (Ivan, $8 / 27$ to 9/18), thick line (recovery, $9 / 18$ to $10 / 8$ ), and thin line (fall, 10/8 to $12 / 1$ ).

Distance along shoreline is from west to east.

3-9. Alongshore (a) $K$ values and their respective (b) $\mathrm{R}^{2}$ values for the 237 transects measured on Panama City beaches, from west to east. Dashed horizontal line (a) is the mean. Circles represent statistically significant $K$ values discussed Results. Solid horizontal line (b) is the critical $\mathrm{R}^{2}$ value of 0.77 at $95 \%$ significance.

3-10. Alongshore $R_{V}$ caused by Hurricane Ivan, from west to east. Vertical solid lines are the western bounds of a borrow pit. Vertical dashed lines are the eastern bounds of a borrow pit. Horizontal lines separate change environments, from mostly accretion at top to mostly erosion at bottom. Distance along shoreline is from west to east.

3-11. Shaded relief map of May CHARTS data. Black line is the approximate location of zero change when differencing December CHARTS data from May CHARTS data. Notice the large depressions which are borrow pit locations. Rectangle is the bounds for Figure 3-12

3-12. Map view of volume change in an area of borrow pit 3 (Transects 74 to 83). Red is erosion and green is accretion. White line is the shoreline extracted from the CHARTS 12/1 data, straight black lines are labeled transects, and black polyline is the active zone. Refer to transects on Figure 3-1 for location, and north is at the top of the page. Figure 3-12 limits can be seen in Figure 3-11.

3-13. Beach profiles extracted from Transect 95 . Horizontal line is the $0.6 \mathrm{~m}$ contour used to designate the shoreline.

4-1. Map showing study area, extent of overlapping CHARTS ALB data, and location of reference transects along the shoreline. Inset map denotes tracks of Hurricanes in 2004. 
4-2. Map of the change grid (left) and geomorphology (right, after Finkl et al., 2005a) for three separate locations along the study area from north to south (top to bottom). Seaward change contour extracted from the change grid is shown with the geomorphology. Seaward locations of the change contour represent the LOC at each transect. The center maps show the area surrounding Hillsboro Inlet.

4-3. Wave data and DOC alongshore. Distance along coastline is from north to south. Hurricane Frances wave height and period (left) from NOAA's Wavewatch III model. Alongshore plot of DOC (right) with calculated DOC using different coefficients. A is from Hallermeier (1977), B and C are from Birkemeier (1985), $\mathrm{D}$ and $\mathrm{E}$ are from Nicholls (1998). A, B, D and $\mathrm{E}$ use Equation 4-1. C uses Equation 4-2.

4-4. Representative profiles of surface change between June and November CHARTS data. Thin horizontal lines are the $\pm 0.3 \mathrm{~m}$ change. Change less than this magnitude is generally not resolvable with ALB data. Vertical thin lines are the LOC. Map view of Transects 316 and 628 are shown in Figure 4-2.

4-5. Horizontal position of hard ground (grey), diabathic channels, and the LOC (black). Hard refers to the landward boundary of hard grounds. Green and red indicate the landward and seaward boundary of diabathic channels, respectively. . 73

4-6. Comparison of the DOC (black) to the extracted depths of the landward location of hard ground (grey) along with the landward location of diabathic channels (green). 


\section{LIST OF ACRONYMS}

\begin{tabular}{|c|c|}
\hline ALB & Airborne Laser Bathymetry \\
\hline ALSM & Airborne Laser Swath Mapping \\
\hline ALTM & Airborne Laser Terrain Mapping \\
\hline CHARTS & Compact Hydrographic Airborne Rapid Total Survey \\
\hline CRAB & Coastal Research Amphibious Buggy \\
\hline DEM & Digital Elevation Model \\
\hline DOC & Depth Of Closure \\
\hline $\mathrm{DOC}_{\mathrm{c}}$ & Depth Of Closure, calculated \\
\hline EAARL & Experimental Airborne Advance Research LIDAR \\
\hline FDEP & Florida Department of Environmental Protection \\
\hline FRT & Florida Reef Track \\
\hline GPS & Geographic Position System \\
\hline IHRC & International Hurricane Research Center \\
\hline LADS & Laser Airborne Depth Sounding \\
\hline LIDAR & LIght Detection And Ranging \\
\hline LOC & Location Of Closure, or location of DOC \\
\hline MHHW & Mean Higher High Water \\
\hline NAVD88 & North American Vertical Datum 1988 \\
\hline NOAA & National Oceanic and Atmospheric Administration \\
\hline RMS & Mean Squared \\
\hline
\end{tabular}




\section{INTRODUCTION}

The state of beaches for Florida residents is of critical importance as they depend on healthy coastlines to stimulate tourism interest and more importantly tourism dollars. A state-wide survey in 1998 found that the majority of Florida beaches had experienced accretion (Dean et al., 1998). Morton and Miller (2005) found similar results, with the east coast of Florida experiencing an average of $0.2 \mathrm{~m}$ of seaward shoreline migration. These results are misleading since both studies found that almost $39 \%$ of east coast Florida beaches were eroding. In fact, Florida's Department of Environmental Protection (FDEP) has declared $385 \mathrm{~km}$ of Florida beaches as critical erosion areas, while only 97 $\mathrm{km}$ are considered non-critical (FDEP, 2006). The FDEP report is based on measurements and observations, and previous research documenting beach change was limited to land survey techniques that produced sparsely located cross-shore profiles or large-scale changes in shoreline position. There is a critical need for high density measurements of beaches in order to effectively mitigate coastal problems and remove discrepancies between observed and measured beach change.

The evolution of beach measurement methods has improved scientists' ability to accurately analyze trends in beach change. Shoreline measurements began as early as the mid 1800's when the U.S. Coast and Geodetic Survey used standard alidade and planetable land surveying techniques to delineate the high water line (Shalowitz, 1964). This method was fairly accurate depending upon the distance from the measuring device. However, the method was time and labor intensive, and only produced a few hundred points in a good day. Recent improvements in land surveying (i.e., total station) have enabled more rapid measurements, but the process is still labor and time intensive. Aerial 
photography became a tool for studying coastal change in the late 1930's. Aerial photographs were an advantage to land surveying, since they could image large areas in a minimal amount of time. Yet three dimensional profile changes cannot be measured because aerial photographs only provide researchers with shoreline position. Advances in Global Positioning System (GPS) have enabled coastal scientists to map the shoreline in relatively high accuracies of up to $1 \mathrm{~cm}$ (Morton et al., 1993). Although GPS can achieve high accuracies, there is an inverse relationship between the accuracies of the GPS and the speed at which measurements can be made.

One of the more recent advances in coastal surveying technology is airborne laser mapping (often referred to as LIDAR). Airborne laser mapping produces extremely dense and relatively accurate elevation measurements for large areas in a short amount of time (Whitman et al., 2003). There has been a steady progression of research into applying airborne laser data to measuring coastal change. Airborne laser measurement accuracies of $\pm 0.15 \mathrm{~m}$ RMS verified that this technology is sufficiently accurate for coastal change measurements (Sallenger et al., 2003). Similar accuracies have been obtained using airborne laser bathymetry (ALB), and new generations of bathymetric and topographic lasers provide seamless data from the ocean floor to subaerial environments (Wozencraft and Lillycrop, 2003). Stockton et al. (2002) showed that shorelines can be extracted from airborne laser data, and Robertson et al. (2004) demonstrated that shorelines derived from local tidal data matched the high water line measured from aerial photographs. Shoreline positions derived from airborne laser are superior to previous methods because they remove human error caused when manually digitizing shorelines from aerial photographs or field identification errors when using GPS. Zhang et al. 
(2005) quantified volume change caused by a passing hurricane, and more importantly developed a tool to separate the alongshore volume change into locations alongshore that can show where relative magnitudes of volume change occurred. Volume change derived from airborne laser is a significant improvement over field beach profiling. Measuring beach profiles using land surveying is time consuming and there are few data sets that cover large areas. The resolution of volume change derived from airborne laser mapping is dependent upon the point spacing and grid resolution. With points typically spaced between 1 to $8 \mathrm{~m}$ over large areas, airborne laser has the ability to measure beach profiles at every meter alongshore or provide a change grid with $1 \mathrm{~m}$ pixels.

This dissertation uses airborne laser to address scientific questions on coastal change. With airborne laser data and customized geographic information systems (GIS) based metric mapping tools, the limitations in previous studies caused by lack of high resolution data can be minimized. Chapters 2 and 3 have been previously published in the refereed journals of Shore \& Beach and Marine Geology, respectively (Robertson et al., 2007; Robertson et al., 2005). Mr. Robertson did a majority of the work for these two publications, and the co-authors represent the normal give-and-take experienced between the student and committee member.

A method for extracting volume change data incrementally alongshore in Palm Beach County, Florida is developed in Chapter 2. By extracting shoreline positions from three ALB data sets and calculating change rates, a direct comparison between shoreline and volume change indicates that shoreline change does not necessarily indicate volume change. 
In Chapter 3, a time series of five separate airborne laser data sets collected in Bay County, Florida, are used to address three questions:

1) Is there a correlation between landward shoreline migration induced by a storm and its subsequent seaward migration during recovery?

2) Does beach width and subaerial volume share a linear relationship?

3) Is there a more effective method than mean change when quantifying volume change measurements?

Although List et al. (2006) have shown that shorelines recover at similar magnitudes to erosion caused by storms, little correlation is found following Hurricane Ivan. Previous studies suggest that individual beaches have a linear relationship between beach width and subaerial volume change, but the beach profile technique limited the relationship to only one profile per beach (Dingler and Reiss, 2002; Thom and Hall, 1991). The high spatial resolution of airborne laser data is utilized in Chapter 3 to demonstrate that the linear relationship in Bay County is spatially variable. In addition, a new ratio is proposed to indicate the relative amount of sediment either entering or leaving a section of coastline. Results show that most sediment remained in the nearshore, and there was mostly a redistribution of sediment along the profile with some loss of sediments offshore. The low amount of change at the seaward limit of the study area suggests that the depth of closure (DOC) could be extracted from ALB data.

A method for extracting the DOC from ALB data is developed in Chapter 4, and the vertical and horizontal position of the DOC is compared to several calculated DOCs and local geology. Results suggest that the southeastern Florida DOC (Palm Beach, Broward, and Miami Dade Counties) is both hydrodynamically and geologically 
controlled. A portion of coastline between Boca Raton and Hillsboro Inlets separates the hydrodynamically controlled DOC to the north from the geologically controlled DOC to the south.

The findings of each chapter along with current airborne laser limitations and future research are summarized in Chapter 5. Airborne laser systems are constantly improving in data quality and measurement resolution. Future studies will benefit from closer point spacing and higher accuracies, but the largest benefit will come from an increase in the airborne laser data library, especially when measuring the same beach over long periods of time. 


\title{
2. SHORELINE AND BEACH VOLUME CHANGE BEFORE AND AFTer THE 2004 Hurricane SEAson, PaLM BEACH COUNTY, FLORIDA ${ }^{1}$
}

\begin{abstract}
This study quantifies the shoreline and volume change utilizing three LIDAR data sets that were collected in Palm Beach County before and after the 2004 hurricane season. The beaches in Palm Beach County were significantly affected by Hurricanes Frances and Jeanne. Shoreline positions were extracted from the LIDAR derived DEMs, and the DEMs were differenced to yield volume change. The $52.4 \mathrm{~km}$ long study area lost nearly 5.8 million $\mathrm{m}^{3}$ of sediment due to the 2004 hurricane season, with major erosion occurring to the berm, sandbar, and the northerly sections of ebb tidal deltas. On average, nearly 10 meters of shore erosion was observed. Correlation between shoreline movement and volume change was quantified. A poor $\mathrm{R}^{2}$ value of 0.39 was found between shoreline and volume change before the hurricane season in the northern section of Palm Beach County because of beach nourishment and inlet dynamics. However, a relatively high $\mathrm{R}^{2}$ value of 0.78 in the southern section of Palm Beach County was found due to little disturbance from tidal inlets and coastal engineering projects. The 2004 hurricane season reduced the $\mathrm{R}^{2}$ values to 0.02 and 0.42 for the north and south sections, respectively.
\end{abstract}

\footnotetext{
${ }^{1}$ Reprinted from Shore \& Beach, v. 73, William Robertson, Keqi Zhang, Dean Whitman, and Stephen Leatherman, Shoreline and beach volume change before and after the 2004 hurricane season, Palm Beach County, Florida, 79-84, with permission from Shore \& Beach
} 


\section{INTRODUCTION}

Beaches are an extremely valuable resource for the recreation and tourism business. Most sandy beaches along the U.S. East Coast suffer from chronic and episodic erosion. Quantifying these changes is critical for understanding why they occurred, for designing and evaluating beach nourishment projects, and for beach management. Threedimensional measurements of subaerial topography and nearshore bathymetry are required for quantifying change because beach morphological change occurs along the entire beach profile. Until the recent advent of airborne laser technology, it has been difficult to obtain measurements of beaches over large areas with sufficient resolution and accuracy to adequately measure three-dimensional volume change.

Traditionally, there were two methods to quantify beach change. One was to compare the beach profile observations along the shore to locate morphological differences and interpolate volume change (Aubrey, 1979; Morton et al., 1995; Morton et al., 1994). This method has been employed by Florida Department of Environmental Protection to monitor beach volume change. A series of monuments along the entire sandy coastline of Florida has been installed, and profiles at monuments have been ground surveyed repeatedly for change determination. However, since the monuments are spaced approximately $300 \mathrm{~m}$ apart, interpolation is necessary to estimate the volume change between monuments. Swales (2002), Finkl (2004), and Zhang et al. (2005) found that the sparse sampling intervals may lead to an inaccurate representation of coastal change, and higher resolution data are needed to accurately quantify beach volume change. 
Beach change can be determined by analyzing the position of the high water line (Galgano et al., 1998; Pajak and Leatherman, 2002; Zhang et al., 2002). Although shoreline position change only represents two dimensional beach variation, the shoreline data are often used to estimate volume change due to a lack of three-dimensional measurements (Jarrett, 1991; Rosati, 2005). It is assumed that the entire active profile which spans from the berm to the depth of closure moves at the same rate as the rate of shoreline change, while the active profile shape remains unchanged. Detailed information for converting shoreline variations into volume change based on this assumption can be found in Rosati (2005). However, little systematic investigation has been undertaken on the relationship between shoreline position and volume change, and the accuracy of such estimations has suffered due to the lack of high-resolution threedimensional measurements.

Airborne laser mapping allows for rapid and dense three-dimensional measurements of the subaerial beach and nearshore bathymetry. The significant increase in resolution makes it possible for researchers to analyze coastal change with great detail. Several studies have demonstrated the effectiveness of airborne laser data when applied to the analysis of coastal morphological change (Brock et al., 2002; Sallenger et al., 2003; Shrestha and Carter, 1998; Shrestha et al., 1999). The shoreline position (Robertson et al., 2004; Stockdon et al., 2002) and beach volume (Irish and White, 1998; White and Wang, 2003; Woolard and Colby, 2002; Zhang et al., 2005) can be computed from airborne laser data due to the three dimensional properties of these remotely sensed measurements. Therefore, airborne laser measurements allow for a direct comparison of 
two separate methods for measuring coastal change: shoreline position and beach volume.

The direct comparison between shoreline position and volume change methods also allow for quantifying their correlation. It has long been recognized that beach profiles will adjust to seasonal wave climates or major storm events (Aubrey, 1979; King, 1972; Shepard, 1950). This adjustment leads to erosion in the upper beach and deposition in lower beach in the form sand bars due to storm events. The profile adjustment will influence the correlation between shoreline and volume change, but previous studies have not quantified the correlation for normal or storm conditions.

Hurricanes Frances and Jeanne affected Palm Beach County's beaches in 2004. Frances was a category two hurricane that made landfall on September 5, 2004 over the southern end of Hutchinson Island, Florida (Beven, 2004). Jeanne made landfall at almost the same position on September 26, 2004 as a category three hurricane (Lawrence and Cobb, 2005). Palm Beach County was approximately 20 kilometers south of the landfall of both hurricanes and on the left or weak side (Figure 2-1). However, Palm Beach County beaches still experienced significant erosion from the storms.

This study utilizes two airborne laser data sets collected before and one collected after the 2004 hurricane season along the Palm Beach County coast. These data consist of both subaerial and bathymetric measurements that provide excellent information for quantifying beach change under normal and storm conditions. The beach extends from the toe of the dune to the depth of closure. The primary objective of this study is to quantify shoreline and beach volume change for central and southern Palm Beach County before and after the 2004 hurricane season. A second objective is to quantify the 
correlation between shoreline movement and volume change under normal and storm conditions.

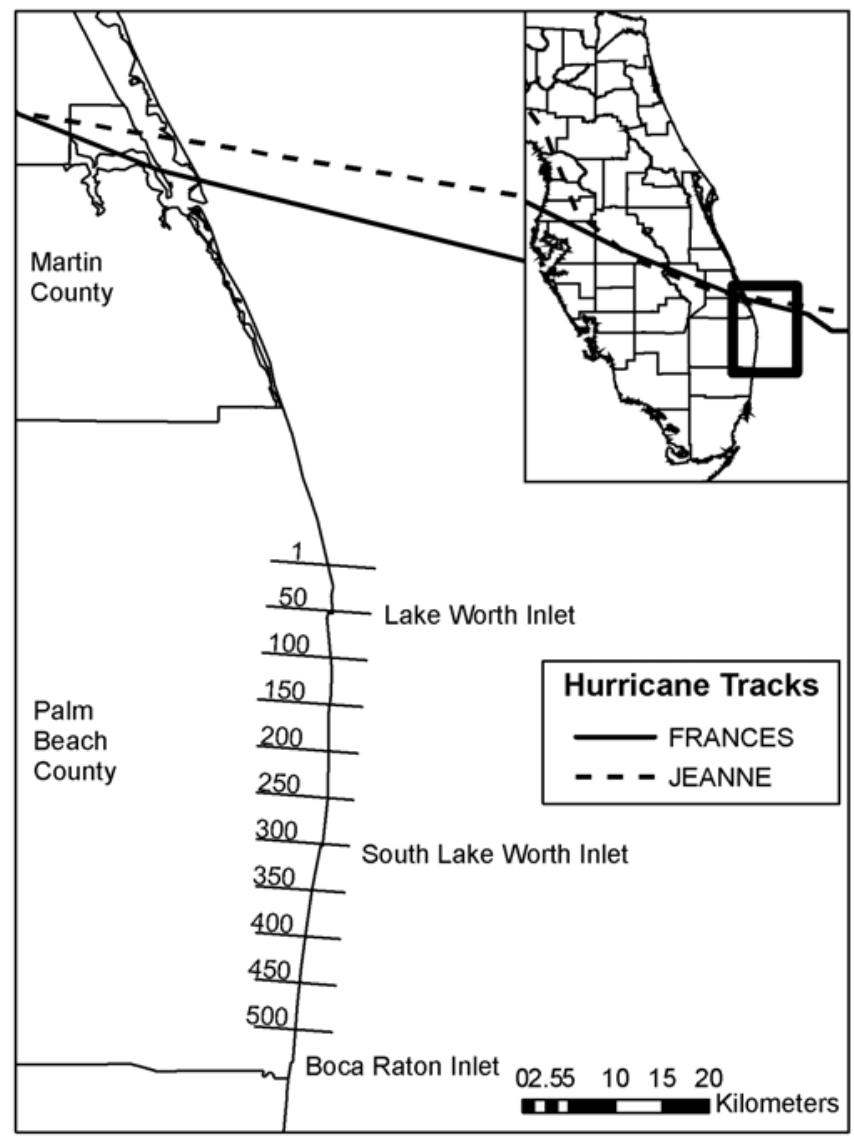

2-1. Study area with hurricane tracks and extent of airborne laser data.

\section{STUDY AREA}

Palm Beach County is located in the southeastern section of the Florida peninsula with over $72 \mathrm{~km}$ of sandy beaches. This study focuses on the southernmost $52 \mathrm{~km}$ of coastline in Palm Beach County and the bathymetry extends approximately $600 \mathrm{~m}$ offshore (Figure 2-1). The coastline is relatively straight and oriented north-northeast to south-southwest. The study area includes two inlets, and offshore is characterized by one to two sandbars. Beach sediments are bimodal containing shell fragments and quartz 
grains. The average deep water wave height is $0.98 \mathrm{~m}$ with the predominant wave direction from the northeast (Benedet et al., 2004).

\section{DATA AND METHODS}

\section{Airborne laser data}

Airborne laser is an active remote sensing technology that determines ground elevations by measuring the travel time of laser pulses transmitted from an aircraft. Over the last decade, several airborne laser systems have been employed to collect data of Florida beaches. This study utilizes airborne laser data collected by two systems: LADS and CHARTS. Laser airborne depth sounding (LADS) was flown in October to November, 2002, by the Tenix LADS Corporation, Coastal Planning and Engineering, and Palm Beach County. The LADS system fired a green laser $(532 \mathrm{~nm})$ at $900 \mathrm{~Hz}$ yielding a point spacing of approximately 4 meters. In June 2004 and November to December 2004, the U.S. Army Corps of Engineers deployed the compact hydrographic airborne rapid total survey (CHARTS) system. CHARTS has two lasers: one hydrographic and the other topographic. The hydrographic laser fired at $1 \mathrm{kHz}$ while the topographic laser fired at $10 \mathrm{kHz}$. This produced point spacing on the ground of approximately 1.5 meters and a bathymetric point spacing of approximately 4 meters.

Vertical offsets between airborne laser data can add a bias to shoreline and volume change calculations. Fortunately, these biases can be estimated by comparing elevations from different airborne laser surveys on unchanged (hard) surfaces such as roads (Zhang et al., 2005). Four profiles were extracted from concurrent roads distributed throughout the study area. The root mean square (RMS) differences between the three data sets were calculated. Results show that the RMS differences were less than 
$12 \mathrm{~cm}$, suggesting that the three airborne laser data sets match well and there were no large systematic offsets. The airborne laser data were provided as irregularly-spaced point measurements including horizontal coordinates and vertical elevations of topography and bathymetry. Analysis required interpolating these data onto a regularlyspaced grid to produce a digital elevation model (DEM). The data were gridded at $2 \mathrm{~m}$ resolution using kriging interpolation and a linear variogram.

\section{Shoreline change}

Since the shoreline is not a topographic feature, its position cannot be directly measured by airborne laser points. Therefore, local tidal datums were used to extract a shoreline contour from the three-dimensional airborne laser data. Previous studies indicate that the digitized high water line from aerial photographs is similar to the contour corresponding to the mean higher high water (MHHW) level datum derived from local tide gauges (Robertson et al., 2004). All data were contoured at the calculated MHHW level of $0.09 \mathrm{~m}$ above NAVD88. The contours were vectors that represented the shoreline position at the time of airborne laser data collection.

Shoreline change was quantified by using the Metric Mapping system developed by the IHRC (Zhang et al., 2005). In this system, a spine was created parallel to the shoreline, and transects perpendicular to the spine were created at every 100 meters producing 524 transects. Distance was measured from the spine to the intersection of each shoreline vector. This allows the calculation of shoreline change as a function of along-shoreline position. 


\section{Volume change}

Volume change was quantified by differencing the airborne laser data sets within a user-digitized mask (Zhang et al., 2005). The mask ensured that volume change was measured from the toe of the dune to the furthest extent of the bathymetry data, approximately $10 \mathrm{~m}$ beneath NAVD88. By differencing the elevations of two DEMs, positive and negative values represent accretion and erosion of sediment, respectively. The map view of coastal volume change provides a synoptic perspective on where sediments were eroded and accreted. Profiles were measured and compared at locations of interest to represent the two-dimensional beach change. The increased profile detail produced from airborne laser data provide a qualitative perspective on the morphodynamic change of the beach.

Volume change was quantified by using an ArcView extension developed by Keqi Zhang of the IHRC. The same spine and 524 transects used for shoreline change were applied with the ALTM tool. The transects created $100 \mathrm{~m}$ bins in the alongshore direction where volume change was calculated (Figure 2-2). This allows the calculation of volume change as a function of distance along the shoreline.

2-1. Shoreline and volume change before and after the 2004 hurricane season.

\begin{tabular}{lllll}
\hline & Mean & Max & Min & St.D. \\
\hline Shoreline Change Before $(\mathrm{m})$ & 3.6 & 48.3 & -32.5 & 12.1 \\
Shoreline Change After $(\mathrm{m})$ & -10.7 & 15.6 & -39.0 & 8.8 \\
Volume Change Before $\left(\mathrm{m}^{3} /\right.$ transect) & -4235 & 37743 & -93085 & 11240 \\
Volume Change After $\left(\mathrm{m}^{3} /\right.$ transect $)$ & -10975 & 75852 & -134218 & 15668 \\
\hline
\end{tabular}




\section{BEACH CHANGE BEFORE AND AFTER 2004 HURRICANE SEASON}

Summary statistics for the entire study area were compiled to reflect shoreline and volume change before and after the 2004 hurricane season (Table 2-1). Shoreline change before the 2004 hurricane season represents the difference between the shorelines extracted from the November 2002 LADS and June 2004 CHARTS airborne laser data. Shoreline change after the 2004 hurricane season represents the difference between the shorelines extracted from the June 2004 and November 2004 CHARTS airborne laser data. Positive values represent seaward movement of the shoreline, and negative values represent landward movement of the shoreline.

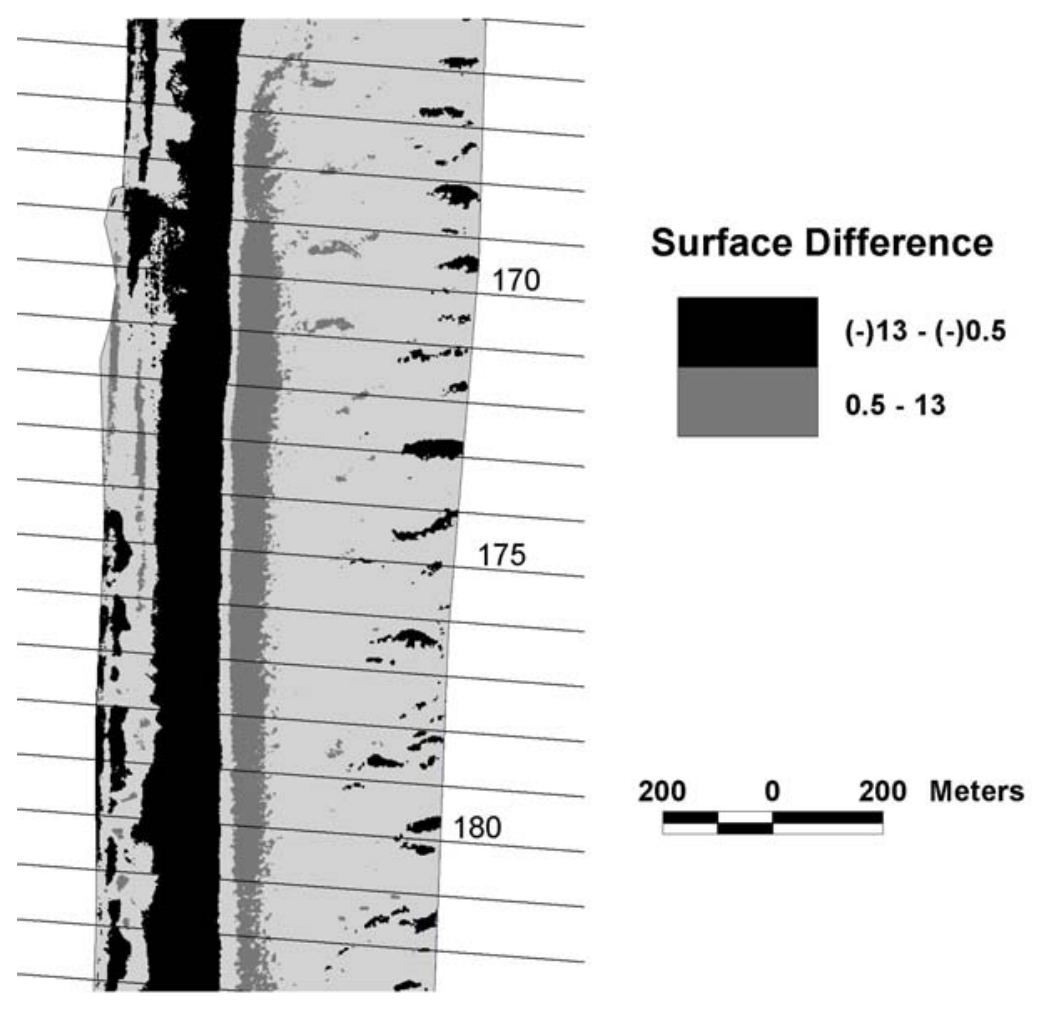

2-2. Volume change due to the 2004 hurricane season for the area surrounding Transect 175.

Results show that the shoreline on average moved seaward $3.9 \mathrm{~m}$ before and retreated more than $10 \mathrm{~m}$ after the 2004 hurricane season. Conditions before the 2004 
hurricane season showed maximum accretion at Transect 119 and maximum erosion at Transect 418. The maximum accretion was due to the 2003 Midtown Palm Beach nourishment project. The maximum erosion at Transect 418 was due to the LADS data being collected immediately after the 2002 Delray Beach nourishment project, and therefore is showing the retreat following the project. Following the 2004 hurricane season, maximum erosion occurred at Transect 515. This area was nourished as part of the 2004 central Boca Raton nourishment project, and the area was significantly eroded following the 2004 hurricane season. The maximum accretion occurred at Transect 12 which is the northern limit of the study area and appears to be due to the offshore bar being driven onshore.

Volume change represents the amount of change that occurred between transects and within the user-specified mask as described in the methods. Average volume change for the entire study area was found to be an erosion of $-4,235 \mathrm{~m}^{3} /$ transect before the 2004 hurricane season and $-10,975 \mathrm{~m}^{3} /$ transect after (Table 2-1). Since the study area contained 524 transects, and each transect was $100 \mathrm{~m}$, the average volume change before the 2004 hurricane season was -2.2 million $\mathrm{m}^{3}$, and -5.8 million $\mathrm{m}^{3}$ after. Increased erosion due to the 2004 hurricane season was expected, and locations of maximum accretion and erosion are caused by site-specific hydrodynamics and beach nourishment projects. Maximum accretion of $37,743 \mathrm{~m}^{3}$ occurred at the 2003 midtown Palm Beach nourishment site at Transect 119 before the 2004 hurricane season, and following the 2004 hurricane season a maximum accretion of $75,852 \mathrm{~m}^{3}$ occurred at Transect 49 at the Lake Worth Inlet channel due to deposition of sediments in the dredged portion of the channel. For maximum erosion, the loss of $-93,085 \mathrm{~m}^{3}$ at Transect 67 before the 
hurricane season was due to the dredging between Transects 55 and 90 for the 2003 midtown Palm Beach nourishment project. Following the 2004 hurricane season, a maximum erosion of $-134,218 \mathrm{~m}^{3}$ was found at Transect 40 . This area before the 2004 hurricane season had a large amount of sand just north of Lake Worth Inlet in the form of an ebb tidal delta. The two hurricanes not only moved the delta closer to the inlet, but they significantly decreased the ebb tidal delta size, resulting in the large volume of sediment loss.

A longitudinal north to south profile of shoreline and volume change is shown in Figure 2-3. The figure shows shoreline and volume change as a function of alongshoreline distance. The shoreline change values were multiplied by 500 to match the signal range of the volume change values. In general, shoreline change values are above zero, and volume change values are below zero before the 2004 hurricane season as summarized in Table 2-1. Volume and shoreline change following the 2004 hurricane season are below the zero line representing the overall erosion caused by the hurricanes. Extremes in the signals were found at and north of the dredged area for the 2003 nourishment project (Transect 69).

\section{RELATIONSHIP BETWEEN SHORELINE AND VOLUME CHANGE}

The shoreline and volume change curves were further compared to examine their correlation. Figure 2-3 shows a good in phase match between two curves before and after the 2004 hurricane season south of Transect 304, and a poor match to the north of Transect 304. The apparent match occurs between South Lake Worth and Boca Raton Inlets. To help understand the correlation between shoreline and volume change, four 
profiles were extracted from the before and after hurricane airborne laser data (Figure 2-

4). Profiles at Transect 420 in Figure 2-4 show berm erosion and shoreline retreat after

the 2004 hurricane season. The volumes of sediment eroded and accreted between 100 to $300 \mathrm{~m}$ along the transect are approximately equal and are averaged out. The volume change mainly reflects the change for the upper portion of the profile, which is closely related to variation in shoreline position.

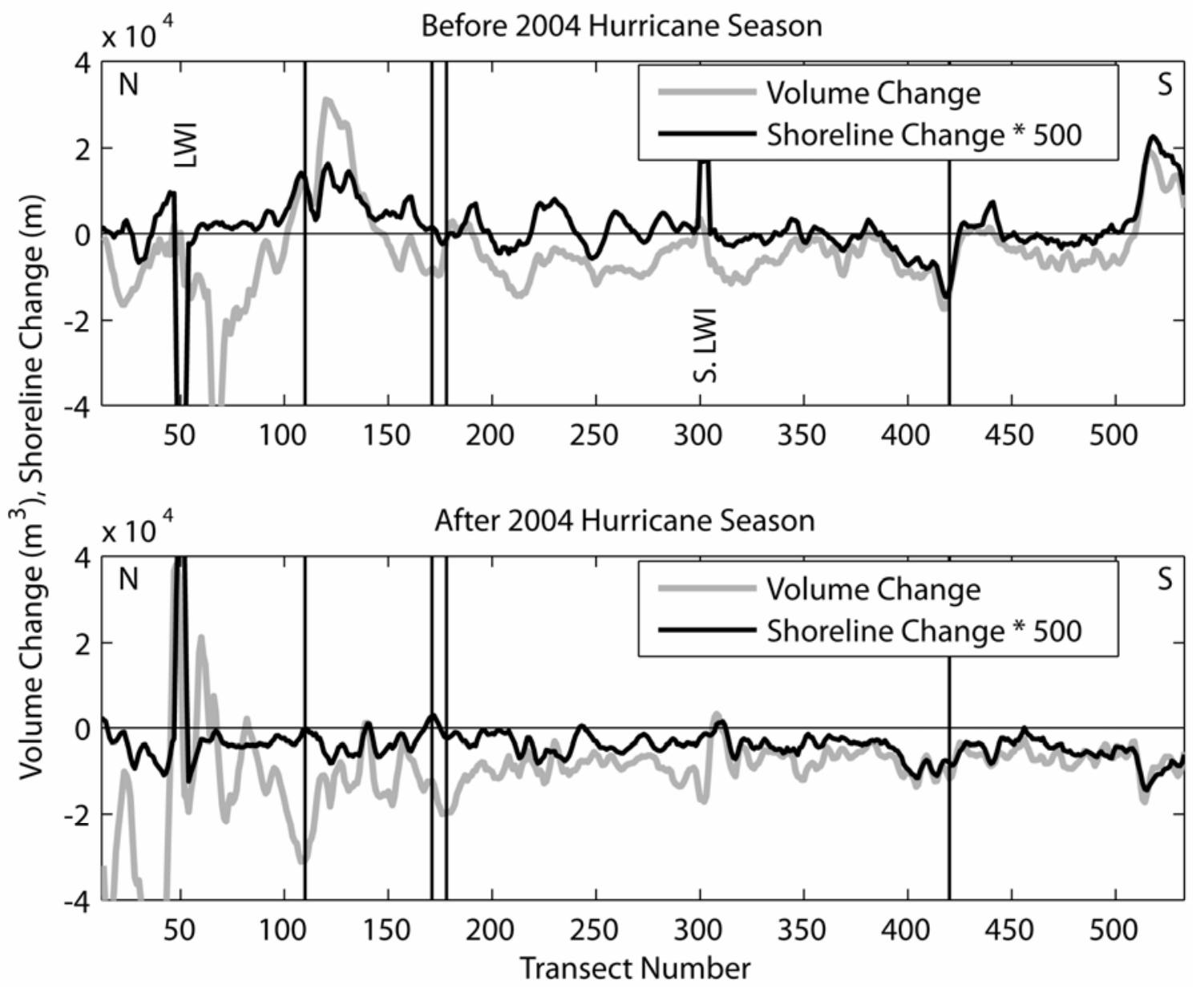

2-3. Shoreline and volume change along entire study area. North to south is from left to right. The interval between two adjacent transects is $100 \mathrm{~m}$. LWI is the location of Lake Worth Inlet. S. LWI is the location of South Lake Worth Inlet. Vertical lines are locations of transects in Figure 2-4. Data were filtered by a 5 point moving average for clarity. 

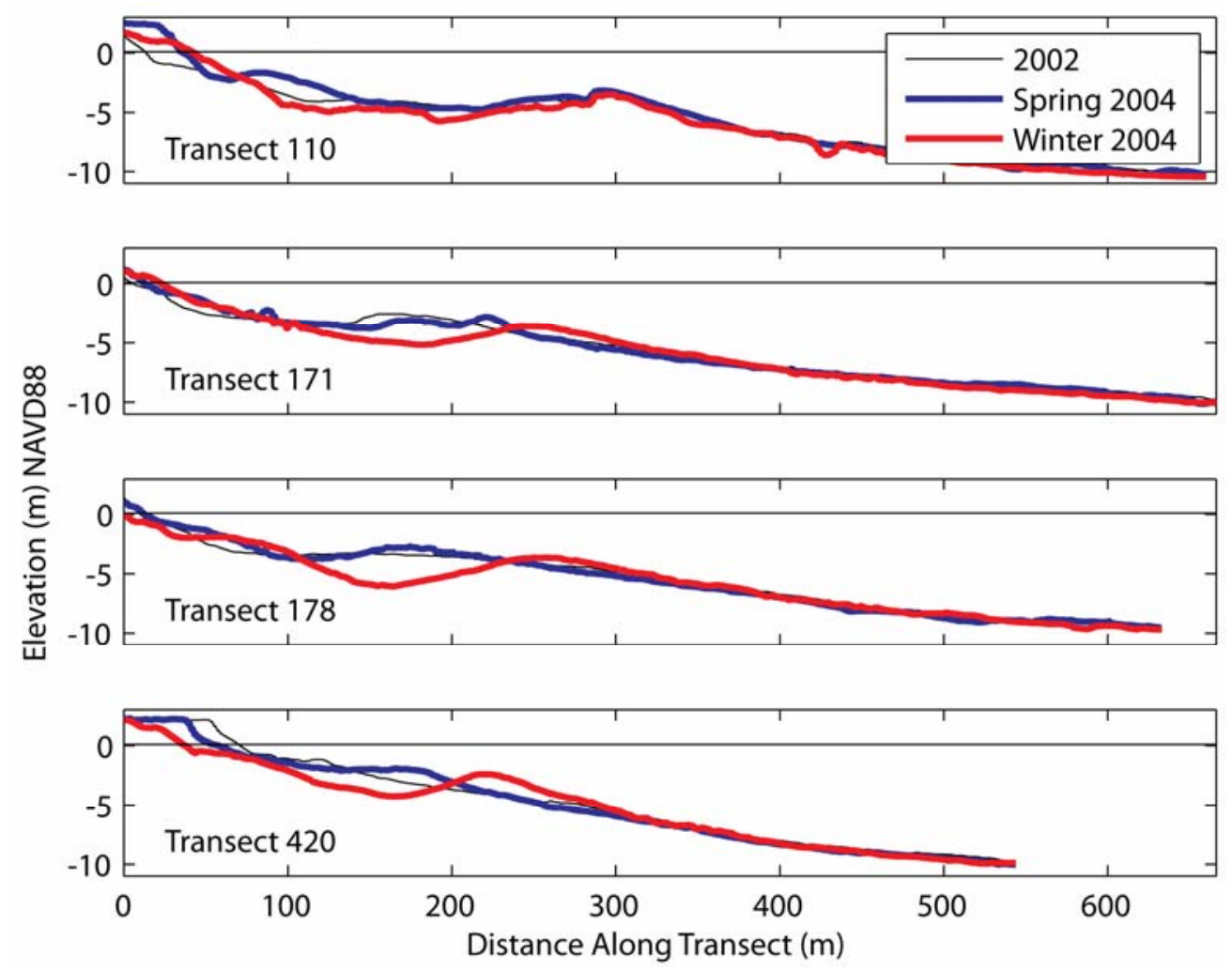

2-4. Perpendicular profiles cut from before and after LIDAR data. Horizontal line represents the MHHW datum.

The relatively poor match spans from just north of Lake Worth Inlet to South Lake Worth Inlet. Large volume change differences between Transects 33 through 47 and 300 to 304 are due to Lake Worth Inlet and South Lake Worth Inlet, respectively. Each inlet area experienced erosion and reduction of the northern half of the ebb tidal delta along with deposition immediately south of the inlet following the 2004 hurricane season. In 2003, a nourishment project was completed between Transects 104 and 140. This project was responsible for the berm buildup and volume accretion before the 2004 hurricane season, and berm reduction and large volume erosion found after the 2004 hurricane season (Figure 2-4, Transect 110). Transect 110 shows a typical beach nourishment profile, where the steep berm and beach face slope was reduced by eroding 
the berm and depositing that sand just offshore. The reworking of sediments resulted in a large sediment loss between 90 and $350 \mathrm{~m}$ along Transect 110 due to the hurricanes.

There were two areas of slight seaward shoreline migration between Lake Worth and Boca Raton Inlets following the 2004 hurricane season at Transects 170 through 174 (Figure 2-2) and Transects 241 through 244. For each area, the position of the offshore bar was completely eroded, with some of the sediment driven ashore and some quantities moved slightly offshore (Figure 2-4, Transect 171). The sediment being driven onshore and pulled offshore resulted in the shoreline position migrating seaward, but still with a significant negative volume change (Figure 2-3). These areas provide an excellent example of how shoreline movement does not coincide with the volume change of the entire profile. However, just south of Transect 171 was Transect 178, where little change occurred between 2002 and spring 2004 (Figure 2-4). Following the 2004 hurricane season, the offshore bar was completely eroded, leading to a significant volume decrease and shoreline retreat. This demonstrates that the coastal morphological response to storms can be different within a short alongshore distance.

To test the correlation between shoreline migration and volume change before and after the 2004 hurricane season, a plot of shoreline position against volume change for each transect along the study area was generated (Figures 2-5 and 2-6). A few outliers greater than three sigma representing locations at or close to inlets were removed. The data were then split into north and south sections at Transect 305 for correlation analysis due to the distinctive beach change behavior based on previous analysis. The $\mathrm{R}^{2}$ value for the south section was 0.78 between 2002 and 2004, and 0.42 following the 2004 hurricane season. The $\mathrm{R}^{2}$ value for the north section was 0.38 and 0.02 for before and 
after hurricane data, respectively. The correlation in the south was significantly better than the north, and the 2004 hurricane season significantly reduced the correlation for both areas.

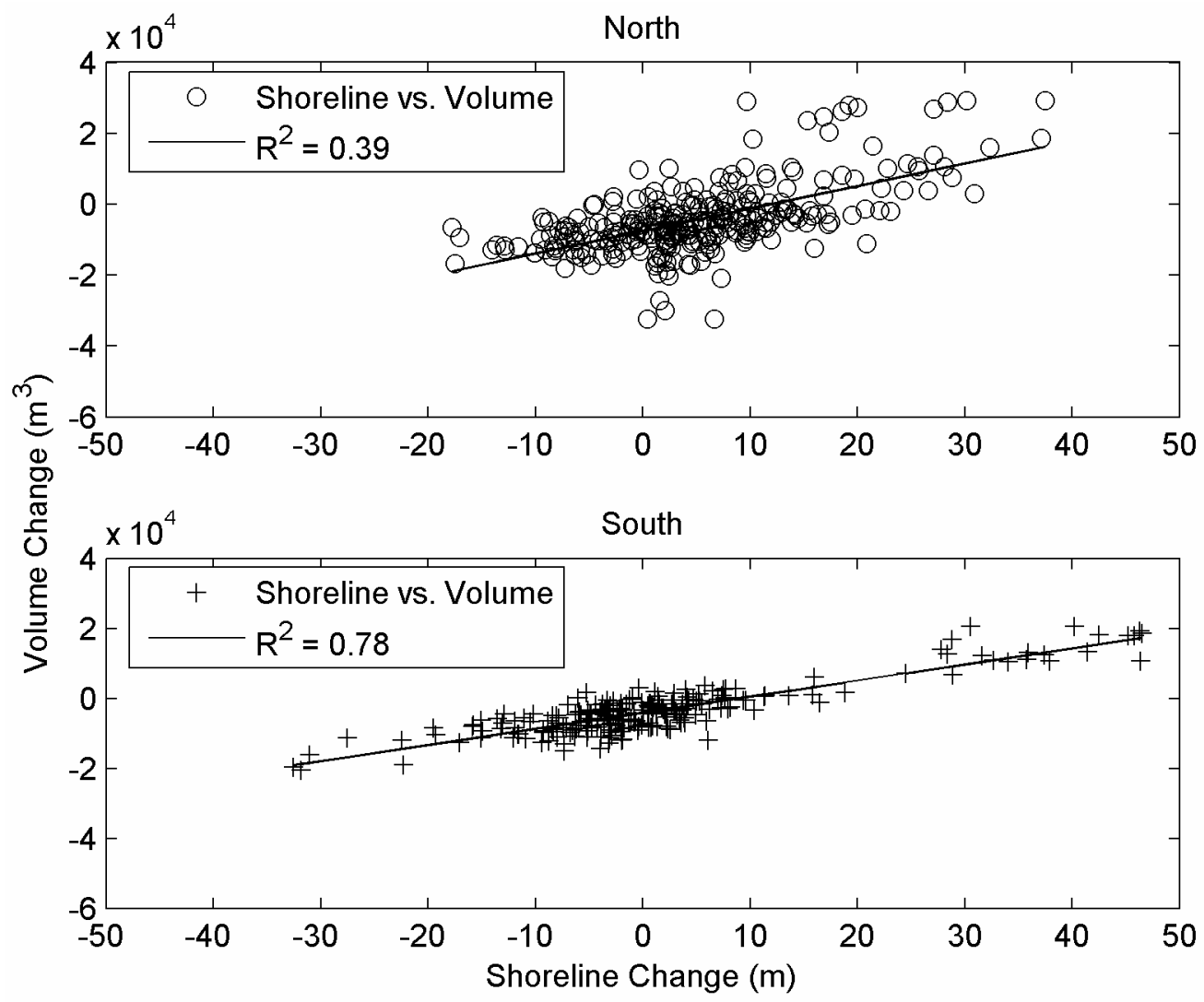

2-5. Plot of shoreline change against volume change to show degree of correlation before the 2004 hurricane season. North represents transects north of Transect 305. South represents transects south of Transect 305.

It is understandable that the correlation between shoreline and volume change was better before the 2004 hurricanes (Figure 2-5). The shoreline position change only reflects the variation of the upper portion of the beach profile, not volume change for the entire beach profile. The requirement for perfect correlation between shoreline and volume change is that the active beach profile has to remain constant and move at the rate of shoreline migration. This is rarely the case for beach profiles because it changes 
constantly as hydrodynamic factors vary. However, during a normal conditions, the profile change is small thus a high $0.78 \mathrm{R}^{2}$ value was derived. This demonstrates that it is reasonable to use shoreline change position to estimate volume change if the shoreline positions are measured during non-storm conditions. The correlation decreased significantly when a large beach profile adjustment, especially episodically storminduced, occurs between two observations (King, 1972). Therefore, it is not appropriate to use storm shoreline positions to estimate volume change.

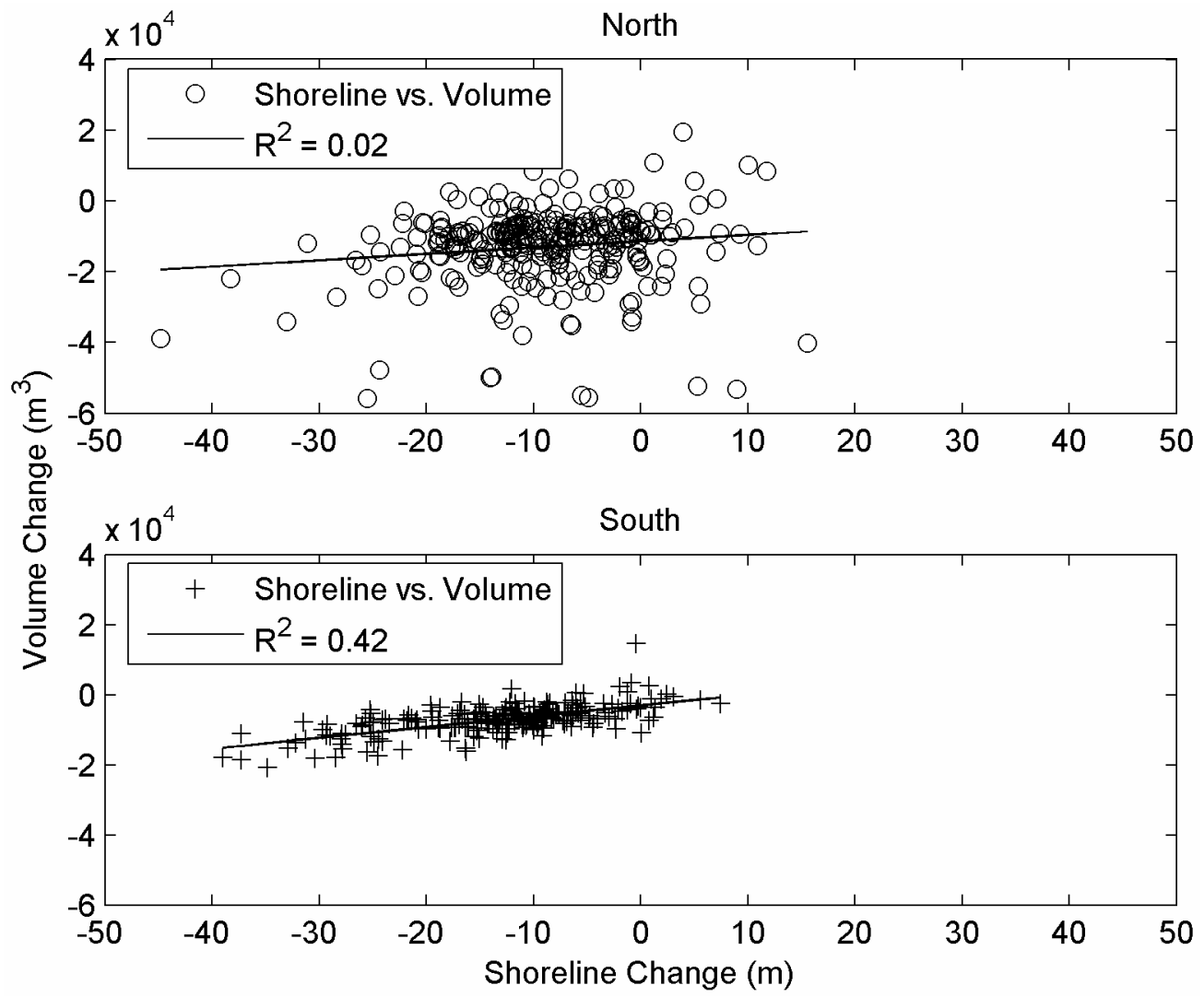

2-6. Plot of shoreline change against volume change to show degree of correlation after the 2004 hurricane season. North represents transects north of Transect 305. South represents transects south of Transect 305.

The spatial correlation difference between north and south sections is mainly due to the inlet activity and beach nourishment projects at the north section. The inlet activity and beach nourishment complicated the beach profile adjustment to changes in 
hydrodynamic factors. However, locations of tidal inlets and beach nourishment do not explain the shoreline migration and volume mismatch between Transects 165 and 208. Reasons for the weak correlation could be due to an active profile beyond the areas captured by the airborne laser data. To fully quantify beach volume change, the offshore profile must cover all significant volume change. Figure 2-2 shows volume change at the offshore edge of the airborne laser measurements, suggesting that sediments were exchanged between the offshore portion and the area beyond the scope of current airborne laser surveys. The role of this sediment exchange on beach volume change needs to be investigated further.

\section{CONCLUSIONS}

This study quantified shoreline and volume change before and after the 2004 hurricane season in Palm Beach County, Florida. Data used for analysis were three topographic and bathymetric airborne laser surveys flown 22 months before, three months before, and two months after the hurricane season. In general, the study area lost 5.8 million $\mathrm{m}^{3}$ of sediments due to the 2004 hurricane season, with major erosion occurring to the berm, sandbar, and northerly sections of ebb tidal deltas. On average, more than 10 meters of shore retreat was observed.

The difference between shoreline and volume change between two observations is determined by the extent of profile adjustment during the same period. Techniques developed by IHRC researchers allowed for extracting the change data as a function of along-shoreline distance for comparative purposes. Alongshore shoreline migration and volume change showed a good correlation with an $\mathrm{R}^{2}$ value of 0.78 south of Transect 305 during normal conditions. North of Transect 305, inlet activity and nourishment projects 
were responsible for complicated adjustments in the beach profile, which lowered the shoreline and volume change correlation to $0.42 \mathrm{R}^{2}$. Shoreline and volume change correlation are strong before the 2004 hurricane season and weak after the 2004 hurricane season, indicating that shoreline change is more representative of volume change when data do not include major storm events. 


\title{
3. HURRICANE-INDUCED BEACH CHANGE DERIVED FROM Airborne LASER MEASUREMENTS NEAR PANAMA City, FLORIDA $^{2}$
}

\begin{abstract}
This study used airborne laser data to investigate spatial variations in shoreline migration, beach width, subaerial volume, and subaqueous volume change due to a hurricane event. Five separate airborne laser data sets of Panama City, FL area beaches were collected during a seven-month period before and after landfall of Hurricane Ivan. Contour shorelines were extracted from digital elevation models interpolated from these laser measurements and were used to measure changes in shoreline position and beach width. The shoreline migrated $16 \mathrm{~m}$ landward due to Hurricane Ivan and migrated $10 \mathrm{~m}$ seaward following Hurricane Ivan. No significant spatial relationship was found between shoreline migration before and after the hurricane. Linear relationships between a time series of beach width and subaerial volume were found at many locations. However, utilization of a single coefficient to represent all relationships is problematic due to the spatial variability in the linear relationship. Differences in two bathymetric data sets for summer and fall show only a small portion of sediments were transported beyond an active zone, and most sediment remain within the active zone despite the occurrence of a hurricane.
\end{abstract}

\footnotetext{
${ }^{2}$ Reprinted from Marine Geology, v. 237, William Robertson, Keqi Zhang, and Dean Whitman, Hurricaneinduced beach change derived from airborne laser measurements near Panama City, Florida, 191-205, Copyright 2007, with permission from Elsevier
} 


\section{INTRODUCTION}

Storm impacts, sea level rise, and human modification make beaches one of Earth's most dynamic landforms. Quantification of storm-induced beach erosion and subsequent recovery is essential for understanding beach response to abrupt changes in hydrodynamics and appropriately designing coastal engineering projects such as beach nourishment. Shoreline position mapping (Crowell et al., 1991; Leatherman, 2003; Pajak and Leatherman, 2002; Thevenot and Kraus, 1995) and beach profile monitoring (Aagaard et al., 2005; Thom and Hall, 1991) are the two primary methods for quantifying coastal change. Shoreline data derived using remote sensing techniques and kinematic GPS surveys are an excellent source for analyzing large-scale beach change temporally and spatially (Moore, 2000; Sallenger et al., 2003; Zhang et al., 2002). Previous studies have found that shoreline response to storms is highly variable along the shore (Robertson et al., 2005; Stockdon et al., 2002; Zhang et al., 2005). List et al. (2006) found that the shorelines at erosion hotspots rapidly recovered to pre-storm positions within a week after the storm, and the magnitudes of shoreline recovery at erosion hotspots are correlated to the magnitudes of erosion induced by storms. List et al. (2006) focused on the relatively high-energy beaches of North Carolina and outer Cape Cod. However, this phenomenon has not been demonstrated on low-energy beaches impacted by frequent hurricanes such as the U.S. Gulf of Mexico coast.

The dynamic interaction between land, wind, and waves creates complicated beach morphologies that change over time. Beach changes not only occur at the shoreline, but also over the entire profile, and these changes cannot be quantified by twodimensional shoreline position data. Monitoring beach profiles using ground surveys can 
provide quantitative information of onshore and offshore changes. By comparing the beach profile measurements on California coasts, Shepard (1950) found that sediments from berms were transported offshore to form sandbars during the winter when storm waves were dominant. Sediment moved toward the shore to form berms during the summer when swell waves were dominant. This cyclic behavior of beach profiles has been found to occur at many coasts during storm weather and the subsequent fair weather periods (Aubrey, 1979; King, 1972; Komar, 1998; Winant et al., 1975). It appears that onshore and offshore sediment movement during a cycle occurs mostly within the active profile zone, defined as the zone landward of the depth where sediment movement by waves is insignificant (Hallermeier, 1977). However, quantitative data on the amount of sediment redistributing within the active profile zone and the amount of sediment exchanged between the active and outside zones are lacking because most beach profile surveys do not extend adequately seaward. Data measuring the active and outside zones are rare, and only a few beaches in the world such as Duck, North Carolina have data that captures most of the active zone (Lee et al., 1998).

Beach profiles have also been used to document the recovery processes. Based on analysis of beach profiles on the Texas coast before and after Hurricane Alicia, Morton et al. (1994) found that the backshore took longer to recover than the foreshore. Thom and Hall (1991) showed that it took several years for the volume of subaerial beaches to recover. In combination with the study of shoreline response to storms (List et al., 2006), these results imply that shoreline and beach volume may recover at different rates. However, the relationship between shoreline and volume change has not been examined in detail. 
Beach profiles are an effective method for estimating sediment volume change, but cost limitations usually require that profiles be widely spaced alongshore to quantify large-scale changes. The large spacing between profiles limits the accuracy of volume change estimates. Alternatively, subaerial beach volume changes can be estimated by assuming that volume changes are proportional to variations in beach width. Several studies have established a linear relationship between the subaerial volume $(V)$ and beach width $(W)$ at a specific location:

$$
V=K W
$$

where the coefficient $K$ is estimated using $V$ and $W$ from a time series of beach profile measurements at individual transects. In Australia, Thom and Hall (1991) measured $K$ values ranging from 2.55 to $2.76 \mathrm{~m}^{2}$ for 4 beach profiles. In Monterey Bay California, Dingler and Reiss (2002) found that $K$ values vary considerably from 1.95 to $4.42 \mathrm{~m}^{2}$ for 7 different beaches. The number of profiles that were used to determine $K$ in these two studies was limited, thus the alongshore variability of $K$ for a single beach has yet to be determined. If there is significant alongshore variation in $K$, then $K$ cannot be treated as a constant, and Equation 3-1 would become location specific. In such a case, it would be very difficult to use temporal variations in beach width to quantify subaerial beach changes at a larger scale. Therefore, it is critical to know how $K$ changes alongshore when applying shoreline positions to estimate subaerial volume.

Panama City on the Florida Gulf of Mexico coast was impacted by Hurricane Ivan in 2004. Five airborne laser surveys measured Panama City beaches before and after Ivan, which produce a unique, high-resolution data set to study the response of lowenergy beaches to a storm. The objectives of this study are: 
1) to determine if there is a correlation between landward shoreline migration induced by a storm and its subsequent seaward migration during recovery,

2) to determine the relationship between beach width and subaerial volume changes, and

3) to quantify sediment redistribution in the active zone and sediment exchange between the active and outside zones.

\section{STUDY AREA}

The Panama City area is located within the Coastal Lowlands (White, 1970) of the Gulf Coastal Plain Physiographic Province (Hunt, 1974). The Province is a wide coastal plain that contains Late Cretaceous to Holocene sedimentary deposits, and this study focuses on the Holocene sediments that have been reworked by waves and currents. Panama City is located between the Apalachicola delta to the east and detached offshore barrier islands with large dunes to the west. The Apalachicola delta received much its sediments from the Appalachian Mountains millions of years ago, and the delta region is a primary source of sediment to Panama City beaches due to the dominant east to west littoral transport (Davis, 1997).

Panama City beaches are on the northwest coast of Bay County, Florida facing the Gulf of Mexico. The study area is located between the Walton-Bay County line and St. Andrews Inlet (Figure 3-1). The shoreline orientation is northwest to southeast, and slightly concave toward the Gulf. This study investigates more than $23 \mathrm{~km}$ of sandy beaches consisting of fine sand to silty sand with shell fragments and a mean grain size of $0.24 \mathrm{~mm}$. The beaches were renourished in 1999 throughout most of the study area, and $4 \mathrm{~km}$ east of the eastern section was further renourished in 2002. The mean tidal range is 
$0.37 \mathrm{~m}$, making the coast microtidal but not necessarily wave dominant. The average deep-water (290 m) significant wave height at NOAA buoy 42039 is $1 \mathrm{~m}$, with September through April greater than $1 \mathrm{~m}$, and May through August below $1 \mathrm{~m}$.

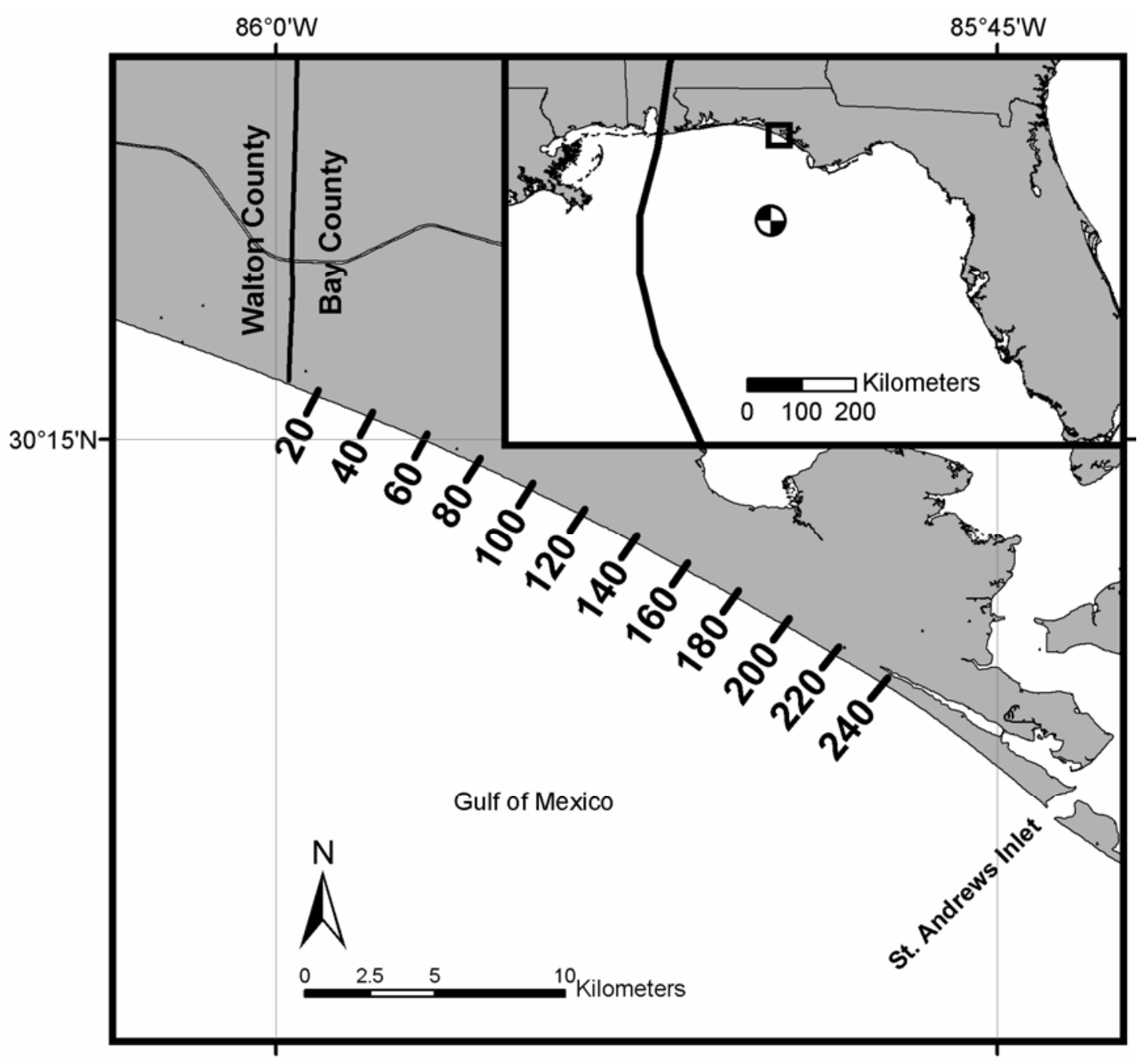

3-1. Map of the study area near Panama City, Florida showing locations of beach transects, track of Hurricane Ivan, and location of NOAA offshore wave buoy 42039.

Hurricane Ivan made landfall east of Mobile, Alabama on September 16, 2004 with maximum sustained winds of $58 \mathrm{~m} / \mathrm{s}$ (Leadon, 2004). Panama City was over 100 $\mathrm{km}$ to the east of the hurricane's landfall with estimated sustained wind speeds of $27 \mathrm{~m} / \mathrm{s}$ (Figure 3-2). The storm surge in the study area was less than $2.5 \mathrm{~m}$ resulting in minor 
overwash and dune erosion (Figure 3-3). Beach change was primarily caused by large waves generated by the hurricane. Significant wave heights greater than $12 \mathrm{~m}$ were measured during Hurricane Ivan from a NOAA buoy (42039) $150 \mathrm{~km}$ offshore. There were two high wave events following Hurricane Ivan, but both were in the offshore direction (Figure 3-4). During early fall, Panama City experienced at least four large onshore wave events.

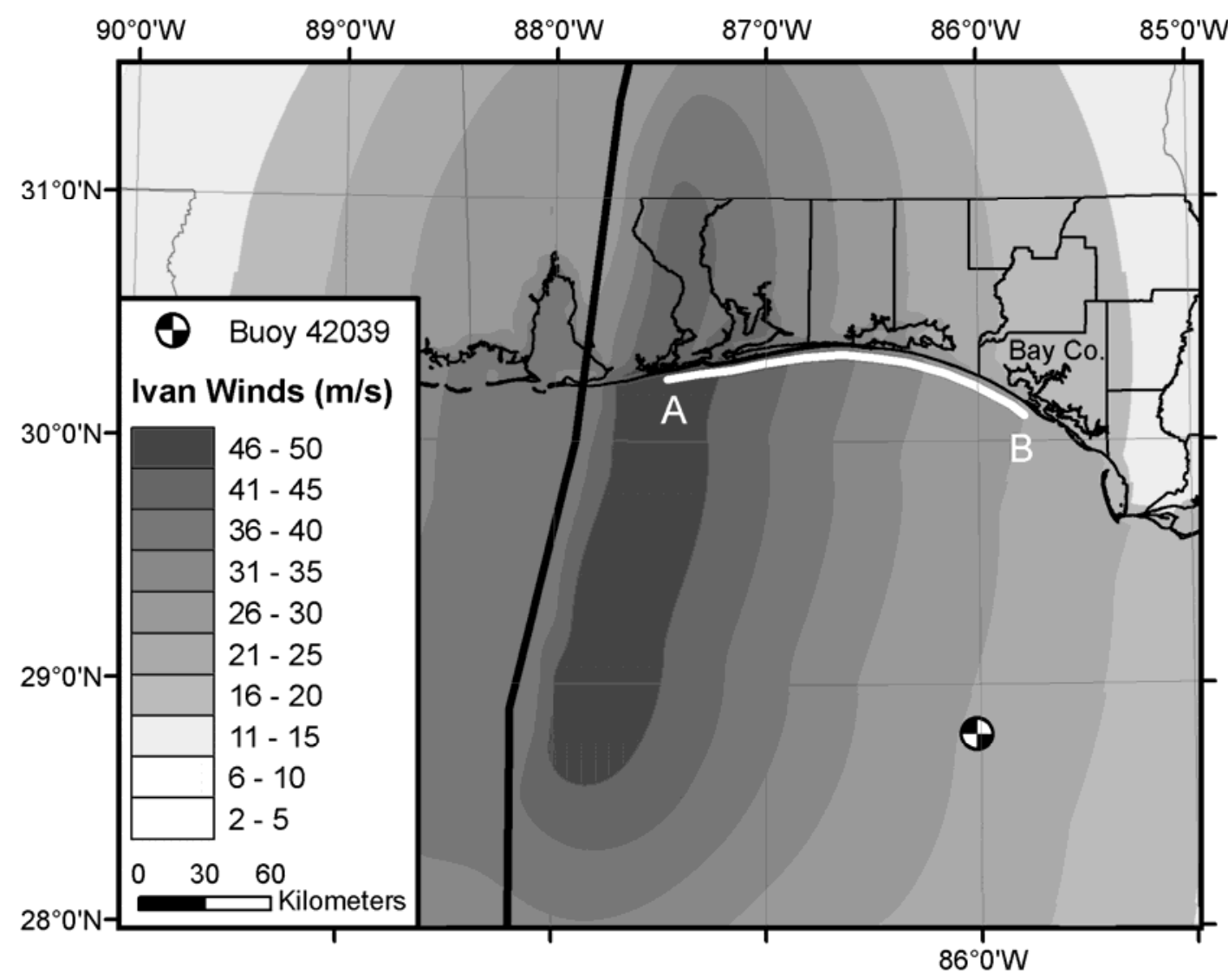

3-2. Map of Hurricane Ivan wind speeds with storm track, location of NOAA offshore wave buoy 42039 , and Transect A to B displayed in Figure 3-3. Wind data courtesy of NOAA's Hurricane Research Division. 


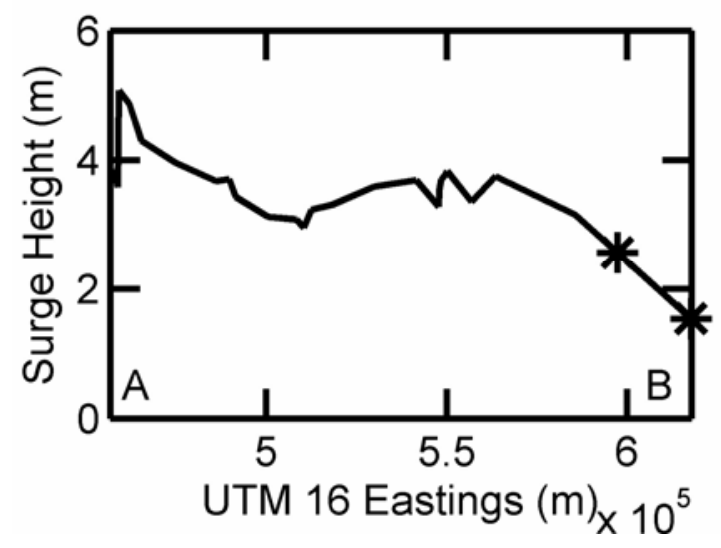

3-3. FEMA surveyed high water marks for Transect A to B in Figure 3-2. The study area is between the asterisks.
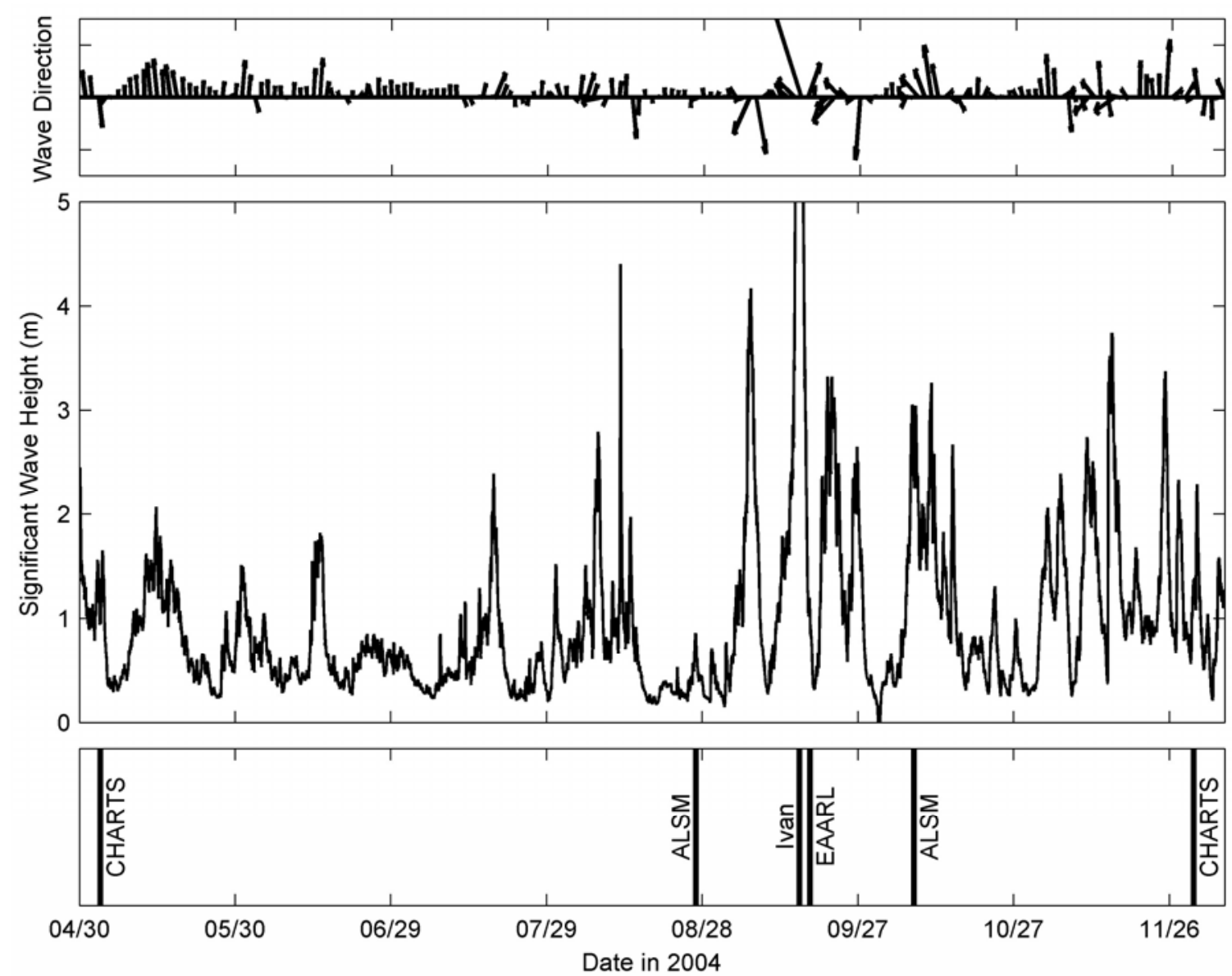

3-4. Significant wave height and wave direction for NOAA buoy 42039 offshore of Panama City during 2004 with timeline showing when airborne laser data were collected and their proximity to Hurricane Ivan. Middle plot represents significant wave height. Upper plot is wave direction, with north at the top of the page. Dates of airborne laser data collections are vertical lines. CHARTS data collection dates were provided in ranges, thus the median date was chosen. 


\section{DATA AND METHODS}

Beach response to a storm occurs three dimensionally, and two-dimensional shoreline and profile measurements limit the understanding of beach response to storms. Until the advent of airborne laser mapping technology (also known as LIDAR), it has been extremely difficult to derive three-dimensional measurements of beach change with sufficient resolution and accuracy. Airborne laser measurements can satisfy many of the needs for quantifying three dimensional coastal change with horizontal resolutions less than several meters and vertical accuracies near 0.15 m RMS (Sallenger et al., 2003). Past coastal studies have shown that shoreline position, beach profile, and beach volume change can be obtained by comparing multiple airborne laser data sets (Irish and White, 1998; Robertson et al., 2004; Robertson et al., 2005; Stockdon et al., 2002; Zhang et al., 2005).

\section{Airborne Laser Data}

Airborne laser mapping is an active remote sensing technology that utilizes a pulsed laser to measure the range between an airborne platform and the Earth's surface. Five airborne laser data sets (Figure 3-4) were collected in 2004 using three systems: the University of Florida and Florida International University's airborne laser swath mapper (ALSM), NASA's experimental airborne advanced research LIDAR (EAARL), and the United States Army Corps of Engineers compact hydrographic airborne rapid total survey (CHARTS). Each system operates somewhat differently, and thus produces a different type of airborne laser data set.

The ALSM instrument is an Optech ALTM 1233 topographic airborne laser system that fires a laser in the near-infrared spectrum $(1.1 \mu \mathrm{m})$. The laser pulses cannot 
penetrate the water column, so the ALSM instrument is only capable of deriving terrestrial surface measurements. A pulse rate of $33 \mathrm{kHz}$ was used which produced less than one meter point spacing on the ground for each flight line. The EAARL system sampled at $3 \mathrm{kHz}$, yielding a relatively sparse $5 \mathrm{~m}$ nominal point spacing per flight line. EAARL utilizes a green laser $(0.532 \mu \mathrm{m})$ which can penetrate water and measure bathymetry. In this study, however, the EAARL data did not extend sufficiently offshore and only terrestrial measurements were used. The CHARTS system uses two lasers, one green and one near-infrared. The green laser is fired at $1 \mathrm{kHz}$ to measure bathymetry, and the near-infrared laser measures topography at $9 \mathrm{kHz}$. This produced a nominal $8 \mathrm{~m}$ point spacing for the bathymetry and a $2 \mathrm{~m}$ point spacing for the topography for each flight line. Due to multiple flight lines, the resulting point density for each airborne laser data collection is slightly higher.

Airborne laser elevations often contain systematic errors that produce offsets between different data sets. Primary sources for airborne laser errors are erroneous laser calibration parameters and inaccurate GPS trajectories. End users are not able to correct laser calibration errors due to unattainable raw data and the proprietary software needed to produce laser points. GPS errors are often generated by incorrect monument elevations and GPS drift caused by inadequate modeling of the changing GPS satellite geometry. If the laser system is properly calibrated and the GPS drift are not large, then the offsets due to GPS errors throughout the data sets for a shoreline less than $50 \mathrm{~km}$ are usually systematic and constant. Fixing systematically shifted data to a known elevation significantly reduces errors in the laser elevations. 
This study compared all five airborne laser data sets to a GPS-surveyed profile on a road surface not influenced by overwash and at multiple locations throughout the study area similar to the technique used by Zhang et al. (2005) and Robertson et al. (2005). The surveyed profile is an independent, high accuracy data set that was collected using rapid-static GPS with a short baseline and consisted of 312 points over $5 \mathrm{~km}$. The GPS profile was located at the western end of the study area approximately $100 \mathrm{~m}$ landward of the shoreline. Mean differences between airborne laser surfaces and the surveyed profile ranged between 0.04 and $0.28 \mathrm{~m}$. The same offsets were found at multiple locations throughout the study area, indicating that the differences between laser surfaces were constant. Offsets were removed by vertically shifting the airborne laser data sets to match the GPS survey data under an assumption that the road surface did not change during the short study period. This procedure resulted in RMS errors of less than $0.10 \mathrm{~m}$ between the airborne laser gridded surfaces and the GPS survey.

Filtering the airborne laser data was necessary since several of the data sets were collected during mid-day hours when the beach was scattered with people and beach accessories. These objects can contribute to inaccurate shoreline positions and volume change. Based on previous studies, a progressive morphological filter with a $3 \mathrm{~m}$ window and 0.05 slope was used to effectively remove the non-terrestrial data without altering the natural beach morphology (Zhang and Whitman, 2005; Zhang et al., 2003).

The final step in processing airborne laser data involved interpolating the irregularly-spaced laser measurements onto a regularly-spaced grid to produce a set of digital elevation models (DEMs). The data were gridded at $1 \mathrm{~m}$ resolution using kriging interpolation with a linear variogram. DEMs for each flight were produced with a 
common origin and cell size to ensure registration. The DEMs were then analyzed to produce elevation contours and transects, or differenced to produce measurements of shoreline and volume change.

\section{Shoreline and Beach Width Change}

The calculation of shoreline change is dependent upon a shoreline that can be measured with consistent methodologies over time. Unfortunately, airborne laser data do not directly measure the wet-dry interface that has historically represented the shoreline position. Recent studies have shown that an elevation contour derived from airborne laser data can represent the shoreline position (Moore et al., 2006; Sallenger et al., 2003; Stockdon et al., 2002). Robertson et al. (2004) found that a contour generated at the mean higher high water (MHHW) tidal datum is compatible to the wet-dry line for North and South Carolina. For this study, the local MHHW datum of $0.30 \mathrm{~m}$ (all elevations in this dissertation are referenced to the NAVD88 datum) produced a noisy contour in some of the laser data sets due to being located seaward of the land-water interface. To avoid this problem, the shoreline contour was located at the $0.60 \mathrm{~m}$ elevation which is below the measured berm crest observed in the study area. The horizontal difference in shoreline positions corresponding to the MHHW datum and $0.60 \mathrm{~m}$ contour was on average less than $3 \mathrm{~m}$ due to a steep beach face slope at the foreshore.

Beach width is defined as the distance from the dune toe to the shoreline. Grids representing degrees of slope were visually compared in a GIS to digitized dune toe positions from DEMs and orthophotographs. A $6.5^{\circ}$ slope most closely matched the digitized dune toe positions, but this study was unable to use slope because the $6.5^{\circ}$ contours generated from the slope grids were not continuous. Therefore, dune toe 
positions were determined using a contour of $3 \mathrm{~m}$ because dune toe positions match this continuous contour well. Calculations of beach width were the horizontal difference between the dune toe and shoreline position for each respective airborne laser survey.

Spatial changes in shoreline and beach width were analyzed using a GIS-based metric mapping system (Robertson et al., 2005; Zhang et al., 2005). This system generates a set of transects perpendicular to the shoreline and calculates the intersection of each transect to shorelines or other linear features. Two hundred and thirty-seven transects (numbered 18-255, Figure 3-1) spaced at $100 \mathrm{~m}$ intervals were analyzed over the area of beach covered by all 5 airborne laser datasets. Distances for each transect from a fixed offshore reference line to each dune toe and shoreline position of the five temporal surveys were measured, and the distances were exported to an ASCII table. Differences between distances were then used to calculate changes in beach width and shoreline over time.

\section{Volume Change}

The DEMs derived from multiple airborne laser data allow an estimation of beach volumes. Volume change was quantified by differencing the DEM surfaces. Analysis of the difference grid allows for the quantification of sediment movement through the series of bins bounded by adjacent transects (Figure 3-1). Two types of volume change were calculated in this study: subaerial and active beach (profile) zones. The subaerial zone was measured between the dune toe and the shoreline location for each respective data set (Figure 3-5). Subaerial volume was calculated using all five airborne laser data sets. Active beach zone change was limited to the two bathymetric CHARTS data sets. The active beach profile was measured from the dune toe to the furthest seaward extent of the 
December CHARTS data (Figure 3-5). The December CHARTS data measured to a distance of about $500 \mathrm{~m}$ offshore and an approximate depth of $11 \mathrm{~m}$, whereas the May CHARTS data measured to a distance of about $1000 \mathrm{~m}$ offshore and an approximate depth of $19 \mathrm{~m}$.

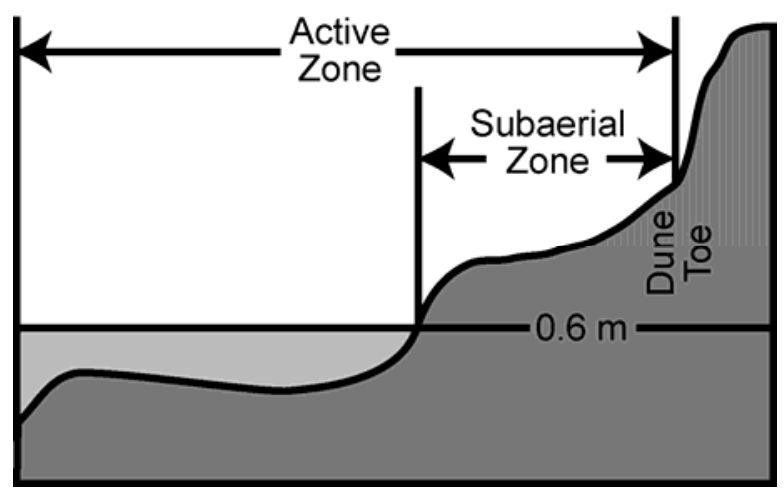

3-5. Simplified beach profile showing the active and subaerial zones defined in this study. Not to scale, as active zone is significantly wider than subaerial zone.

Volume change within each bin was summarized in terms of the total positive, negative, and net volume change (Zhang et al., 2005). The volumes were then normalized by the bin width $(100 \mathrm{~m})$ resulting in a table of positive, negative, and net volume change per alongshore length $\left(\mathrm{m}^{3} / \mathrm{m}\right)$. Positive grid values in a bin represent areas of accretion whereas negative grid values represent areas of erosion. Since little overwash occurred in the study area due to the low surge height and high dunes, sediment exchange across the landward boundary of the bin was negligible. The sediment exchange mainly occurred across the seaward boundary of the bin and across the two lateral boundaries.

\section{RESULTS}

The alongshore variations in beach width and volume calculated from the five airborne laser data sets are shown in Figures 3-6 and 3-7. There is a high alongshore 
variability in beach width and subaerial volume. In general, areas of large beach width and volume correspond to coastlines with less coastal infrastructure, while areas of small beach width and volume tend to be adjacent to infrastructure that is close to the shoreline and often protected by hard and soft stabilization. In addition, beaches in the western section of the study area are on average about $10 \mathrm{~m}$ narrower with standard deviations 4 $\mathrm{m}$ smaller than in the eastern section (Figure 3-6). The boundary separating the west and east section is located approximately at the $13 \mathrm{~km}$ distance. The alongshore variability in beach volume exhibits a similar spatial pattern (Figure 3-7). These general spatial relationships changed little throughout the study period.

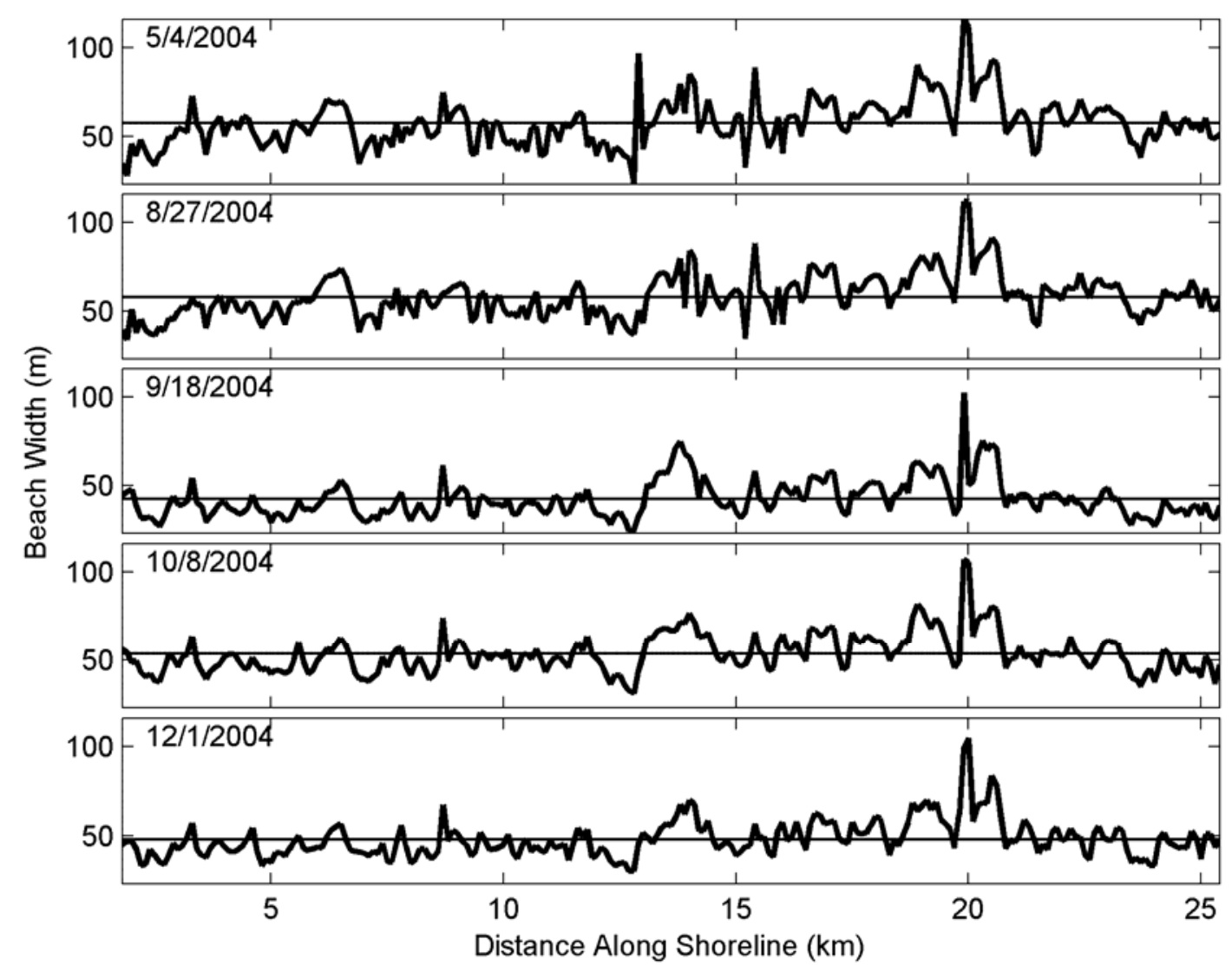

3-6. Evolution of beach width over time for Panama City beaches. Top to bottom are the five sequential data sets from Figure 3-4, starting with the May 5, 2004 CHARTS data. Distance along shoreline is from west to east. Horizontal lines are average beach width for the respective date. 


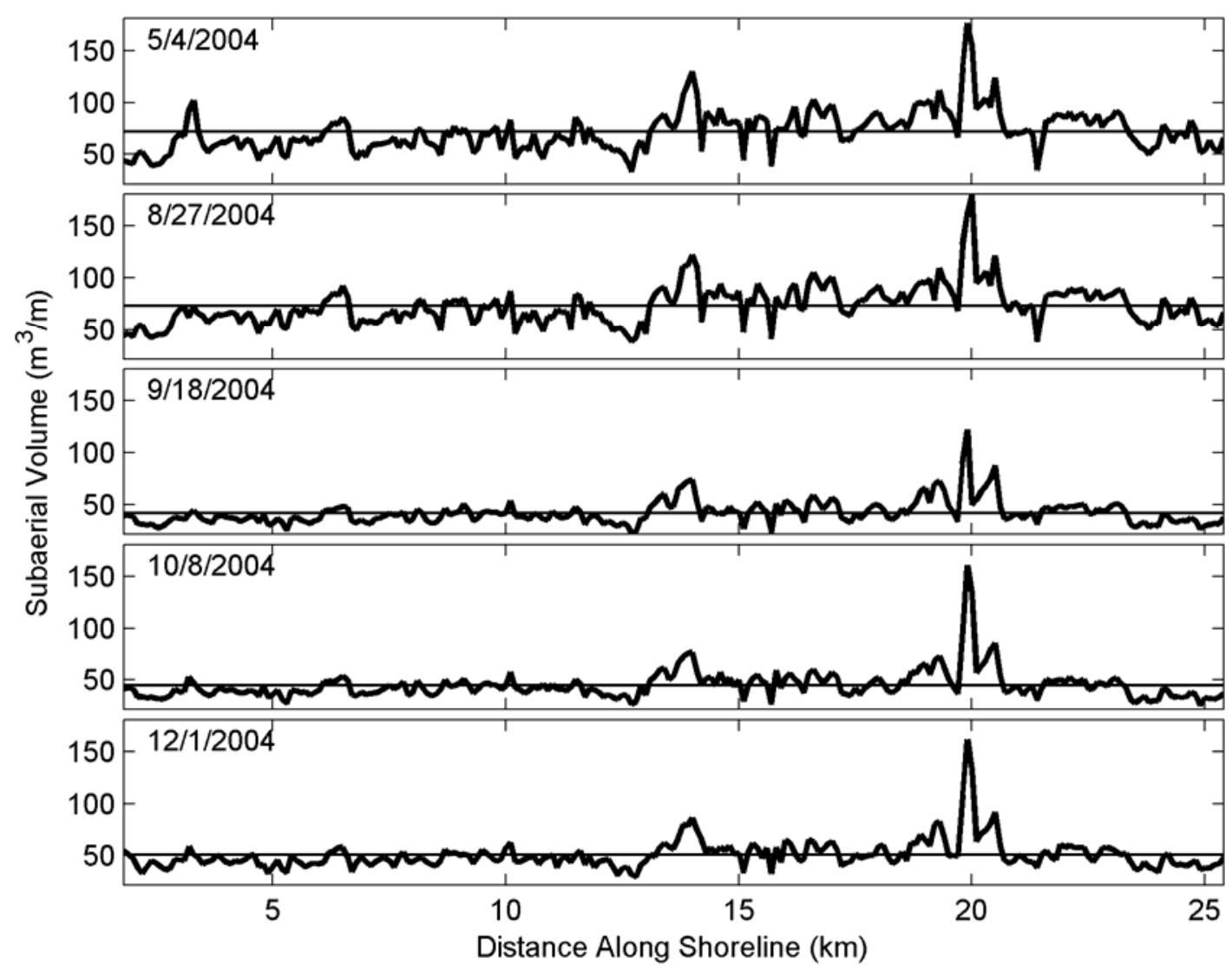

3-7. Evolution of subaerial volume over time for Panama City beaches in 2004. Top to bottom are the five sequential data sets from Figure 3-4, starting with the May CHARTS data. Distance along shoreline is from west to east. Horizontal lines are average subaerial volume for the respective date.

\section{Shoreline Migration, Beach Width Change, and Subaerial Beach Volume Change}

The five data sets formed the basis for quantifying beach change into four time intervals between the data acquisitions (Figure 3-4): May 4 to August 27 for summer change (115 days), August 27 to September 18 for change caused by Hurricane Ivan (22 days), September 18 to October 8 for change during the post-Ivan recovery period (20 days), and October 8 to December 1 for fall change (54 days). Summary statistics for each time period are provided in Table 3-1. Hurricane Ivan caused significant landward shoreline migration with a reduction of the average beach width from $58 \mathrm{~m}$ to $42 \mathrm{~m}$ 
(Figure 3-6, 8/27/04 to 9/18/04). In addition, subaerial volume was reduced from an average of $73 \mathrm{~m}^{3} / \mathrm{m}$ to $42 \mathrm{~m}^{3} / \mathrm{m}$ (Figure 3-7, 8/27/04 to $9 / 18 / 04$ ). This period of shoreline retreat and erosion was followed by a relatively rapid recovery in beach width from $42 \mathrm{~m}$ to $53 \mathrm{~m}$ (Figure 3-6, 10/8/04). Somewhat surprisingly, a corresponding recovery in subaerial beach volume did not occur (Figure 3-7, 10/8/04).

3-1. Panama City shoreline (S), beach width (W), and subaerial volume (V) change for four periods in 2004. First numeric column represents mean change, SD represents standard deviation.

\begin{tabular}{lllll}
\hline Date Range & $\mathrm{dS}(\mathrm{m})$ & $\mathrm{dS}$ SD & Min dS & Max dS \\
\hline Summer & 2.3 & 1.9 & -4.0 & 6.3 \\
Hurricane Ivan & -16.5 & 3.4 & -22.8 & -3.1 \\
Recovery & 10.1 & 2.3 & 1.9 & 14.3 \\
Fall & -6.0 & 2.7 & -14.7 & 2.3 \\
\hline & $\mathrm{dW}(\mathrm{m})$ & $\mathrm{dW}$ SD & Min dW & Max dW \\
\hline Summer & 0.8 & 2.4 & -5.7 & 5.3 \\
Hurricane Ivan & -16.2 & 5.0 & -31.0 & 0.2 \\
Recovery & 11.2 & 2.4 & 2.3 & 19.0 \\
Fall & -5.4 & 2.7 & -13.9 & 2.4 \\
\hline & $\mathrm{dV}\left(\mathrm{m}^{3} / \mathrm{m}\right)$ & $\mathrm{dV} \mathrm{SD}$ & Min dV & Max dV \\
\hline Summer & 1.2 & 2.8 & -12.7 & 5.8 \\
Hurricane Ivan & -30.9 & 7.7 & -57.9 & -12.2 \\
Recovery & 2.7 & 3.7 & -0.6 & 27.5 \\
Fall & 5.7 & 1.9 & 0.5 & 11.8 \\
\hline
\end{tabular}

Shoreline, beach width, and subaerial volume differences between sequential data sets over 4 time periods provide more details of the alongshore beach change (Figure 3-8, Table 3-1). For this analysis, a $500 \mathrm{~m}$ moving average filter was applied to each differenced data set to reduce the noise caused by high frequency spatial variations. Shoreline and beach width change signals were similar, which was expected because beach width was calculated using shoreline position, and the dune toe position changed little during the study period. Comparison of shoreline and subaerial beach volume change in Figure 3-8 illustrates that both measures show seaward shoreline migration and 
profile accretion during summer months and significant landward migration along with erosion due to Hurricane Ivan. Following Hurricane Ivan, the relationships between shoreline migration and volume change differ remarkably. The shoreline shows significant seaward migration during recovery, while subaerial volume increased only 2.7 $\mathrm{m}^{3} / \mathrm{m}$ (Table 3-1). Shoreline and subaerial volume change differed during fall as well, with a landward migration of shoreline, but an increase in subaerial volume.

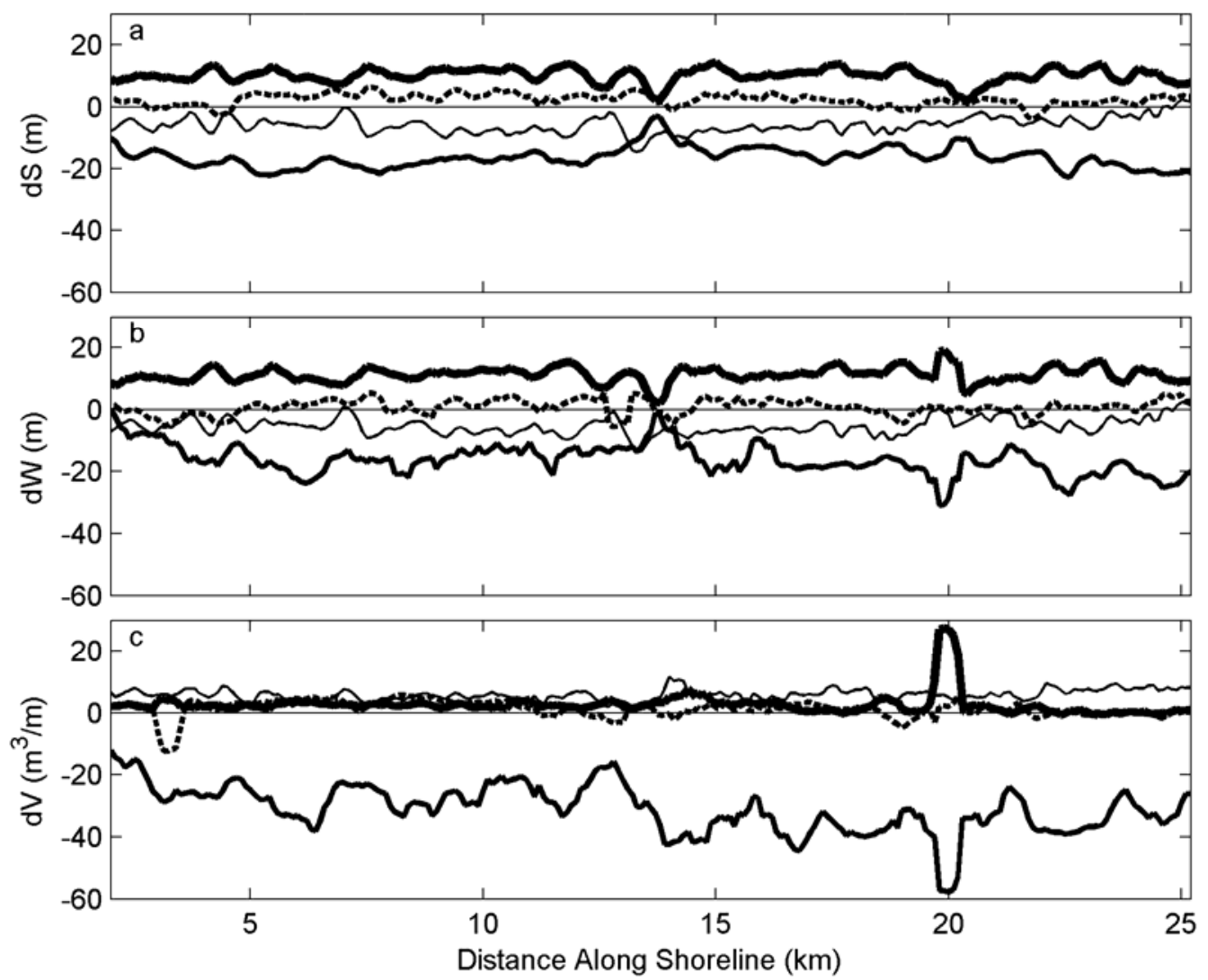

3-8. (a) Alongshore shoreline, (b) beach width, and (c) subaerial volume change calculated over four time periods in 2004. Lines correspond to the time intervals defined in Results: dashed line (summer, $5 / 4$ to 8/27), medium line (Ivan, 8/27 to 9/18), thick line (recovery, 9/18 to 10/8), and thin line (fall, 10/8 to 12/1). Distance along shoreline is from west to east.

Previous studies have found strong correlations between shoreline migration caused by hurricanes and the subsequent recovery periods (List et al., 2006). Linear correlation coefficients were calculated to test the relationships between change in 
shoreline position, beach width, and subaerial volume (Table 3-2). Shoreline migration caused by Hurricane Ivan and its subsequent recovery were weakly correlated (-0.38). Slightly higher correlations were found with the change in beach width (-0.44) and subaerial volume (-0.46) in the same period. For this dataset consisting of 137 transects, the critical t-value at the $95 \%$ significance level is 1.98 . This corresponds to a critical value of \pm 0.17 for the correlation. Therefore, the correlations between each relationship with exception to the summer to Hurricane Ivan change in subaerial volume are statistically significant.

3-2. Correlation coefficients for changes in shoreline position (S), beach width (W), and subaerial volume (V) for respective time intervals.

\begin{tabular}{llll}
\hline & $d S R^{2}$ & $d W R^{2}$ & $d V R^{2}$ \\
\hline Summer - Ivan & -0.20 & -0.22 & 0.02 \\
Ivan - Recovery & -0.38 & -0.44 & -0.46 \\
Recovery - Fall & -0.37 & -0.28 & -0.18 \\
\hline
\end{tabular}

\section{Relationship Between Beach Width and Subaerial Volume}

Previous studies have proposed a temporal linear relationship between beach width and subaerial volume (Dingler and Reiss, 2002; Thom and Hall, 1991) where $K$ is the constant of proportionality between beach width and volume (Equation 3-1). This study utilized the high spatial resolution of airborne laser measurements to examine the alongshore variation in $K$. Beach width and subaerial volume were regressed over the five data acquisitions in each of the 237 bins.

Figure 3-9a shows that $K$ varies considerably alongshore, ranging between 0.75 and $1.79 \mathrm{~m}^{2}$ with a mean of $1.09 \mathrm{~m}^{2}$. However, this study utilizes only five airborne laser data sets during 2004; therefore not all $K$ values are significant due to the limited sample size. The critical t-value at the $95 \%$ significance level with 5 samples is 3.18 . This 
corresponds to a critical $\mathrm{R}^{2}$ value of 0.77 , and values below 0.77 indicate linear relationships are not significant between beach width and subaerial volume. When only analyzing transects above the critical $\mathrm{R}^{2}$ value (66 of 237), the high variability in $K$ remained, ranging from 0.75 to $1.79 \mathrm{~m}^{2}$ with a mean of $1.10 \mathrm{~m}^{2}$.
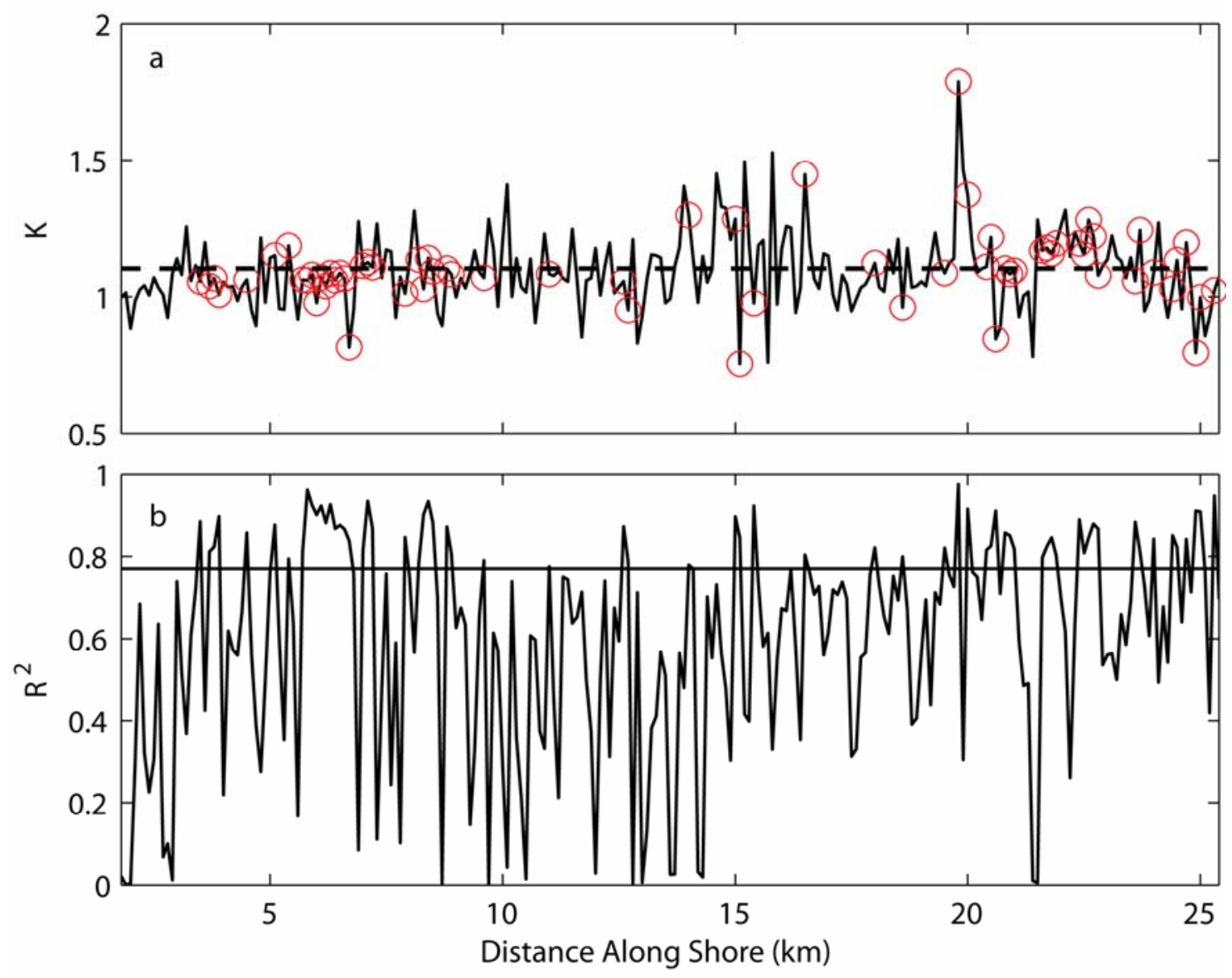

3-9. Alongshore (a) $K$ values and their respective (b) $\mathrm{R}^{2}$ values for the 237 transects measured on Panama City beaches, from west to east. Dashed horizontal line (a) is the mean. Circles represent statistically significant $K$ values discussed Results. Solid horizontal line (b) is the critical $\mathrm{R}^{2}$ value of 0.77 at $95 \%$ significance.

\section{Active Zone Sediment Movement}

The two CHARTS airborne laser data sets allow quantification of both onshore and offshore sediment movement. The net sediment exchange $\left(V_{N}\right)$ represents the 
amount of sediments added or removed from a bin and is equal to the sum of the deposition $\left(V_{D}>0\right)$ and erosion $\left(V_{E}<0\right)$ :

$$
V_{N}=V_{D}+V_{E}
$$

Results show that on average $27 \mathrm{~m}^{3} / \mathrm{m}$ of sediment left the measured area during the summer to fall time period (Table 3-3). Net sediment exchange is helpful when quantifying changes for an entire study area, but it includes both removal and deposition of sediment and cannot distinguish the magnitudes of erosion and accretion that occur within the active profile zone. The amounts of sediment redistribution within the active profile zone and the relative magnitude of sediment exchange with the outside zone are critical for designing coastal engineering projects. If all sediment are contained in a given bin, then $V_{N}=0$. For this case, $V_{D}$ and $V_{E}$ are equal in magnitude, all sediment movement is due to redistribution, and the volume of redistributed sediment is equal to $V_{D}$ (or $\left|V_{E}\right|$ ). For most cases, the net sediment exchange is not zero. Therefore, the volume of redistributed sediment is equal to the lesser of the volumes of deposition or erosion. Thus, the volume of redistributed sediment $\left(V_{R}\right)$ within the bin can be expressed as:

$$
V_{R}=\min \left(V_{D},\left|V_{E}\right|\right)
$$

The following ratio is proposed:

$$
R_{V}=\frac{V_{N}}{V_{R}}
$$

to measure the relative magnitude of sediment exchange with outside areas to the sediment redistribution within a bin. When the majority of sediments are contained 
within a bin, $V_{R}$ is greater than $V_{N}$ and $R_{V}$ is less than 1 . When the majority of sediments are deposited in or eroded from a bin, $V_{N}$ is greater than $V_{R}$, and the absolute value of $R_{V}$ is greater than 1 . The sign of $R_{V}$ indicates if the net change was deposition (positive) or erosion (negative). In the rare case when the entire profile sustains deposition or erosion, then $V_{R}$ would be equal to zero. This would result in $R_{V}$ equaling positive or negative infinity, representing complete deposition or erosion. Based on change of the $R_{V}$ value, sediment movement for a bin can be separated into four categories: accretion dominated when $R_{V}$ is greater than 1 , mix of accretion and redistribution when $R_{V}$ is greater than zero but less than 1, mix of erosion and redistribution when $R_{V}$ is less than zero but greater than -1, and erosion dominated when $R_{V}$ is less than -1 (Figure 3-10).

3-3. Active zone volume change for all bins (top) and excluding bins containing borrow pits (bottom) between May and December, 2004.

\begin{tabular}{|c|c|c|c|c|c|c|c|c|c|}
\hline & \multicolumn{4}{|c|}{$\mathrm{V}_{\mathrm{N}}\left(\mathrm{m}^{3} / \mathrm{m}\right)$} & \multicolumn{4}{|c|}{$\mathrm{V}_{\mathrm{R}}\left(\mathrm{m}^{3} / \mathrm{m}\right)$} & \multirow[t]{2}{*}{$R_{V}$} \\
\hline & Mean & St.D. & Min & Max & Mean & St.D. & Min & Max & \\
\hline All Bins & -27 & 59 & -238 & 136 & 177 & 36 & 51 & 241 & -0.21 \\
\hline Borrow Pit Bins Excluded & -13 & 47 & -153 & 136 & 184 & 32 & 83 & 241 & -0.07 \\
\hline
\end{tabular}

The difference grid from two CHARTS DEMs was further analyzed to examine the spatial change of $R_{V} . R_{V}$ for the entire study area is -0.21 , indicating that the sediment movement was dominated by redistribution and a relatively small amount of sediment moved further offshore or alongshore (Table 3-3, Figure 3-10). This agrees with the pattern of sediment movement in the active zone from the summer and winter conceptual model. For 224 out of the 237 transects, the magnitude $R_{V}$ is less than 1 and greater than -1 , indicating that most sediment was redistributed within the same bin. In 12 locations, however, the active zone shows mostly erosion $\left(R_{V}<-1\right) . R_{V}$ values less than -1 are proximal to borrow pits excavated for a 1999 beach replenishment project (Figures 3-10 


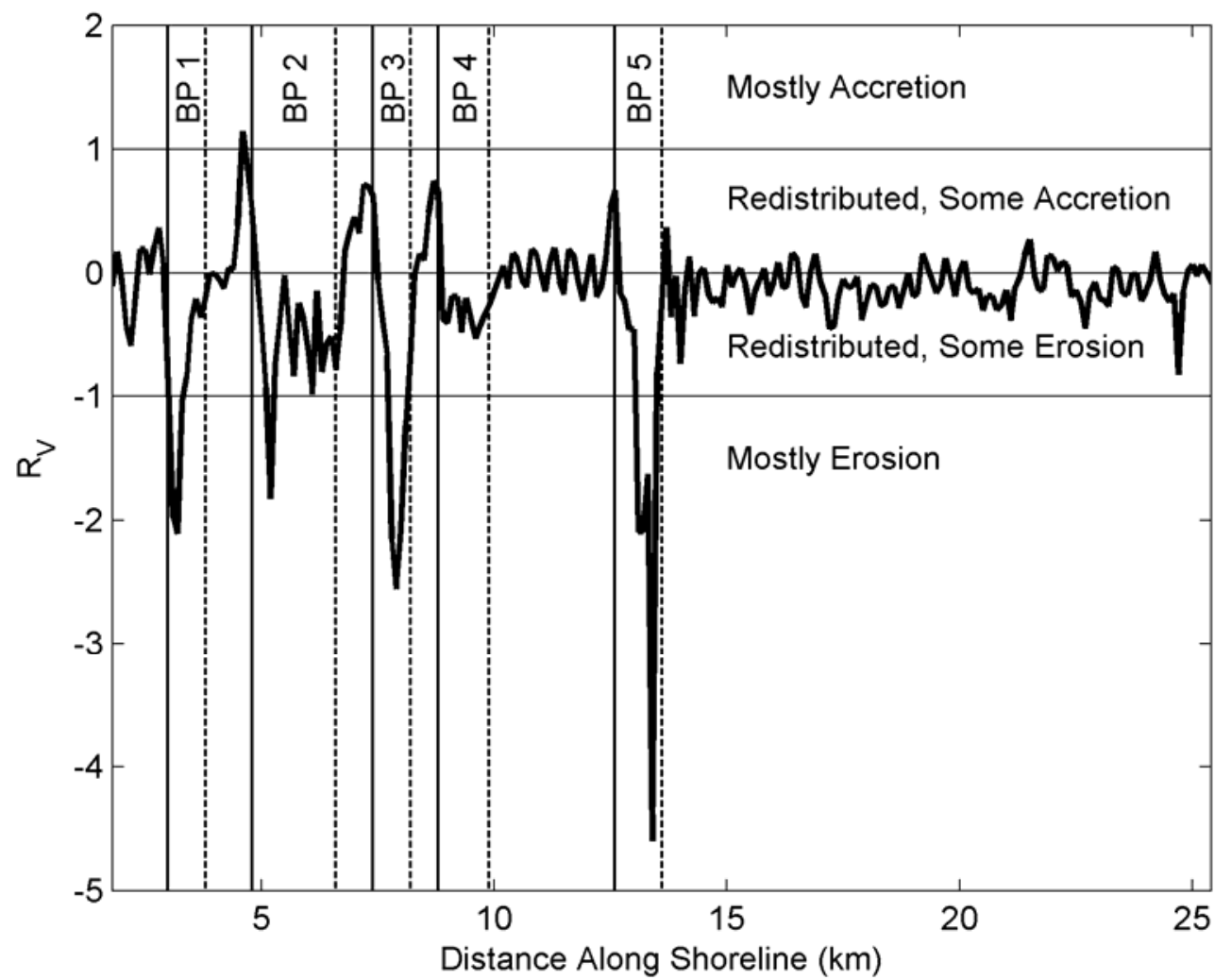

3-10. Alongshore $R_{V}$ caused by Hurricane Ivan, from west to east. Vertical solid lines are the western bounds of a borrow pit. Vertical dashed lines are the eastern bounds of a borrow pit. Horizontal lines separate change environments, from mostly accretion at top to mostly erosion at bottom. Distance along shoreline is from west to east.

and 3-11). The offshore bar inshore of a borrow pit is more eroded than offshore bars west and east of the borrow pits (Figure 3-12). It is not possible to compute the exact amount of sediment trapped by the borrow pit because the December CHARTS data do not extend seaward enough to measure the entire borrow pit.

Since incomplete coverage for a borrow pit will produce abnormally large $R_{V}$ values for bins containing borrow pits, it is necessary to remove the bins influenced by borrow pits for an estimation of the average $R_{V}$ for the study area. The locations of borrow pits were identified with the May CHARTS data and the mean $R_{V}$ were recalculated by using transect bins that did not contain borrow pits (Figures 3-10 and 3- 


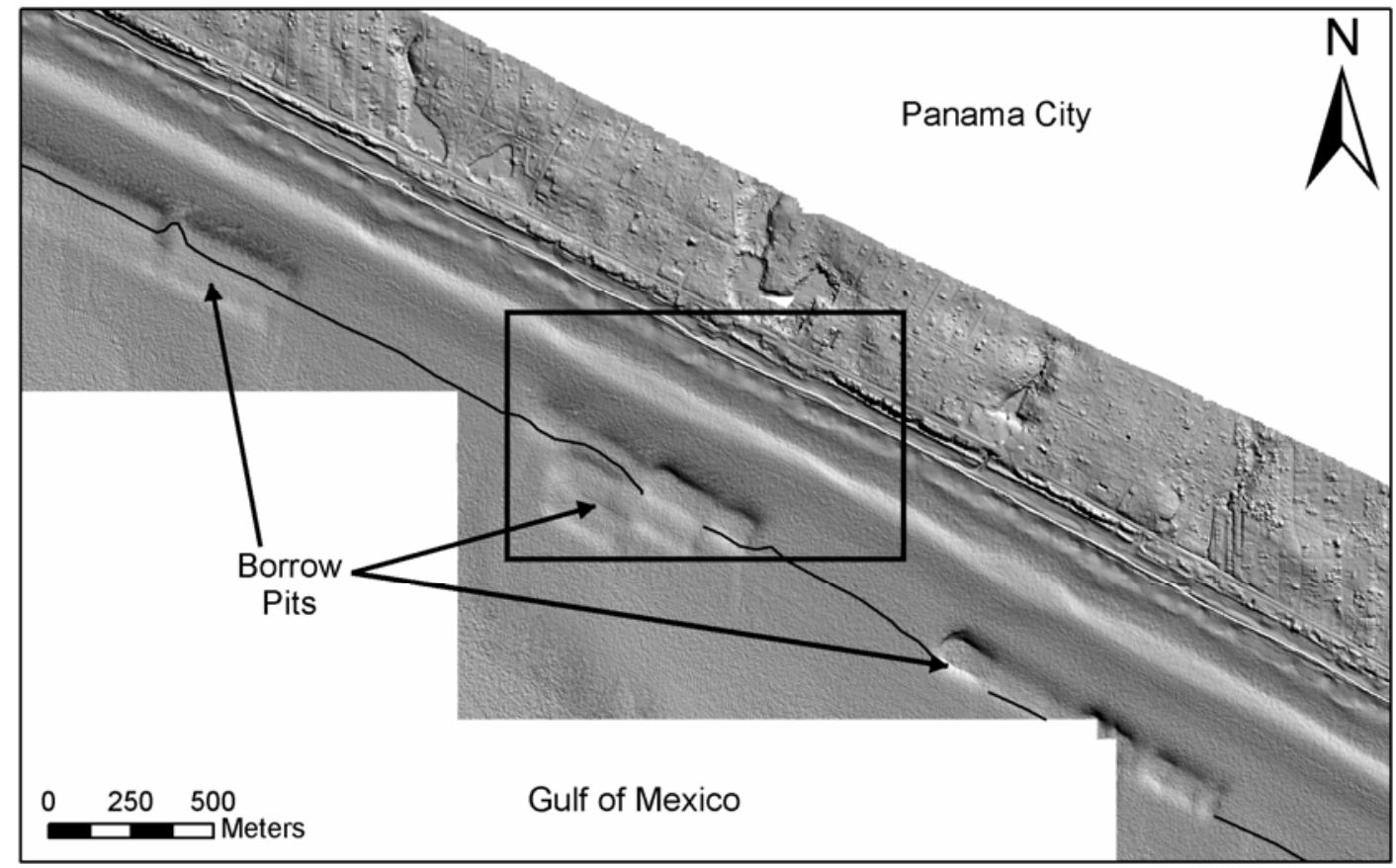

3-11. Shaded relief map of May CHARTS data. Black line is the approximate location of zero change when differencing December CHARTS data from May CHARTS data. Notice the large depressions which are borrow pit locations. Rectangle is the bounds for Figure 3-12.

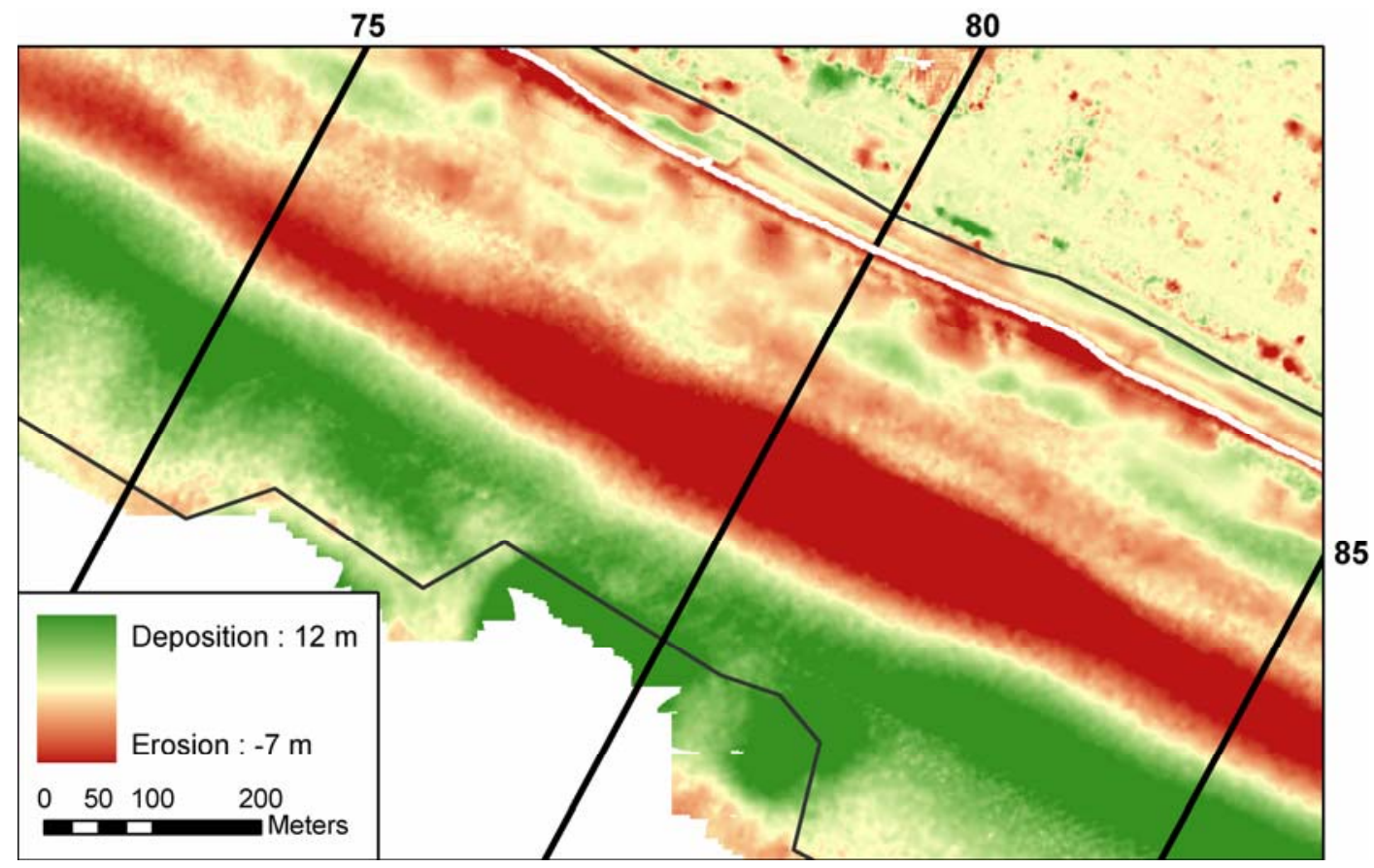

3-12. Map view of volume change in an area of borrow pit 3 (Transects 74 to 83). Red is erosion and green is accretion. White line is the shoreline extracted from the CHARTS 12/1 data, straight black lines are labeled transects, and black polyline is the active zone. Refer to transects on Figure 3-1 for location, and north is at the top of the page. Figure 3-12 limits can be seen in Figure 3-11. 
11). Removal of bins that did not contain borrow pits reduced $R_{V}$ to -0.07 (Table $3-3$ ).

The lower ratio indicates that most sediment remained within the study area from summer to fall in 2004 even with the impact of Hurricane Ivan.

\section{DISCUSSION}

Beach recovery following storm events is essential for beach sustainability. If beaches recover more at areas of higher erosion, then the natural recovery of beaches could slow landward migration of the shoreline. For North Carolina and Cape Cod coasts, List at al. (2006) found the magnitude of shoreline recovery was small at locations with less erosion and large at locations with severe erosion. It appears qualitatively that a similar relationship also exists between the Ivan-induced landward shoreline migration and recovery at Panama City beaches (Figure 3-8a). However, the correlation between landward and seaward shoreline migration is -0.38 (Table $3-2$ ), which is low compared to those reported in the List et al. (2006) study that range from -0.31 to -0.80 . The major reason for this difference is there are many erosion hot spots along North Carolina and Cape Cod coasts. Erosion hot spots are sections of coastline that erode significantly more than adjacent sections. It is the large magnitudes of landward migration at these hot spots and corresponding seaward migration during recovery that improves the correlation between shoreline changes found in the List et al. study. This study does not have large alternating erosion hot spots. The spatial variability of shoreline change is small with a standard deviation less than $3.4 \mathrm{~m}$ (Table 3-1).

Estimation of subaerial volume from shoreline change appears problematic due to the differences between shoreline and subaerial volume change curves (Figure 3-8a and 3-8c). Examination of individual beach profiles demonstrates why shoreline and 
subaerial volume do not change at the same rate. Transect 95 is representative of many profiles in the study area (Figure 3-13). Prior to Hurricane Ivan, the profile shows a well defined berm. On the September profile, the berm is significantly eroded and flattened by Hurricane Ivan with a corresponding landward migration of the shoreline and a decrease in subaerial volume. The October and December profiles show the progressive formation and landward migration of a sand ridge. The sand ridge buildup resulted in an increase in subaerial volume along with a landward migration of shoreline position during the fall period. This demonstrates that using shoreline migration to represent subaerial volume change after a storm could lead to incorrect results.

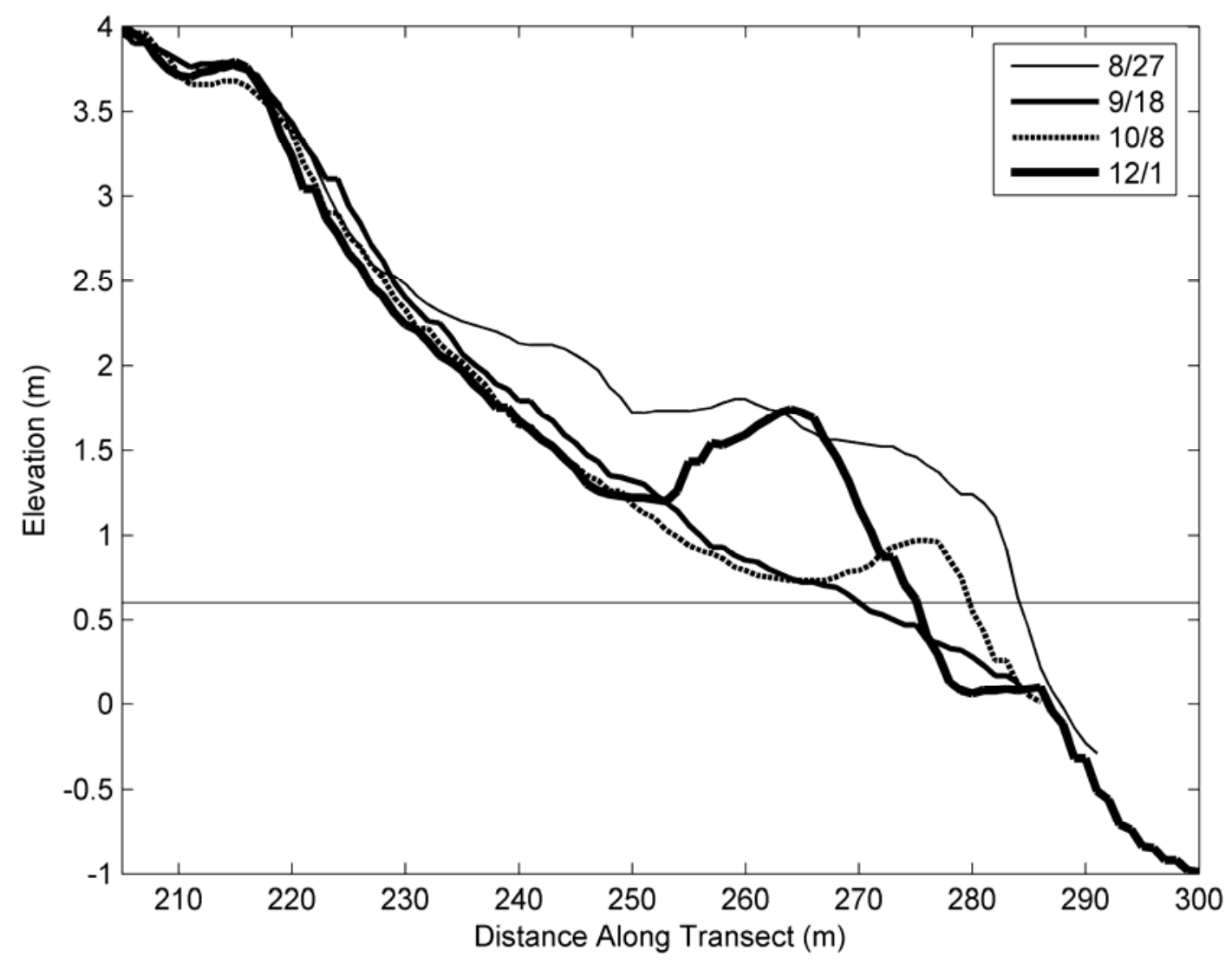

3-13. Beach profiles extracted from Transect 95 . Horizontal line is the $0.6 \mathrm{~m}$ contour used to designate the shoreline. 
Previous studies have found a temporal linear relationship ( $K$, Equation 3-1) between beach width and subaerial volume (Dingler and Reiss, 2002; Thom and Hall, 1991). These relationships were based on a time series of beach profile measurements for individual transects that were spaced far apart, often on entirely different beaches. The spatial limitation of beach profiles did not allow researchers to test alongshore variability in $K$. Airborne laser data greatly increase the spatial resolution of beach measurements, but few airborne laser data sets measuring overlapping areas exist. This study was temporally limited to 5 data sets measuring the same beaches in 2004 . It was determined that 66 of the 237 transects were statistically significant at the $95 \%$ significance level.

For the statistically significant transects, the high $\mathrm{R}^{2}$ values indicate that a strong linear relationship between beach width and subaerial beach volume exists, but the spatial variability of $K$ values suggests that the linear relationship is different from one transect to another. $K$ values for adjacent Transects 150 and 151 (15.0 and $15.1 \mathrm{~km}$ for Figure 39a) differ by 0.53 , more than $70 \%$ of the $0.75 \mathrm{~K}$ value for Transect 151 . Estimation of subaerial beach volume from beach width using Equation 3-1 with a constant $K$ value could yield large uncertainties depending on where transects were measured. Future airborne laser surveys are needed to increase the sample size to produce a more strict statistical analysis. The increased confidence will aid in determining the effectiveness of Equation 3-1.

There appears to be a "depth of closure" along the beach profile as suggested by Hallermeier $(1977 ; 1981 b)$, and sediment movement is small beyond this depth. The most seaward zero change contour for the difference grid of two CHARTS DEMs is 
located around $10 \mathrm{~m}$ in depth (Figure 3-11). Estimated depth of closure for the study area is unavailable due to lack of wave data. However, the depth of closure was estimated to be $6.3 \mathrm{~m}$ at Destin Beach in terms of extreme wave height and period exceeding 12 hours per year, about $50 \mathrm{~km}$ west of the study area (Hallermeier, 1981b). Hallermeier's estimate of the depth of closure is determined by an average wave condition. Hurricanes often induce storm waves with large heights and long periods, therefore the depth of closure for storm wave condition is larger than those from a typical annual wave condition. The borrow pits close to the depth of closure are acting as a sediment sink, thus leading to more erosion from adjacent landward bars. Since having borrow pits close to the closure depth can lead to large sediment loss from nourished beaches, it would be more effective to place borrow pits further seaward to avoid losing sediment from nourished beaches. However, poor quality sand beyond the depth of closure may limit the location of borrow pits.

The depth of closure concept forms the basis for designing coastal engineering projects such as beach nourishment, but this concept remains controversial. In general, a number of coastal geologists refute the existence of the depth of closure due to a significant sediment exchange between the active beach zone and continental shelf (Pilkey et al., 1993). Coastal engineers defend the depth of closure concept and suggest that sediment exchange between the active zone and continental shelf is insignificant over the time frame of an engineering project (less than 50 years). One key reason for this controversy is the lack of accurate large-scale three-dimensional field observations of bathymetry for the active zone. Airborne laser measurements provide unprecedented high resolution measurements of bathymetry that can reach a depth of $60 \mathrm{~m}$ in clear water 
environments such as the Florida coast (Finkl, 2004). Repeat surveys before and after storms will provide critical information for solving the depth of closure controversy. The noise in airborne laser measurements makes it difficult to accurately measure small changes $(<0.15 \mathrm{~m})$. However, the signal of sediment loss from an active zone will be much stronger because significant amounts of sediment have to be eroded from the active zone to deposit a thin layer of sediment in the offshore area. Therefore, threedimensional decadal monitoring of sand loss and gain in an active zone will allow quantification of sediment exchange between the active zone and continental shelf.

\section{CONCLUSIONS}

Large-scale beach response to Hurricane Ivan was quantified using five airborne laser data sets measuring Panama City beaches. On average, Hurricane Ivan caused $16 \mathrm{~m}$ of landward shoreline migration across the study area, and the shoreline recovered by 10 $\mathrm{m}$ in a 20-day period following the storm. The hurricane also caused similar erosion in subaerial beach volume. However, unlike the shoreline position, a corresponding recovery in subaerial volume magnitude was not observed. Sediment sources to the east combined with additional sediment from beach replenishment projects would form a beach profile vulnerable to storm-induced erosion. It appears that at least some of the eroded sediments were being returned to the beach face during the low wave environment following Hurricane Ivan.

Weak spatial relationships were found between shoreline migration caused by Hurricane Ivan and the subsequent recovery period. Beach width reduction and subaerial volume erosion due to Ivan and accretion after the storm event had low correlations as well. Spatial change in subaerial beach volume differed from shoreline and beach width 
changes, and the change was often opposite in sign. This suggests that using shoreline migration during and immediately after a storm to predict subaerial volume change can yield incorrect results. For 66 of the 237 transects, beach width and subaerial volume showed a linear relationship. However, the variation of the linear relationship alongshore suggests that the coefficient $(K)$ for a linear equation between beach width and subaerial volume are not spatially constant. The sample size for estimating $K$ is limited by five data sets. Future airborne laser surveys will provide a more strict analysis to determine if a linear relationship can be used to effectively estimate subaerial volume change from changes in shoreline position.

Sediment movement in the active zone during the summer and fall seasons was analyzed using water-penetrating airborne laser measurements. A negative net volume change suggests sediment loss, but a $-0.21 R_{V}$ value suggests most sediment remained in the measured area. Further analysis found that borrow pits, which supplied sediment for beach nourishment projects, trapped sediment transported offshore, and lead to more erosion of sand bars next to the borrow pits. The $R_{V}$ value was reduced to -0.06 when analyzing beaches not influenced by borrow pits, indicating that most sediment movement was confined to the active zone despite the impact of Hurricane Ivan. However, there appears to be some change seaward of the airborne laser data coverage, thus the full extent of sediment migration was not quantified in this study. Additional bathymetric airborne laser measurements are needed further offshore to confirm the depth of closure measurement and to fully understand the sediment exchange between the active zone and continental shelf. 


\title{
4. HURRICANE-INDUCED DEPTH OF CLOSURE DERIVED FROM AIRBORNE LASER BATHYMETRY, SOUTHEAST FLORIDA
}

\author{
ABSTRACT \\ This study develops a method to identify the depth of closure using airborne laser \\ bathymetric data, and compares the measured depth of closure to calculated depth of \\ closures and subaqueous geomorphology. Airborne laser data sets were collected before \\ and after the 2004 hurricane season along the beaches of Palm Beach, Broward, and \\ Miami-Dade Counties in southeast Florida. Calculated depth of closures in terms of \\ wave data are compatible to the measured depth of closures. However, the calculated \\ depth of closure is on average larger than was measured, especially in the southern end of \\ the study area. Horizontal differences between geomorphic maps and calculated depth of \\ closures suggest geologic control to the south of Hillsboro Inlet, where hard ground \\ consistently match the measured depth of closure. Diabathic channels best match the \\ measured depth of closure to the north. Since diabathic channels are hydrodynamically \\ formed, the northern study area appears to be hydrodynamically controlled.
}

\section{INTRODUCTION}

Protection of coastal infrastructure and public beaches has become a primary concern for coastal communities due to a rapidly increasing coastal population, active hurricane seasons, higher sea levels, and diminishing sand supplies. Strategies for preserving coastal sediments range from hard to soft stabilization, and recent trends have used soft stabilization (beach nourishment) as the principal defense from the encroaching ocean (Finkl et al., 2006b). Effective preparation for soft stabilization involves careful 
consideration when observing and modeling the geologic and physical environments, as well as locating suitable sediments and determining their ideal placement.

It is essential to not only locate sediment that will favor beach continuity, but also to mine the sediment from a location that will not disproportionately modify surrounding geomorphology that would in turn impact nearby beaches by wave forcing. A previous study has shown that mining sediment too close to the active zone removes material from the offshore sandbar (Robertson et al., 2007; Chapter 3). The locations for beach sediment extraction often rely on the determination of the depth of closure (DOC). The DOC is the location at which repetitive cross-shore profile surveys show little change (Hallermeier, 1978). Theoretically, insignificant profile change occurs seaward of the DOC, thus sand mining beyond this depth should have a minimal impact on the surrounding geomorphology. Past methods for measuring change in elevation of the sea floor included the combination of beach profiles with bathymetric (fathometer) surveys. Unfortunately, these methods were both time consuming and cost prohibitive, thus few surveys occurred. Limitations in coastal measurement methods have forced researchers to estimate the DOC from linear relationships derived from models and confirmed by site-specific field data.

Hallermeier (1977) assumed that most sediments eroded during storm events remained in relatively shallow water, and he calculated the DOC based on the wave energy needed to suspend and transport bottom sediments. By using linear wave theory, Hallermeier (1978) proposed the popular equation for estimating DOC:

$D O C_{c}=a H-b\left(\frac{H^{2}}{g T^{2}}\right)$ 
where $\mathrm{DOC}_{\mathrm{c}}$ is the calculated DOC, $H$ is wave height, $g$ is gravity, and $T$ is the wave period. Values for $H$ and $T$ represent a single location at one point in time, but in the natural environment, $H$ and $T$ vary spatially and temporally. Hallermeier used extreme wave conditions to provide an estimation of the DOC for longer periods of time. Coefficients $a$ and $b$ were calculated by satisfying the linear relationship forced through the origin between measured $\mathrm{DOC}$ and $\mathrm{DOC}_{\mathrm{c}}$ from multiple laboratory studies (Hallermeier, 1977). Research has shown that the coefficients can vary (Table 4-1) depending on the profile location and wave conditions (Birkemeier, 1985; Nicholls et al., 1998). In fact, Birkemeier found a reasonable linear fit by applying only wave height with the equation:

$D O C_{c}=a H$

Coefficients A through D (Table 4-1) were calculated by applying the highest significant wave heights that occur $0.137 \%$ over a one year period, or 12 hours in that given year (Birkemeier, 1985; Hallermeier, 1977; Nicholls et al., 1998). Coefficient E was calculated using the peak wave heights for a specific storm (Nicholls et al., 1998). Further research is needed at other beach types in order to test the effectiveness of each set of coefficients.

4-1. Coefficients used to calculate the DOC. A is from Hallermeier (1977), B and C are from Birkemeier (1985), D and E are from Nicholls (1998). A, B, D and E use Equation 4-1. C uses Equation 4-2.

\begin{tabular}{llll}
\hline \multicolumn{1}{c}{ Source } & & \multicolumn{2}{c}{ Coefficient } \\
$\mathrm{A}$ & & $\mathrm{a}$ & $\mathrm{b}$ \\
$\mathrm{B}$ & & 1.28 & 68.5 \\
$\mathrm{C}$ & & 1.57 & N/A \\
$\mathrm{D}$ & & 1.70 & 82.3 \\
$\mathrm{E}$ & & 1.33 & 43.9 \\
\hline
\end{tabular}


Assumptions that form the foundation of the DOC equations are often questioned by geologists who insist that geologic control has significant influence on the location of the DOC and should be modeled accordingly (Browder and McNinch, 2006; Jackson et al., 2005; Pilkey et al., 1993). Hallermeier's (1981a) equation is based on linear wave theory with homogenous sands, thus it cannot account for hard-bottom structure that may limit erosion or deposition of loose sediments. Several barrier islands on the U.S. east coast are perched barriers where the locations of the barrier islands are largely determined by erosion-resistant geologic units beneath and seaward of the island (Finkl, 1993; Riggs et al., 1995). Perched barriers often consist of thin layers of sand lying on top of the geologic units, and the thin sand layers easily erode during storm conditions (Finkl, 2004; Thieler et al., 1995). Beach changes caused by storm events are complicated when the beach profile contains loose sediments and harder grounds (i.e., limestone outcrops). Small variations in the change profile are often controlled by the location of the hard ground, and no change could reflect rock outcrops rather than minimal wave activity. Since Hallermeier's DOC model assumes unlimited sediments and ignores hard ground, it is unrealistic to presume that coefficients $a$ and $b$ in Equations 4-1 or 4-2 could accurately predict the DOC for all areas. Some numerical models like SBEACH (Larson and Kraus, 2000) are able to include hard ground in their simulations. However, this study focuses on the physical location of the DOC and not change that occurs landward.

Because of the variability of the DOC, multiple bathymetric measurements rather than individual profiles are required to locate the DOC. Although long-term trends are beneficial for predicting future coastal change, multiple 3-dimensional high-resolution 
data are needed to detect the spatial variation of sediment movement. Brown (1998) investigated whether southeast Florida beaches are controlled by underlying geology by analyzing beach profiles, but his conclusions were limited due to the two dimensional properties of the beach profiling technique and the inability to directly compare the DOC with geologic data. Advances in remote sensing techniques have improved the ability to measure large-scale coastal change, and airborne laser bathymetry (ALB) provides unprecedented resolution of bathymetric measurements at relatively high accuracies (Irish et al., 2000). Multiple ALB data measuring the same areas over time yield 3dimensional spatial change. Seaward locations of no change should represent the DOC location, thus ALB data could possibly measure DOC for large areas.

With perched barrier islands, offshore reefs, and an active beach replenishment program, southeast Florida is an ideal location for comparing measured DOC to calculated DOC and regional geology. Two ALB data sets were collected before and after the 2004 hurricane season, thus providing a storm environment that represents longer periods of time due to the increased energy for suspending sediments. The main objective of this study is to develop a method for extracting DOC information from multiple ALB data sets, and use that data to answer several questions:

(1) Can ALB effectively measure the DOC?

(2) How variable is the location and depth of the DOC alongshore?

(3) Does alongshore change in the wave climate correspond to an alongshore change in the depth of closure?

(4) How well does the measured DOC match geologic units? 
This study presents alongshore variations in the DOC similar to shoreline and volume changes quantified in Robertson et al. (2005), Zhang et al. (2005), and List et al. (2006). The extracted locations and depths of the DOC are compared to calculated DOCs from wave data and geomorphic locations. Results are discussed in terms of physical and geologic control on the DOC for southeast Florida.

\section{STUDY AREA}

The peninsula of Florida is located on the southeastern tip of the United States. Florida is within the Atlantic Coastal Plain physiographic province, and southeastern Florida is located on the Pamlico Terrace within the Atlantic Coastal Ridge physiographic region (Schmidt, 1997). This study focuses on southeast Florida, including Palm Beach, Broward, and Miami-Dade Counties (Figure 4-1). The study area is determined by the area of overlapping ALB data, and extends alongshore from $2 \mathrm{~km}$ north of South Lake Worth Inlet (south-central Palm Beach County) to the southern point of Miami Beach (Government Cut) and approximately $600 \mathrm{~m}$ offshore. The total length of coastline is over $100 \mathrm{~km}$ with 6 inlets.

Florida geology is considered uncomplicated due to its young age and relative lack of structural degradation, metamorphism, or presence of igneous petrology. Conversely, the mixture of loose sediments with irregular hard grounds and sedimentary outcrops make south Florida beaches extremely complicated. Hard grounds include the Anastasia Formation, Key Largo Limestone, Florida reef tract (FRT), relict barrier reefs, and structural sand flats. The Anastasia and Key Largo Limestone formed during several sea transgressions, most notably during the Sangamon approximately 120 kya (Finkl and Warner, 2005; Scott, 1997). The Anastasia Formation is composed of sands and 


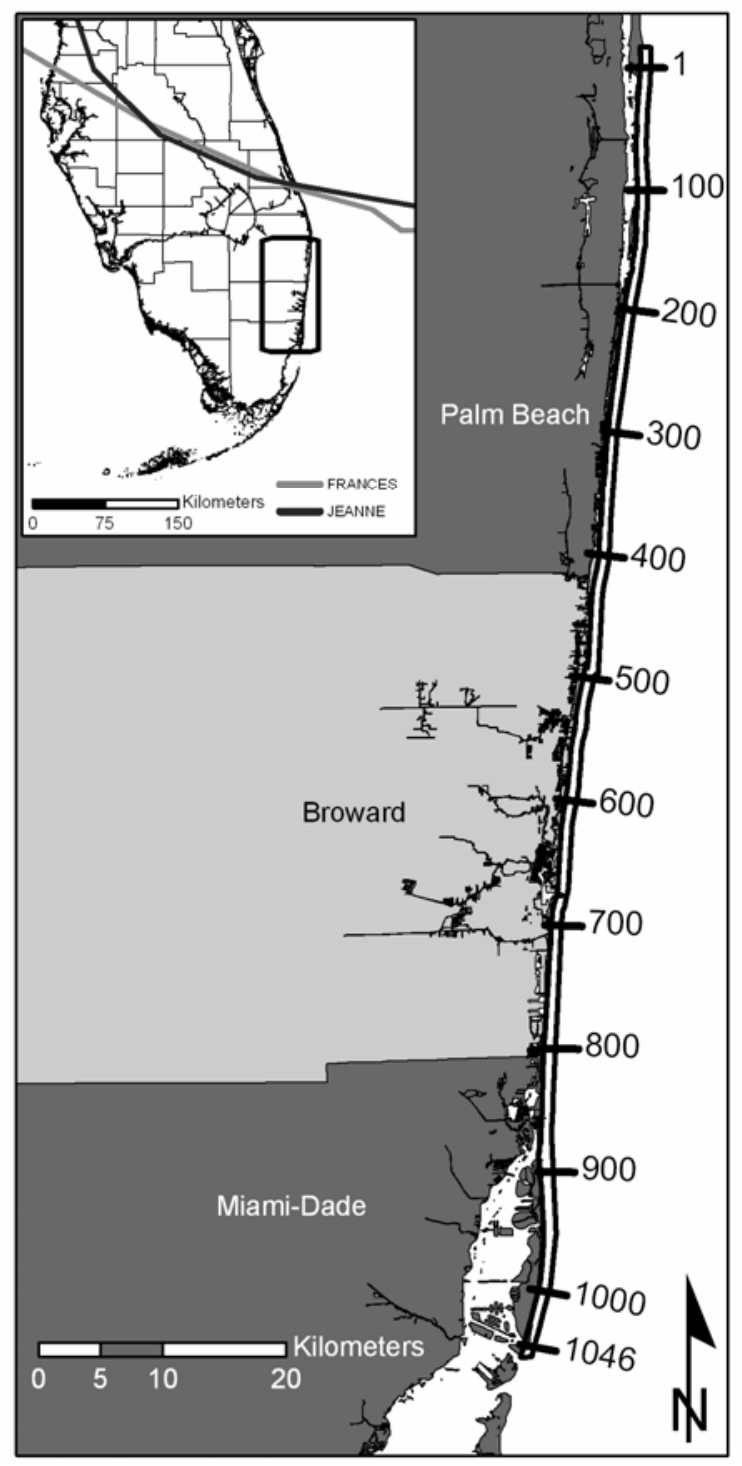

4-1. Map showing study area, extent of overlapping CHARTS ALB data, and location of reference transects along the shoreline. Inset map denotes tracks of Hurricanes in 2004.

coquinoid limestones, and it anchors Palm Beach area barrier islands so they cannot migrate landward due to sea level rise (Davis, 1997). The Key Largo Limestone is a marine limestone that contains numerous coral fossils and anchors Miami Beach. The FRT is a subaqueous coral-algal reef system that contains long troughs between the reefs (Finkl et al., 2005a; Finkl et al., 2005b). Structural sand flats are areas of thin layers of sand overlying hard ground (Finkl and Warner, 2005). Loose sedimentary mixtures of 
quartz and carbonates make up the sand composition for the beaches and sand flats. Sand flats are loose sedimentary mixtures trapped between the FRT and relict barrier reefs and are considered possible sources for beach replenishment projects (Finkl et al., 2006b). Permanent loss of sediments is speculated during high wave events when sand flats match the elevation of the hard grounds or offshore moving bottom currents force sediments through gaps in the hard grounds (Finkl, 2004).

Although sea level rise and frequent hurricane activity contribute to beach erosion, past comprehensive studies show net accretion for south Florida beaches (Dean et al., 1998). A causal factor for seaward shoreline migration could be the extensive beach replenishment programs that have been implemented throughout the study area, and several south Florida beaches are considered successful beach replenishment projects (Benedet et al., 2005). Cited reasons for the success of south Florida beaches include its surrounding geology, large area of nourishment, high construction densities, and lower wave energies (Finkl et al., 2006b).

\section{DATA}

Successful alongshore extraction of the DOC location requires high resolution three-dimensional data over relatively large areas. Although recent advances in sea floor mapping (i.e., sonar, optical, GPS positioning, etc.) have produced high accuracies, the data do not compare to ALB data in areas measured. The ALB data provide researchers with unprecedented spatial bathymetric resolution that minimizes the need to interpolate between sparse measurements. By utilizing ALB data with estimated wave data and geomorphic maps, this study can determine how well changes in subaqueous geomorphology matches calculated DOC and geomorphic units. 


\section{ALB Data}

The U.S. National Oceanographic and Atmospheric Administration's (NOAA) Coastal Services Center houses many airborne laser and interferometric synthetic aperture radar (IfSAR) data sets measuring coastal environments. This study utilizes the Joint Airborne Lidar Bathymetry Technical Center of Expertise's (JALBTCX) compact hydrographic airborne rapid total survey (CHARTS) ALB data collected on the southeastern coast of Florida in June and November 2004. The CHARTS system uses two lasers, one green and one near-infrared. The green laser is fired at $1 \mathrm{kHz}$ to measure bathymetry, and the near-infrared laser measures topography at $9 \mathrm{kHz}$. This produced a nominal $8 \mathrm{~m}$ point spacing for the bathymetry and a $2 \mathrm{~m}$ point spacing for the topography for each flight line. Due to multiple flight lines, the resulting point density for each airborne laser data collection is slightly higher. The June CHARTS data measured from the beach to approximately $1 \mathrm{~km}$ offshore, and the November CHARTS data measured from the beach to approximately $600 \mathrm{~m}$ offshore.

Quantification of the inaccuracies of ALB data require comparison with data of higher accuracies. Previous studies have successfully removed shifted data to improve the accuracy of changes determined from the airborne laser data (Robertson et al., 2005; Zhang et al., 2005). However, these studies focused on subaerial change that can be confirmed with higher-order accuracy methods (i.e., differential leveling, rapid-static GPS), and this study analyzes bathymetric change that can only be confirmed with methods of similar accuracy to ALB instrumentation (i.e., sonar). Since change in subaqueous locations cannot be confirmed during the 2004 year, this study is forced to compare subaerial change on a hard road surface. Two locations found that the June data 
were slightly higher than the November data, but the mean vertical difference was less than $0.1 \mathrm{~m}$. The small offset is well within measured topographic accuracies $(0.15 \mathrm{~m})$, consequently the ALB data were not shifted (Sallenger et al., 2003).

Noise in airborne laser measurements is generally on the order of $1 \sigma$ when comparing laser measurements to known elevations. An in-depth accuracy assessment for the CHARTS system was carried out prior to the June 2004 data collect (Optech, 2004). Mean offsets between CHARTS measurements and known elevations ranged between -0.18 to $0.23 \mathrm{~m}$, but most measurements were within $\pm 0.15 \mathrm{~m}$. The noise in the measurements ranged between 0.05 to $0.28 \mathrm{~m}$, which would suggest that changes within this range would be difficult to resolve.

The final step in processing airborne laser data involved interpolating the irregularly spaced laser measurements onto a regularly spaced grid to produce a set of digital elevation models (DEMs). The data were gridded at $4 \mathrm{~m}$ resolution using kriging interpolation with a linear variogram. DEMs for each flight were produced with a common origin and cell size to ensure registration. The DEMs were then differenced to produce a change grid (Figure 4-2, left).

\section{Wave Data}

Calculation of the DOC with Equations 4-1 or 4-2 requires wave data, more specifically wave height and wave period. NOAA monitors wave activity with many wave gauges throughout the world, but the closest wave gauge to the study area is located off Cape Canaveral, approximately $200 \mathrm{~km}$ north of the most northerly measured area. Therefore, deep water wave heights and periods were estimated using NOAA's Wavewatch III model (Tolman, 1992) for 19 locations along the study area spaced 

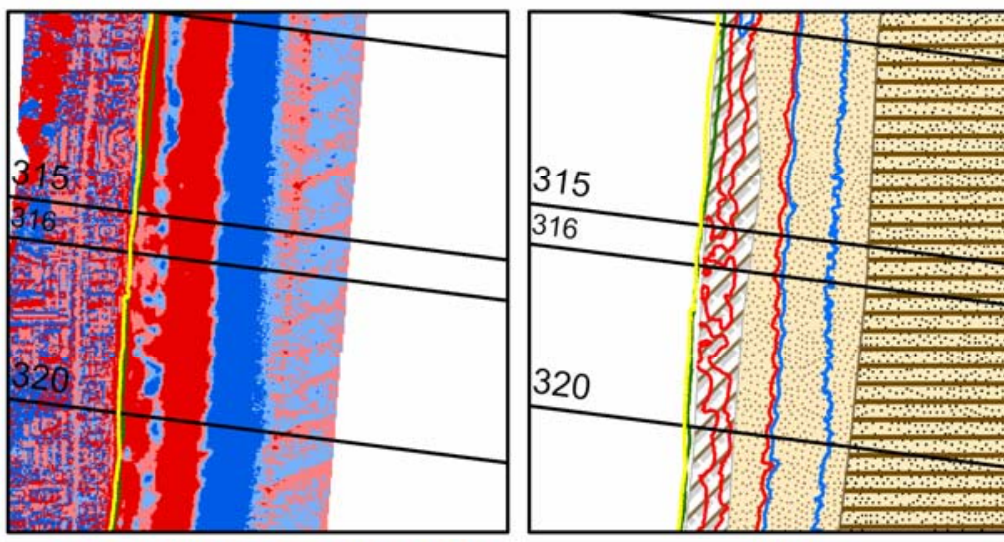

\section{Legend}
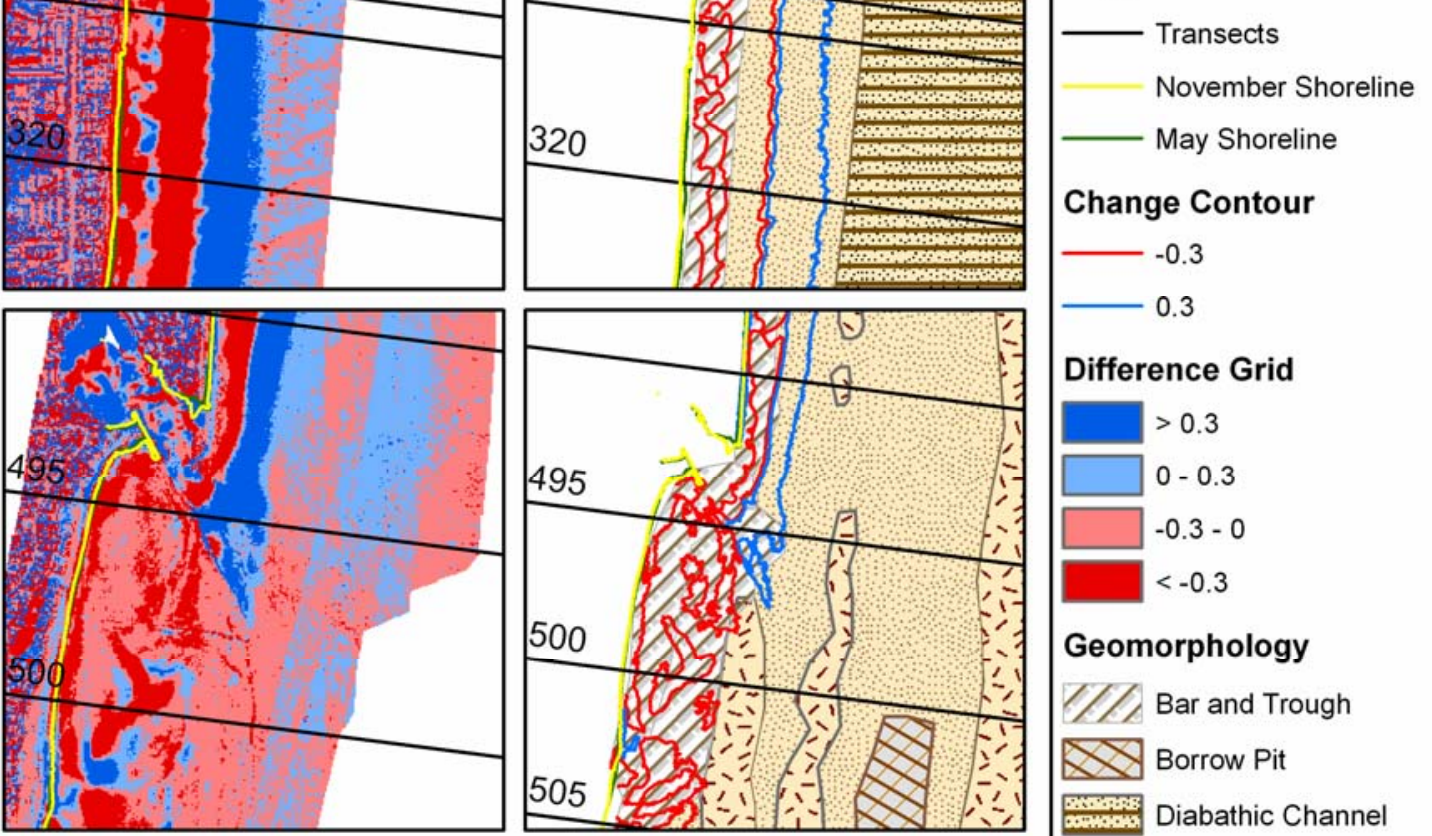

\section{Difference Grid}

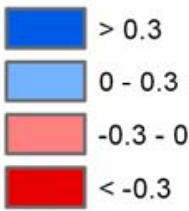

\section{Geomorphology}

W/2, Bar and Trough

Borrow Pit
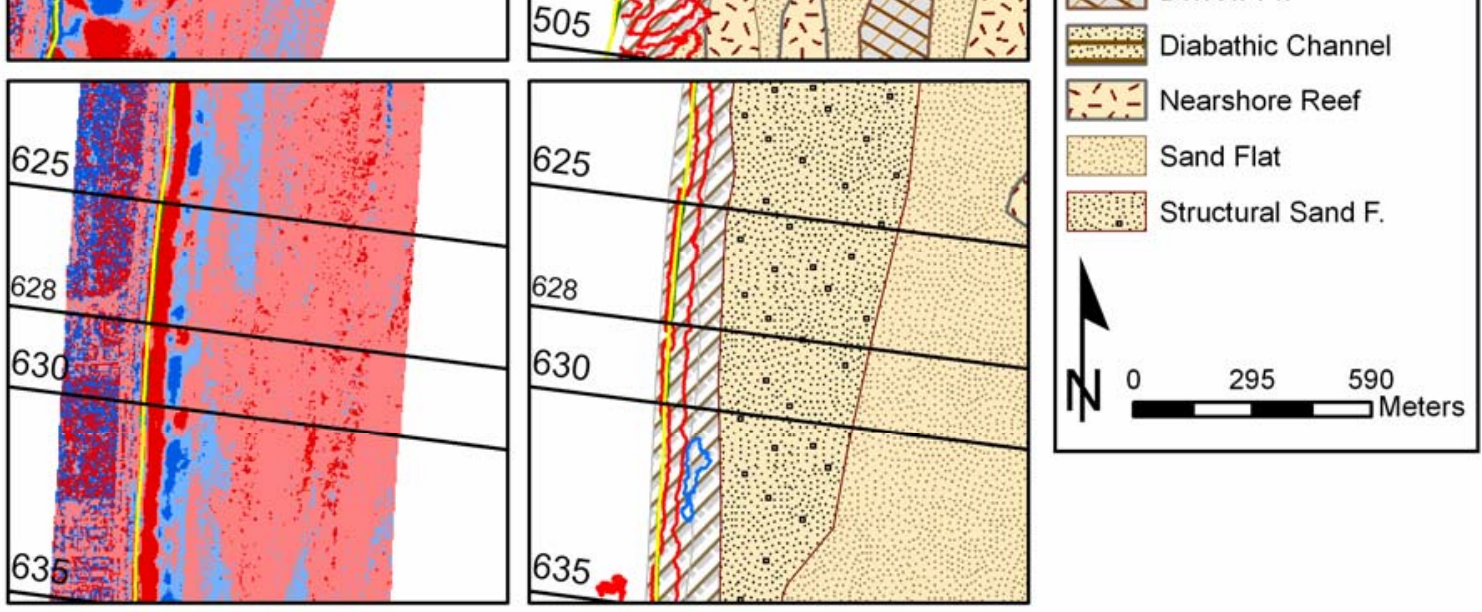

4-2. Map of the change grid (left) and geomorphology (right, after Finkl et al., 2005a) for three separate locations along the study area from north to south (top to bottom). Seaward change contour extracted from the change grid is shown with the geomorphology. Seaward locations of the change contour represent the LOC at each transect. The center maps show the area surrounding Hillsboro Inlet.

approximately $5 \mathrm{~km}$ apart. Peak conditions during Hurricanes Frances and Jeanne were tabulated. Although Hurricane Jeanne (Category 3) was one category larger than Hurricane Frances (Category 2) on the Saffir-Simpson scale, the relatively slow-moving 

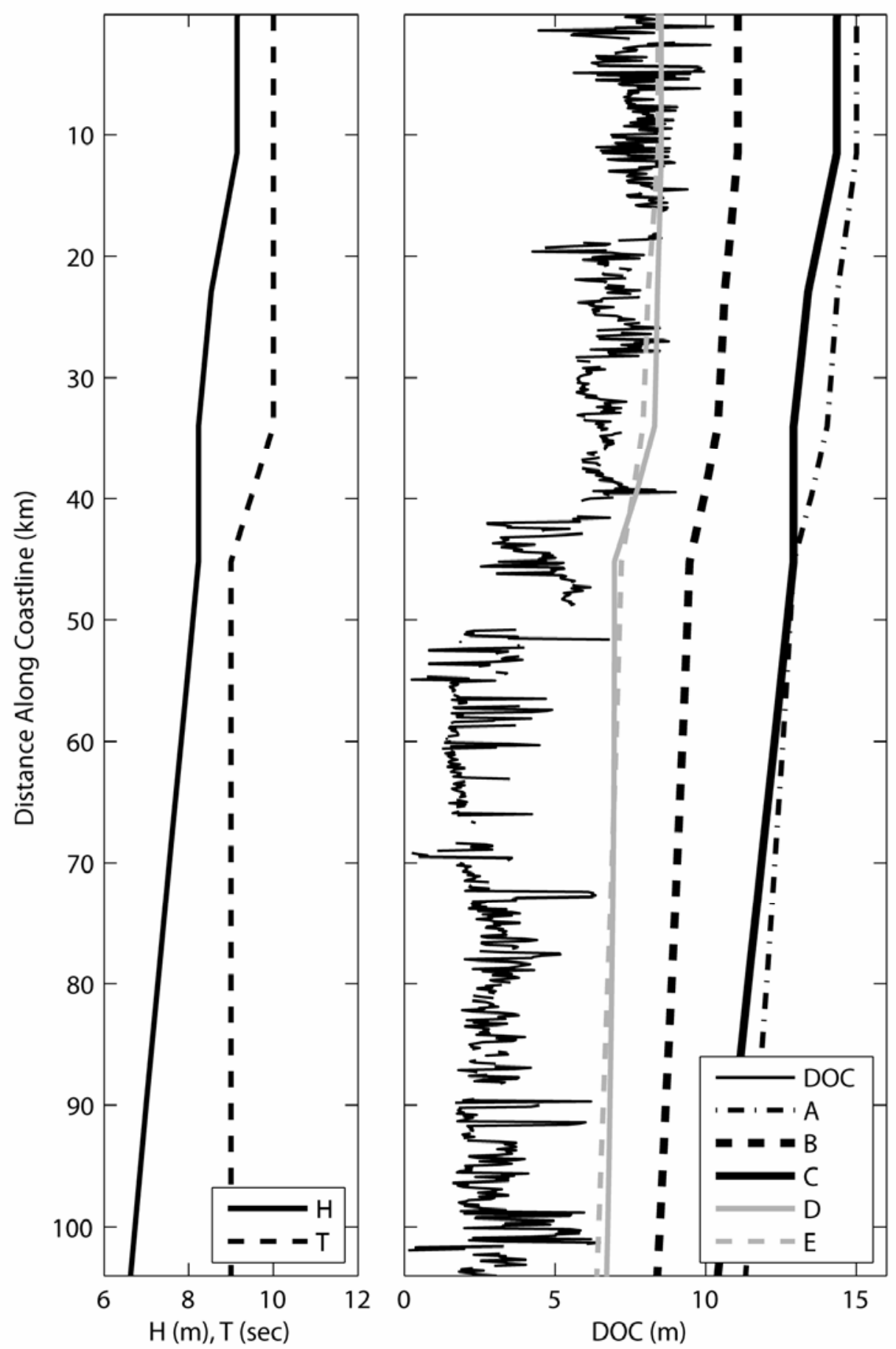

4-3. Wave data and DOC alongshore. Distance along coastline is from north to south. Hurricane Frances wave height and period (left) from NOAA's Wavewatch III model. Alongshore plot of DOC (right) with calculated DOC using different coefficients. A is from Hallermeier (1977), B and C are from Birkemeier (1985), D and E are from Nicholls (1998). A, B, D and E use Equation 4-1. C uses Equation 4-2. 
Frances produced wave heights in excess of $9 \mathrm{~m}$ and wave periods greater than 9 seconds, while Jeanne produced wave heights less than $5 \mathrm{~m}$ and wave periods as low as 6 seconds (Beven, 2004; Lawrence and Cobb, 2005). Higher values are found to the north, as the northern areas were closer to the impact of Hurricane Frances (Figure 4-3, left).

Calculation of the DOC utilized the Hurricane Frances wave data due to the higher values and therefore deeper energy to suspend bottom sediments.

\section{Geology}

The continuing work of Finkl and others have produced seafloor geologic maps for most nearshore areas in southeastern Florida (Finkl, 2004; Finkl et al., 2005a; Finkl et al., 2005b; Finkl and Warner, 2005). By utilizing high-resolution ALB data and comparing the morphology to aerial photography, satellite imagery, side-scan sonar, subbottom profiling, cores, and diver logs, Finkl and others were not only able to map differences between hard and soft ground, but also differentiate between different types of hard and soft grounds (Figure 4-2, right).

For the purposes of this study, it is useful to differentiate between two major types of submarine geomorphology: hard ground and soft ground. Bars and troughs, sand flats, and diabathic channels are soft ground, while nearshore reefs and structural sand flats are hard grounds (Finkl and Warner, 2005). The longshore bars are shore parallel ridges of sand lying between 70 and $300 \mathrm{~m}$ seaward of the shoreline. Troughs are depressions mostly associated with longshore bars, but they are also located landward of reefs and sand flats. Sand flats are sandy bottoms that occur seaward of the shoreface and between coral reefs. Diabathic channels are large, shore-parallel areas with an average range from $100 \mathrm{~m}$ wide by $300 \mathrm{~m}$ long and $3 \mathrm{~m}$ deep (Finkl et al., 2006a). They are considered 
"channels" due to the small scale shore-perpendicular ridges that have 75 to $150 \mathrm{~m}$ wavelengths with $1 \mathrm{~m}$ of relief. Diabathic channels are areas surrounded by sand flats, but they are lithologically distinct and represent the seaward extent of seafloor and wave interaction during large wave conditions.

Hard grounds range from structural sand flats to present and relict reefs to bedrock (Anastasia Formation). Structural sand flats are thin layers of sand lying on top of hard ground. Since the ALB change data cannot detect changes to structural sand flats due to minimal amounts of sand, they are considered hard ground. Hard grounds are not expected to endure large changes during hurricane conditions unless they are covered by sediments or the reefs are eroded due to increased wave activity.

\section{METHODS}

\section{The LOC Contour}

Identification of the DOC is a multi-step process that requires an understanding of measurement limitations. The initial step is to identify differences between the two ALB surfaces by subtracting the older DEM from the younger DEM. The resulting raster image contains pixels that represent change in volume (Figure 4-2, left). It stands to reason that locations of zero change would represent the spatial location of the DOC. However, this interpretation is limited by noise in the CHARTS measurements.

The three-dimensional change can be represented two dimensionally by contouring the change grid. The change surface was contoured at $5 \mathrm{~cm}$ increments to empirically determine what level of change yielded a contour that can be relatively consistent and measurable. The goal was to find a change contour that represents the alongshore trend of volume change, but not small localized areas of change. This 
analysis indicated that regions in the change grid where the magnitude of depth change was greater than $0.3 \mathrm{~m}$ generally defined coherent alongshore regions of positive or negative change, whereas changes less than this threshold were in general localized and non-coherent. Therefore, the seaward most contour at either $\pm 0.3 \mathrm{~m}$ was used to denote the seaward limit of change corresponding to the location of the DOC (Figure 4-2, right). This location of the DOC is termed the location of closure, or LOC.

Selection of $\pm 0.3 \mathrm{~m}$ as the threshold of no change is illustrated by analyzing profiles in the change grid. Transects 66,316 , and 628 represent the change profile offshore of Palm Beach, Boca Raton, and Fort Lauderdale, respectively (Figure 4-4). Each profile sustained large change near the shoreline, but the change diminished to low level fluctuations further offshore. The low level fluctuations correspond to locations of hard ground or diabathic channels that sustain little change if any during storm conditions, thus it is reasonable to assume that these fluctuations are due to measurement noise (Finkl and Warner, 2005). The low-level fluctuations are effectively filtered out when only analyzing change that occurs landward of the most seaward change greater than $0.3 \mathrm{~m}$ or less than $-0.3 \mathrm{~m}$. When confirming Equation $4-1$ with field data, Hallermeier (1977) determined that change less than $\pm 0.3 \mathrm{~m}$ was negligible due to limitations in fathometer measurement resolution. Although more recent studies have achieved higher orders of vertical resolution of up to $0.03 \mathrm{~m}$ using U.S. Army Corps of Engineers coastal research amphibious buggy (CRAB), the CRAB's inability to measure large areas in short time intervals limits its ability to measure longshore variations in the DOC (Birkemeier, 1985; Nicholls et al., 1998). 

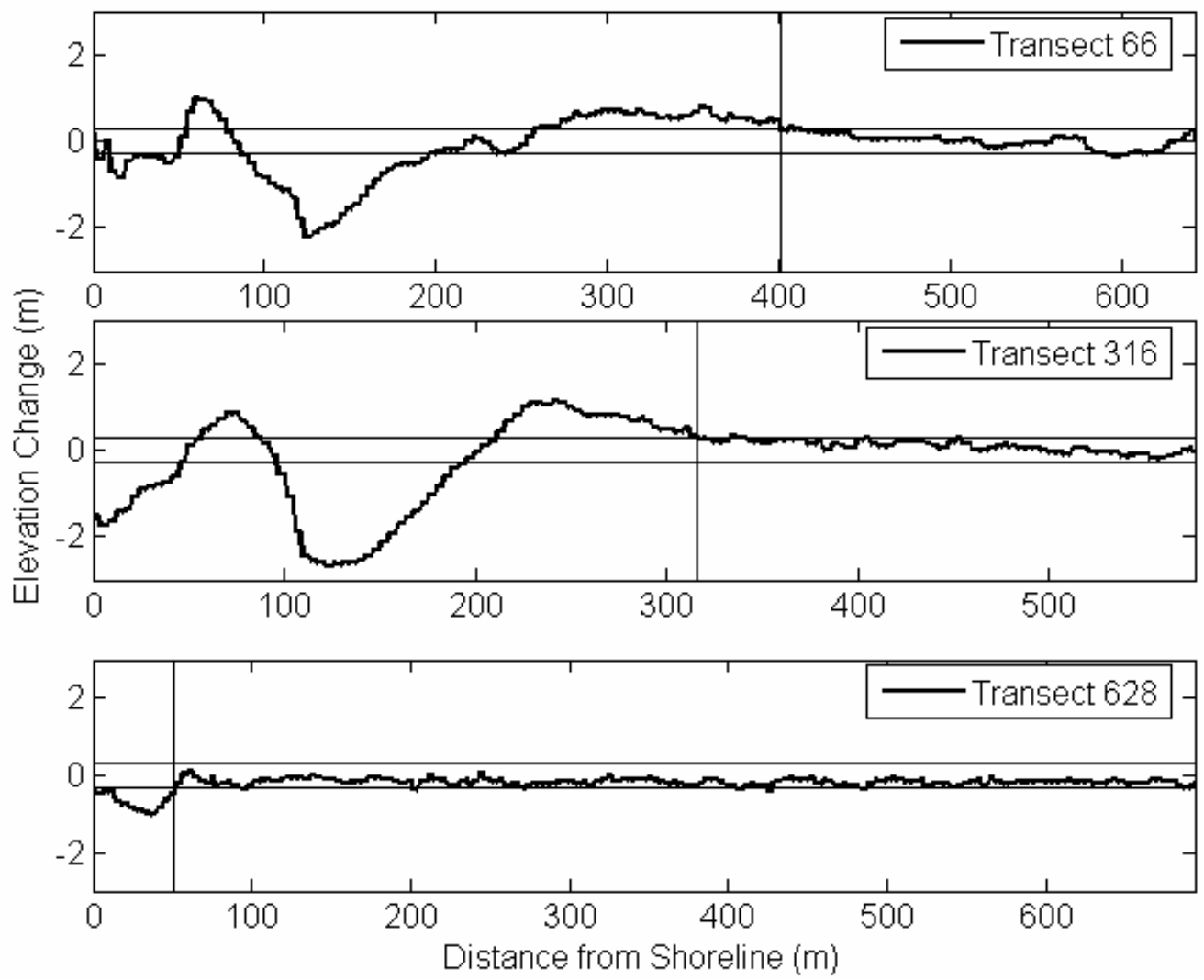

4-4. Representative profiles of surface change between June and November CHARTS data. Thin horizontal lines are the $\pm 0.3 \mathrm{~m}$ change. Change less than this magnitude is generally not resolvable with ALB data. Vertical thin lines are the LOC. Map view of Transects 316 and 628 are shown in Figure 4-2.

\section{Metric Mapping and DOC Extraction}

The relative positions of the LOC and geologic units were measured using a GISbased metric mapping system (Robertson et al., 2005; Zhang et al., 2005). This system generates a set of transects perpendicular to the coastline and calculates distance to the intersection of each transect with other linear features. One thousand and forty-six transects spaced $100 \mathrm{~m}$ were analyzed over the $104 \mathrm{~km}$ length of shoreline (Figure 4-1). Based on geomorphic unit descriptions, changes in bathymetry should only occur landward of hard ground or diabathic channels (Finkl et al., 2005b; Finkl and Warner, 2005). Distances were measured for each transect from a fixed offshore reference line to 
the LOC and the most landward boundary of the hard grounds. Distance to the landward and seaward position of the diabathic channels were also measured.

$\mathrm{DOC}_{\mathrm{c}}$ is calculated using Equations 4-1 and 4-2 with the Hurricane Frances wave data, producing $19 \mathrm{DOC}_{\mathrm{c}}$ depths at specific locations alongshore (Figure 4-3, right). Since the LOC represents location, the depth at LOC needs to be determined to compare vertically with $\mathrm{DOC}_{\mathrm{c}}$. Intersections between transects generated by metric mapping and the LOC are converted to points. Elevations are assigned to each point based on the CHARTS November DEM. The depth at the LOC represents the measured depth of closure, or DOC. Since each point retains the transect number attribute, the DOC can be directly compared to $\mathrm{DOC}_{\mathrm{c}}$ depths alongshore. Due to the alongshore variability in the DOC, a moving average filter was applied with a window size of $5(500 \mathrm{~m})$ to reduce the effect of possible outliers. The same depth extraction technique to convert the LOC to DOC was applied to the intersection between transects and geomorphic units to determine geomorphic unit depth.

All data are presented as distance along the coastline, from north to south. Each successive transect represents an alongshore position $100 \mathrm{~m}$ south of the previous position. Since this study is trying to locate the DOC offshore of beaches, data that contain transects that intersect with inlet-related morphologies as defined by the geologic map were removed (i.e., ebb tidal delta, dredge spoil).

\section{RESULTS}

The DOC is highly variable alongshore but with a clear decrease in depth from north to south (Figure 4-3, right). DOC ranges from 10.3 m north of South Lake Worth Inlet to only $0.1 \mathrm{~m}$ located off of Miami Beach. The upper limit represents localized 
areas of change in the diabathic channel region, and the $0.1 \mathrm{~m}$ is an unusual location of almost no change offshore. In order to better quantify along coast change in DOC, summary statistics were compiled in each of six sections of coastline separated by inlets (Table 4-2). The average DOC decreases from $7.8 \mathrm{~m}$ in the north to $3.0 \mathrm{~m}$ in the south. The decrease in depths appears to stop between Boca Raton and Hillsboro Inlet (40 and $50 \mathrm{~km}$ in Figure 4-3,respectively), and the Pompano Beach to Fort Lauderdale section of coastline (Hillsboro Inlet to Port Everglades Inlet, 50 to $66 \mathrm{~km}$ ) shows a relatively shallow DOC average of $2.2 \mathrm{~m}$. The same signal is found when analyzing the distance of the DOC from the shoreline. DOC is on average located $266 \mathrm{~m}$ from the shoreline in the north and $116 \mathrm{~m}$ offshore in the south, with the Pompano Beach to Fort Lauderdale section averaging only $54 \mathrm{~m}$ offshore (Table 4-2). Although DOC outliers force the range to differ from the mean by as much as $3 \mathrm{~m}$, the alongshore variability in the DOC indicates that a single transect cannot explain the DOC for a specific area.

4-2. Measured DOC values split by inlets, from north to south. Distance along coastline is the location of data on Figures 4-3, 4-5, and 4-6. LOC Dist. is the distance from the shoreline to the LOC. DOC is the depth, in meters.

\begin{tabular}{|c|c|c|c|c|c|c|}
\hline \multirow[t]{2}{*}{ Location } & \multirow{2}{*}{$\begin{array}{l}\text { Distance Along Coastline } \\
(\mathrm{km})\end{array}$} & \multicolumn{4}{|c|}{$\overline{\mathrm{DOC}}$} & \multirow{2}{*}{$\begin{array}{l}\text { LOC Dist. } \\
\text { Mean }\end{array}$} \\
\hline & & Mean & Min & Max & St.D. & \\
\hline North limit to South Lake Worth & 1 to 16.4 & 7.8 & 4.5 & 10.3 & 0.93 & 266 \\
\hline South Lake Worth to Boca Raton & 18.1 to 40.2 & 6.7 & 4.3 & 9.0 & 0.74 & 259 \\
\hline Boca Raton to Hillsboro & 41.5 to 48.9 & 4.7 & 2.6 & 6.7 & 1.00 & 163 \\
\hline Hillsboro to Port Everglades & 50.8 to 66.8 & 2.2 & 0.3 & 6.8 & 1.00 & 54 \\
\hline Port Everglades to Haulover & 68.4 to 88.2 & 2.9 & 0.3 & 6.3 & 0.93 & 124 \\
\hline Haulover to Government Cut & 89.5 to 104.0 & 3.0 & 0.1 & 6.5 & 1.30 & 116 \\
\hline
\end{tabular}

The calculated depth of closure $\left(\mathrm{DOC}_{\mathrm{c}}\right)$ shows the same north to south decrease as seen in the observed data (Figure 4-3, right). This suggests that the DOC is physically linked to wave dynamics. Since Hurricane Frances made landfall immediately north the study area limits (Figure 4-1), the increased wave activity to the north should contribute to deeper northern DOC values. The $\mathrm{DOC}_{\mathrm{c}}$ calculated from Nicholls (1998; E in Table 4- 
1) best fit the observations (E in Table 4-3 and Figure 4-3). This is not surprising since this study applied peak significant wave heights when calculating Equations 4-1 and 4-2 similar to Nicholls. Filtering the DOC signal to assure differences were not from values representing outliers provided similar results (Table 4-3).

4-3. Vertical difference between measured and calculated DOC, in meters. Source of A-E same as Table 4-1 and Figure 4-3. Filtered data were smoothed by a 5 point $(500 \mathrm{~m})$ moving average.

\begin{tabular}{llllll}
\hline Coefficients & Data & dMean & dMin & dMax & dSt.D. \\
\hline \multirow{2}{*}{ A } & raw & -8.4 & -5.2 & -10.9 & 1.6 \\
& filtered & -8.0 & -6.1 & -10.9 & 1.4 \\
\hline \multirow{2}{*}{ B } & raw & -4.9 & -2.3 & -7.5 & 1.7 \\
& filtered & -4.6 & -2.5 & -7.6 & 1.5 \\
\hline \multirow{2}{*}{ raw } & -7.8 & -4.3 & -10.7 & 1.8 \\
& riltered & -7.4 & -5.5 & -10.6 & 1.5 \\
\hline \multirow{2}{*}{ D } & raw & -2.7 & 0.0 & -5.2 & 1.8 \\
& filtered & -2.4 & -0.2 & -5.3 & 1.6 \\
\hline \multirow{2}{*}{ raw } & -2.6 & 0.1 & -5.3 & 1.8 \\
& filtered & -2.2 & -0.1 & -5.4 & 1.6 \\
\hline
\end{tabular}

In principle, the coefficients for Equations 4-1 and 4-2 could have been derived directly from the observations. However, given that these equations are based on beaches with unlimited sands and no hard ground, calculation of coefficients based on the DOC values for this study may not be practical. Figure 4-2 (right) clearly shows reefs and structural sand flats near the LOC which suggests structural control in some areas. Comparison between the LOC and geologic units is needed to determine if hard ground is proximal to and possibly controls the LOC.

In many locations striking similarities are found between the positions of hard ground and the LOC (Figure 4-5). The extracted hard grounds include the most landward position of the structural sand flats and reefs. With a few exceptions, south of $50 \mathrm{~km}$ the landward locations of hard grounds match the DOC location extremely well. The horizontal difference was less than 100 m, on average, between Hillsboro and Haulover 

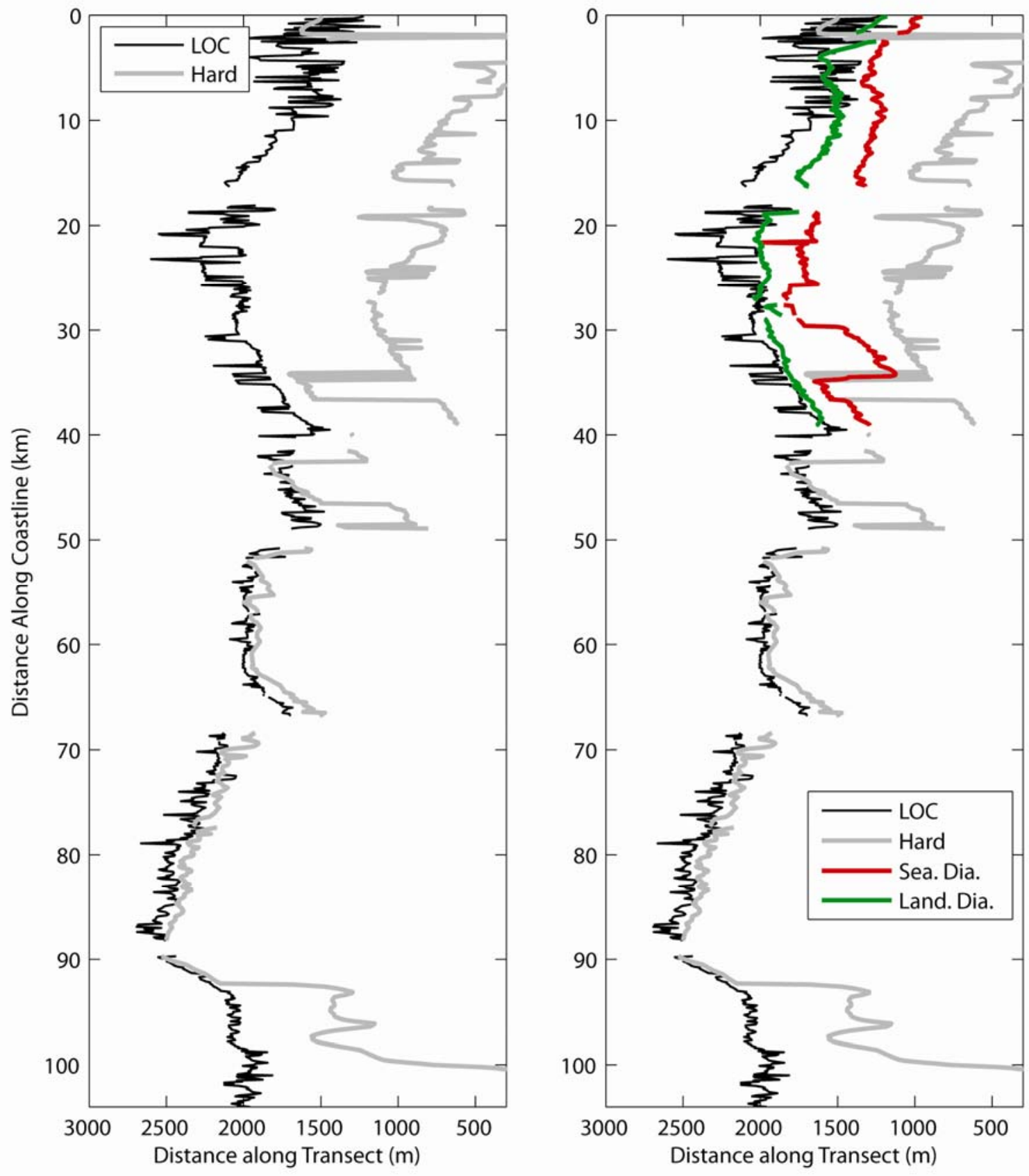

4-5. Horizontal position of hard ground (grey), diabathic channels, and the LOC (black). Hard refers to the landward boundary of hard grounds. Green and red indicate the landward and seaward boundary of diabathic channels, respectively.

Inlets (Table 4-4). The small differences and the apparent match between the LOC and hard ground in Figure 4-5 for this area suggests that geology determines the LOC.

However, south of Transect 923 the average difference is over $750 \mathrm{~m}$, and Figure 4-5 
shows that the hard ground moves offshore. Transect 923 is in the area of Surfside, 3.2 $\mathrm{km}$ south of Haulover Inlet, where a large sand flat progressively extends offshore down to Government Cut (92 km to southern limit of Figure 4-5). Areas offshore of this location have a larger self and provide more accommodation space for sediments to accumulate than areas to the north. The LOC moves further offshore in this region and does not match the hard grounds suggesting that geology does not determine the LOC south of Surfside. This may be due to limitations in the geomorphic interpretation or overestimation of the wave environment for this area.

4-4. Horizontal difference in meters between the LOC and landward boundaries of hard ground (left) or hard ground and diabathic (right). Values are split by inlets, from north to south. Refer to Table 4-2 for location.

\begin{tabular}{|c|c|c|c|c|c|c|c|c|}
\hline \multirow[t]{2}{*}{ Location } & \multicolumn{4}{|c|}{ LOC - Hard Ground } & \multicolumn{4}{|c|}{ LOC - Hard Ground \& Diabathic } \\
\hline & Mean & Min & Max & St.D. & Mean & Min & Max & St.D. \\
\hline North limit to South Lake Worth & 965.8 & -482.1 & 1779.7 & 476.6 & 161.0 & -482.1 & 1625.9 & 262.8 \\
\hline South Lake Worth to Boca Raton & 984.0 & 164.9 & 1848.6 & 371.1 & 180.9 & -76.1 & 1319.2 & 245.1 \\
\hline Boca Raton to Hillsboro & 285.2 & -149.0 & 886.0 & 307.7 & 285.2 & -149.0 & 886.0 & 307.7 \\
\hline Hillsboro to Port Everglades & 90.3 & -124.0 & 328.4 & 68.3 & 90.3 & -124.0 & 328.4 & 68.3 \\
\hline Port Everglades to Haulover & 98.6 & -118.4 & 311.2 & 70.7 & 98.6 & -118.4 & 311.2 & 70.7 \\
\hline Haulover to Government Cut & 752.4 & -94.7 & 2029.6 & 565.5 & 752.4 & -94.7 & 2029.6 & 565.5 \\
\hline
\end{tabular}

Between Boca Raton and Hillsboro Inlets, the nearshore reefs and structural sand flats are no longer continuous and nearshore. The hard grounds just north of Hillsboro Inlet and south of Boca Raton Inlet (Figure 4-5) are further offshore and create large discrepancies between the LOC and hard ground and increase the average difference to $285 \mathrm{~m}$ (Table 4-4). The hard grounds progressively move further offshore and away from the zone of wave impact north of Boca Raton Inlet. The difference between the LOC and hard ground north of Boca Raton Inlet is greater than $950 \mathrm{~m}$, indicating that geology does not determine the LOC for this section of coastline. 
Diabathic channels are storm deposits that are hydrodynamically formed due to strong underflow (Finkl and Warner, 2005). They are found only to the north of Hillsboro Inlet, and this geomorphic unit appears to match the LOC in the north (Figure 4-5). Figure 4-5 shows the LOC matches the landward edge of the diabathic channels, with some locations where the LOC is within the diabathic channel unit. When including diabathic channels as the geologic positions landward limit, the geologic positions continue to match LOC well, with a mean offset of less than $180 \mathrm{~m}$ seaward of the LOC (Figure 4-5, Table 4-4). Since the LOC matches the diabathic channels north of Boca Raton Inlet and diabathic channels are hydrodynamic features, the strong fit between the two suggests hydrodynamic control of the LOC for this region. This supports the earlier interpretation by Finkl (2005).

Vertical comparison between the DOC and the depth of geomorphic unit boundaries show a poor fit north of Boca Raton Inlet (50 km, Figure 4-6), and a good fit south of Boca Raton Inlet. The northern section where the nearshore reefs move offshore differs greater than $8 \mathrm{~m}$, on average (Table 4-5). However, the depth for the landward edge of the diabathic channels matches the DOC to within $2 \mathrm{~m}$, on average. South of Boca Raton Inlet, vertical differences are less than $3.5 \mathrm{~m}$, on average. The strong fit between geologic depths and the DOC suggest some level of geologic control. The surprising location is the section of coastline between Haulover and Government Cut Inlets (89 to $104 \mathrm{~km}$, Figure 4-6). This area had a vertical difference of only $3 \mathrm{~m}$, while the horizontal difference in Figure 4-5 showed the hard grounds more than $750 \mathrm{~m}$ offshore of the LOC. Vertical change in this region is small due to the wider shelf offshore, and this creates a shallower slope and less vertical discrepancy between the 


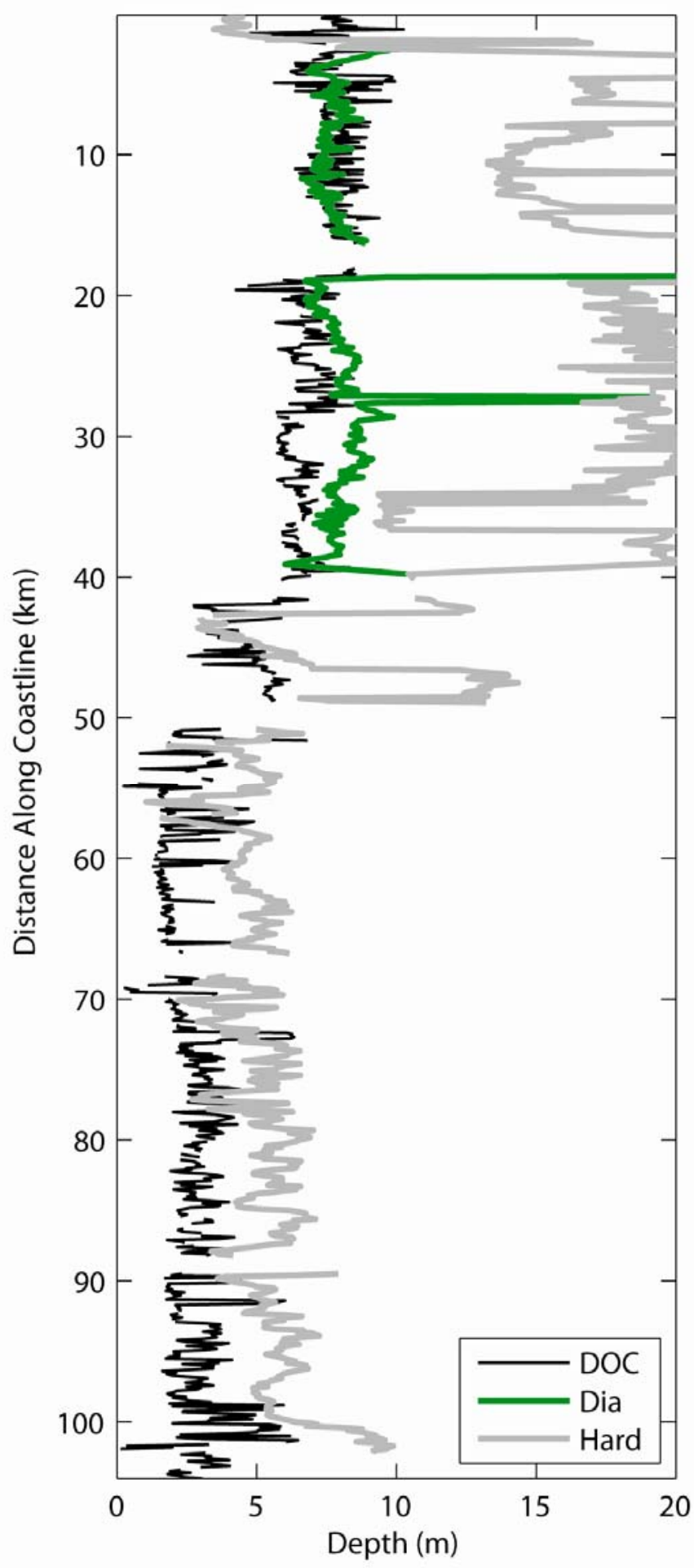

4-6. Comparison of the DOC (black) to the extracted depths of the landward location of hard ground (grey) along with the landward location of diabathic channels (green). 
geologic units and the DOC. While geology cannot be linked to the DOC for this location, the small vertical differences show that geology is as effective as DOC model calculations when locating the DOC.

4-5. Vertical difference in meters between the DOC and landward boundaries of hard ground (left) or hard ground and diabathic (right). Values are split by inlets, from north to south. Refer to Table 4-2 for location.

\begin{tabular}{|c|c|c|c|c|c|c|c|c|}
\hline \multirow[t]{2}{*}{ Location } & \multicolumn{4}{|c|}{ DOC - Hard Ground } & \multicolumn{4}{|c|}{ DOC - Hard Ground \& Diabathic } \\
\hline & Mean & Min & $\operatorname{Max}$ & St.D. & Mean & Min & Max & St.D. \\
\hline North limit to South Lake Worth & -8.5 & -21.2 & 6.8 & 6.1 & 0.3 & -10.2 & 6.8 & 2.0 \\
\hline South Lake Worth to Boca Raton & -11.7 & -21.8 & -2.3 & 4.1 & -2.0 & -18.5 & 1.4 & 2.7 \\
\hline Boca Raton to Hillsboro & -3.5 & -9.5 & 2.9 & 3.6 & -3.5 & -9.5 & 2.9 & 3.6 \\
\hline Hillsboro to Port Everglades & -2.3 & -4.7 & 2.3 & 1.4 & -2.3 & -4.7 & 2.3 & 1.4 \\
\hline Port Everglades to Haulover & -2.2 & -5.1 & 2.4 & 1.4 & -2.2 & -5.1 & 2.4 & 1.4 \\
\hline Haulover to Government Cut & -3.0 & -9.5 & 2.3 & 1.7 & -3.0 & -9.5 & 2.3 & 1.7 \\
\hline
\end{tabular}

The similarities between the DOC, LOC, and geologic map show that both geologic control and hydrodynamically forced geomorphology adequately indicates the DOC location. The distinct change in signals shown in Figures 4-3, 4-5, and 4-6 are spatially linked to a transition zone between Boca Raton $(40 \mathrm{~km})$ and Hillsboro $(50 \mathrm{~km})$ Inlets. It is at this location where outcrops of the Anastasia Formation that anchors the perched barrier islands to the north trends offshore and primarily makes up the offshore hard grounds to the south. South of Hillsboro Inlet, the DOC is spatially and vertically linked to hard ground (Figures 4-5 and 4-6). Since hard grounds rarely change, the link between the DOC and geologic map indicate geologic control. However, north of Boca Raton Inlet the DOC is linked to diabathic channels. Diabathic channels are storm deposits that are hydrodynamically formed due to strong underflow. Therefore, the DOC location north of Hillsboro Inlet is hydrodynamically determined. Although geologic units better explain the location of the DOC south of Boca Raton Inlet, hydrodynamics play an important role in the location of the DOC north of Boca Raton Inlet. 


\section{DISCUSSION}

The depth of closure concept forms the basis for designing coastal engineering projects, but this concept is not without controversy. Pilkey et al. (1993) cite sediment exchange between the active beach zone and continental shelf, and sediment movement caused by hurricanes has been measured at $60 \mathrm{~m}$ depths (Mitchell et al., 2005; Teague et al., 2006). But Hallermeier (1977) defines the DOC as the location where changes in a two dimensional profile are insignificant. Although sediment exchange seaward of the DOC has been measured, the location where minimal sediment exchange occurs is critical for many uses like determining where to extract sediments for beach replenishment projects. Locations of borrow areas should have minimal effect on the surrounding geomorphology, and the DOC represents the most landward position for borrow area placement.

The major limitation when using ALB data to derive the DOC is vertical resolution. By only looking at differences greater than $\pm 0.3 \mathrm{~m}$, change less than this threshold is lost. However, given that the changes caused by the 2004 hurricane season created the large differences close to the shoreline, the small scale changes further offshore are more than likely generated by noise in the ALB system. Previous studies were able to minimize noise found in difference grids by shifting each grid to match survey data utilizing higher-order accuracy methods (Robertson et al., 2007; Zhang et al., 2005). The previous studies compared subaerial laser data to hard surfaces that remain fixed over time (i.e., roads). ALB data are more difficult to verify due to their subaqueous measurements and how water movement is constantly changing the geomorphology of the sea floor. Unfortunately, this study did not have survey data to 
confirm the vertical accuracy of each ALB flight. Differences between multiple ALB flights could be minimized by comparing the ALB data to higher-order accuracy bathymetry that were measured within hours of the ALB flight. Regardless, the similarities in curves found in Figures 4-3, 4-5, and 4-6 suggest that the DOC measured in this study is the actual DOC.

Figure 4-3 and Table 4-3 show that the $\mathrm{DOC}_{\mathrm{c}}$ is a good general estimate of the $\mathrm{DOC}$, but the $\mathrm{DOC}_{\mathrm{c}}$ tends to the overestimate the $\mathrm{DOC}$ at varying degrees depending on the coefficients applied. Overestimations are expected since Hallermeier was trying to estimate the deepest location of the DOC, but it is also important to understand the data that are used to calculate the $\mathrm{DOC}_{\mathrm{c}}$. The $\mathrm{DOC}_{\mathrm{c}}$ is determined by an average offshore wave condition estimated by the Wavewatch III model at 19 locations alongshore. Increasing the locations of wave estimations would not improve the differences in Table 4-3 since the waves were consistently decreasing from north to south. True wave measurements throughout the study area would confirm the effectiveness of Equations 4-1 and 4-2, but these measurements are extremely expensive and not available for this study. Hydrodynamic measurements during storm conditions are needed to confirm these findings.

Hurricanes often induce storm waves with large heights and long periods. Therefore, the depth of closure for storm wave conditions is larger than those from a typical annual wave condition. Wave heights and periods are spatially linked to the hurricane tracks; the closer the hurricane, the larger the wave height and period. This study is no exception, as locations to the north experience larger wave heights and periods than those to the south. To calculate a more average wave condition, Hallermeier 
suggested using the significant wave height that is exceeded only 12 hours per year. This study was limited to peak wave heights during the hurricanes, and therefore represents a larger wave field and deeper calculated DOC. Nicholls took into account 12 hour and peak waves, and recalculated $a$ and $b$ for Equation 4-1 for each. His coefficients best match the measured DOC, but using the peak wave coefficients did not significantly improve the $\mathrm{DOC}_{\mathrm{c}}$ (Table 4-2). The large overestimations of the DOC could be explained by the lack of wave measurements close to the study area, but they also suggest that other controls like geology determine the DOC location.

Closer examination of the geomorphic maps shows sandy areas that are often broken by hard ground (Figure 4-2, right). It is at the hard grounds where change is minimized, and change seaward of these locations is assumed to be small. Figures 4-5 and 4-6 demonstrate that hard ground matches the LOC and DOC between 50 and $92 \mathrm{~km}$. Although the average offset between the LOC and hard ground for this location is between 90 and $98 \mathrm{~m}$ (Table 4-4), the average vertical difference between the DOC and hard ground is less than $2.3 \mathrm{~m}$ (Table 4-5). These areas are dominated by nearshore hard grounds that are within $200 \mathrm{~m}$ of the shoreline. Further north, the hard grounds are less continuous and move offshore, and there is no surprise that the DOC is located further offshore. It is at these locations (north of $40 \mathrm{~km}$, Figures 4-5 and 4-6) that diabathic channels match the LOC and DOC. Since diabathic channels are storm deposits that represent the seaward limit of wave-sediment suspension and change is limited seaward of hard grounds, the geologic maps confirm the DOC that was extracted from the ALB data is most likely the true DOC (Table 4-5). 


\section{CONCLUSIONS}

Changes in bathymetry were measured along the southeastern Florida coast from two ALB data sets collected before and after the 2004 hurricane season. Contours were extracted from the change grid to represent the measured location of closure, or LOC. Noise in the ALB data limit the vertical resolution of the change grid. Measurement of the LOC from ALB data is possible when analyzing changes greater than $\pm 0.3 \mathrm{~m}$. The DOC is the depth that corresponds to the LOC.

The DOC is highly variable alongshore, and a single transect cannot adequately measure the DOC. The observed DOC matches the general trend calculated from models, but the overestimations in the depth suggest that it is not exclusively determined by waves and that wave models combined with DOC coefficients do not sufficiently estimate the DOC for southeast Florida. The geomorphic map matches the DOC extremely well. North of Boca Raton Inlet, the landward limit of the hydrodynamically formed diabathic channels confirm the DOC extracted from ALB data is the true DOC. South of Hillsboro Inlet, structural sand flats and rock outcrops match the DOC. It is evident that a mixture of hydrodynamic and geologic control determines the DOC position for southeast Florida. Higher resolution hydrodynamic data are needed to fully understand how water affects sediment movement. Potential sand mining sites for future beach replenishment projects should be located seaward of the landward boundaries of the diabathic channels and nearshore reefs. 


\section{SUMMARY}

This dissertation quantified coastal change with airborne laser data, and applied those numbers to answer specific scientific questions. The advantage of using shorelines to measure coastal change is that the measurements can be compared to existing databases of shoreline position that often extend back many decades. The long-term data set provides researchers the evidence they need to determine if recent shoreline change is part of a yearly or decadal trend. However, when analyzing shoreline change, it is often assumed that seaward shoreline migration corresponds to net sediment erosion, whereas landward shoreline migration indicates accretion. This assumption was tested in Chapter 2 where shoreline and beach volume change caused by the 2004 hurricane season in Palm Beach County, southeast Florida. In general, little correlation was found between shoreline and volume change, with some correlation in the southern section before the hurricane season. The poor correlation of change during the hurricane season was expected since shoreline response to a hurricane event is usually erratic. But the low correlations before the hurricane season suggest that shoreline change is not necessarily linked to volume change. Since volume change was analyzed from the dune toe to furthest extent of the ALB data, it is reasonable to assume that either overwash or seaward transport of sediments could have increased the quantified volume loss and subsequently lessened the correlation.

Western Bay County (Florida panhandle) beaches that were over $100 \mathrm{~km}$ away from hurricane landfall with minimal to no overwash were analyzed in Chapter 3. The setting represented more normal storm conditions and not the catastrophic conditions endured by beaches significantly closer to Hurricane Ivan's landfall. With five airborne 
laser data sets before and after the 2004 hurricane season, the study in Chapter 3 was able to determine if landward shoreline migration due to hurricane impacts matched the seaward shoreline migration during recovery. Low spatial correlation was found between shoreline migration before and after the storm event indicating that the beaches did not recover immediately following a hurricane impact. However, the study in Chapter 2 indicated that shoreline and volume change were not necessarily linked, and the five airborne laser data sets allow for a direct comparison between beach widths with subaerial volume. Although only 66 out of the 237 transects were determined to be statistically significant, the range of those measurements indicate that the relationship between beach width and subaerial volume change is spatially variable, and application of a single coefficient to describe the relationship is not possible when describing a beach. The findings in Chapters 2 and 3 are further evidence that it is improper to use shoreline data following storms since they do not accurately represent the beach volume. Long-term shoreline change studies should only utilize shoreline positions that were not affected by storms.

The development of alongshore quantification of beach volume change in Chapter 2 provided the means to directly compare measurements to shoreline change, but the change in each bin was limited to net change. A new ratio was proposed in Chapter 3 to describe the volume change characteristics of beach profile change. By dividing the net change by the amount of redistributed sediments, the sign of the quotient indicates positive or negative net change, and the amount of the quotient indicates if the bin change was dominated by sediment redistribution or an increase/decrease in sediments. The average quotient, or $R_{V}$, was -0.06 , indicating that most sediments were redistributed and 
few sediments were transported out of the bins. Since most sediment remained close to the coastline, it appears that ALB data can locate the depth of closure (DOC).

Two high resolution ALB flights were flown before and after the 2004 hurricane season in southeast Florida, and their extensive offshore coverage allow for locating and extracting the DOC. A method for measuring the DOC was developed in Chapter 4 given the measurement noise levels at approximately $\pm 0.3 \mathrm{~m}$. The DOC was compared to calculated DOCs and geologic units. Results show that the DOC closely matches hard ground, but north of Hillsboro Inlet represents a transition zone between geologic and hydrodynamic control. North of Boca Raton Inlet diabathic channels most closely match the DOC. Diabathic channels are storm deposits composed of sand from the subaerial beach that result from strong offshore underflow caused by high waves and winds. Despite the fact that the geologic map best indicates where the DOC is located north of Boca Raton Inlet, the DOC is hydrodynamically controlled for this area since diabathic channels are storm deposits. South of Hillsboro Inlet, however, the DOC is geologically determined by structural sand flats and reefs. Hydrodynamic data is needed to confirm these results to actual water movement during storm events.

Limitations in data derived from airborne laser measurements include vertical and horizontal resolution, in addition to the lack of temporal resolution and area coverage. Topographic airborne laser systems typically have noise levels between 0.05 and $0.1 \mathrm{~m}$, and ALB system noise ranges between 0.05 and $0.3 \mathrm{~m}$. Sources for the noise include laser resolution, GPS drift and inertial measurement drift which is compounded by increased scan angle, and incorrect calibration coefficients. ALB data also have to correct for light refraction and changing water levels. Over time the noise levels are 
reduced due to an increase in data acquisition and processing experience. Noise levels in topographic data can be minimized by shifting the data to a known elevation on unchanged surfaces (i.e. roads). However, ALB data measure the sea floor and locations of unchanged surfaces are difficult to locate or control. Therefore, it is complicated to reduce noise levels and change less than $\pm 0.3 \mathrm{~m}$ is probably not resolvable.

The most significant airborne laser limitation is temporal resolution and areas covered. The five airborne laser data sets measuring western Bay County are atypical, and more data are needed to increase the significance of the variability in the linear relationship between subaerial volume and beach width. All shoreline and volume change studies would benefit from the increased temporal resolution by lengthening the trends analyzed. An increase in the areas measured is also needed. Results were limited in Chapter 4 by the lack of data in the immediate vicinity of the DOC. Decadal monitoring of seabed morphology in the areas surrounding the DOC would help confirm the DOC position and significantly aid coastal engineering projects. Future coastal studies using airborne laser data will also benefit from increasing sample rates. Airborne laser systems today sample at rates greater than $100 \mathrm{kHz}$ and measure the surface of the earth at a point spacing less than 1 meter. The increase in horizontal resolution will allow for finer resolution DEMs and lead to quantification of higher frequencies of change. 


\section{LIST OF REFERENCES}

Aagaard, T., A. Kroon, S. Andersen, R.M. Sorensen, S. Quartel and N. Vinther, 2005. Intertidal beach change during storm conditions; Egmond, The Netherlands. Marine Geology, 218(1-4): 65-80.

Aubrey, D.G., 1979. Seasonal patterns of onshore/offshore sediment movement. Journal of Geophysical Research, 84(C10): 6347-6354.

Benedet, L., T. Campbell, C.W. Finkl, M.J.F. Stive and R. Spadoni, 2005. Impacts of Hurricanes Frances and Jeanne on two nourished beaches along the southeast Florida coast. Shore \& Beach, 73(2\&3): 43-48.

Benedet, L., C.W. Finkl, T. Campbell and A. Klein, 2004. Predicting the effect of beach nourishment and cross-shore sediment variation on beach morphodynamic assessment. Coastal Engineering, 51(8-9): 839-861.

Beven, J.L., 2004. Tropical cyclone report: Hurricane Frances, National Hurricane Center, Miami, 28 pp.

Birkemeier, W.A., 1985. Field data on the seaward limit of profile change. Journal of Waterway, Port, Coastal and Ocean Engineering, 111(3): 598-602.

Brock, J.C., C.W. Wright, A.H. Sallenger, W.B. Krabill and R.N. Swift, 2002. Basis and methods of NASA airborne topographic mapper lidar surveys for coastal studies. Journal of Coastal Research, 18(1): 1-13.

Browder, A.G. and J.E. McNinch, 2006. Linking framework geology and nearshore morphology: Correlation of paleo-channels with shore-oblique sandbars and gravel outcrops. Marine Geology, 231(1-4): 141-162.

Brown, K.E., 1998. Morphological analysis of beach profiles in relation to shoreline change. Master of Science Thesis, Florida Atlantic University, Boca Raton, 144 pp.

Crowell, M., S.P. Leatherman and M.K. Buckley, 1991. Historical shoreline change: error analysis and mapping accuracy. Journal of Coastal Research, 7(3): 839-852.

Davis, R.A., 1997. Geology of the Florida coast. In: A.F. Randazzo and D.S. Jones (Editors), The Geology of Florida. University Press of Florida, Miami, 155-168.

Dean, R.G., J. Cheng and S. Malakar, 1998. Characteristics of shoreline change along the sandy beaches of the State of Florida: an atlas. UFL/COEL-98/015, University of Florida, Gainesville, 302 pp. 
Dingler, J.R. and T.E. Reiss, 2002. Changes to Monterey Bay beaches from the end of the 1982-83 El Nino through the 1997-98 El Nino. Marine Geology, 181(1-3): 249263.

FDEP, 2006. Critically eroded beaches in Florida, Florida Department of Environmental Protection, Tallahassee, $74 \mathrm{pp}$.

Finkl, C.W., 1993. Pre-emptive strategies for enhanced sand bypassing and beach replenishment activities in southeast Florida: a geological perspective. Journal of Coastal Research, SI 18(1): 59-89.

Finkl, C.W., 2004. Leaky valves in littoral sediment budgets: Loss of nearshore sand to deep offshore zones via chutes in barrier reef systems, southeast coast of Florida, USA. Journal of Coastal Research, 20(2): 605-611.

Finkl, C.W., L. Benedet and J.L. Andrews, 2005a. Interpretation of seabed geomorphology based on spatial analysis of high-density airborne laser bathymetry. Journal of Coastal Research, 21(3): 501-514.

Finkl, C.W., L. Benedet and J.L. Andrews, 2005b. Submarine geomorphology of the continental shelf off southeast Florida based on interpretation of airborne laser bathymetry. Journal of Coastal Research, 21(6): 1178-1194.

Finkl, C.W., L. Benedet and J.L. Andrews, 2006a. Impacts of high energy events on sediment budgets, beach systems and offshore sand resources along the southeast coast of Florida. ICCE 2006 Proceedings, Coastal Engineering Research Council, San Diego: in press.

Finkl, C.W., L. Benedet and T.J. Campbell, 2006b. Beach nourishment experience in the United States: status and trends in the 20th Century. Shore \& Beach, 74(2): 8-16.

Finkl, C.W. and M.T. Warner, 2005. Morphologic features and morphodynamic zones along the inner continental shelf of Southeastern Florida: An example of form and process controlled by lithology. Journal of Coastal Research, Special Issue(42): 79-96.

Galgano, F.A., B.C. Douglas and S.P. Leatherman, 1998. Trends and variability of shoreline position. Journal of Coastal Research, Special Issue(26): 282-291.

Hallermeier, R.J., 1977. Calculating a yearly limit depth to the active beach profile. 77-9, Army Corps of Engineers, Fort Belvoir, 28 pp.

Hallermeier, R.J., 1978. Uses for a calculated limit depth to beach erosion. Sixteenth Conference on Coastal Engineering Proceedings, ASCE, Hamburg Germany: 2, 1493-1512. 
Hallermeier, R.J., 1981a. Critical wave conditions for sand motion initiation. CETA 8110, Coastal Engineering Research Center, Fort Belvoir, 16 pp.

Hallermeier, R.J., 1981b. A profile zonation for seasonal sand beaches from wave climate. Coastal Engineering, 4: 253-277.

Hunt, C.B., 1974. Natural regions of the United States and Canada. W.H. Freeman, San Francisco, $725 \mathrm{pp}$.

Irish, J.L., J.K. McClung and W.J. Lillycrop, 2000. Airborne lidar bathymetry: the SHOALS system. PIANC Bulletin, 103: 43-53.

Irish, J.L. and T.E. White, 1998. Coastal engineering applications of high-resolution lidar bathymetry. Coastal Engineering, 35(1-2): 47-71.

Jackson, D.W.T., J.A.G. Cooper and L. del Rio, 2005. Geological control of beach morphodynamic state. Marine Geology, 216(4): 297-314.

Jarrett, J.T., 1991. Coastal sediment budget analysis techniques. Coastal Sediments '91 Proceedings, USACE, New York, NY, 2223-2233.

King, C.A.M., 1972. Beaches and coasts. St. Martin's Press, New York, 570 pp.

Komar, P.D., 1998. Beach Processes and Sedimentation. Prentice Hall, Upper Saddle River, NJ, 544 pp.

Larson, M. and N.C. Kraus, 2000. Representation of non-erodible (hard) bottoms in beach profile change modeling. Journal of Coastal Research, 16(1): 1-14.

Lawrence, M.B. and H.D. Cobb, 2005. Tropical cyclone report: Hurricane Jeanne, National Hurricane Center, Miami, 20 pp.

Leadon, M.E., 2004. Hurricane Ivan, beach and dune erosion and structural damage assessment and post-storm recovery plan for the panhandle coast of Florida, Florida Department of Environmental Protection, Tallahassee, $61 \mathrm{pp}$.

Leatherman, S.P., 2003. Shoreline change mapping and management along the U.S. East Coast. Journal of Coastal Research, Special Issue(38): 5-13.

Lee, G.H., R.J. Nicholls and W.A. Birkemeier, 1998. Storm-driven variability of the beach-nearshore profile at Duck, North Carolina, USA, 1981-1991. Marine Geology, 148(3-4): 163-177.

List, J., A.H. Farris and C. Sullivan, 2006. Reversing storm hotspots on sandy beaches: Spatial and temporal characteristics. Marine Geology, 226(3-4): 261-279. 
Mitchell, D.A., W.J. Teague, E. Jarosz and D.W. Wang, 2005. Observed currents over the outer continental shelf during Hurricane Ivan. Geophysical Research Letters, 32(11): L11610.

Moore, L.J., 2000. Shoreline mapping techniques. Journal of Coastal Research, 16(1): 111-124.

Moore, L.J., P. Ruggiero and J.H. List, 2006. Comparing mean high water and high, water line shorelines: Should proxy-datum offsets be incorporated into shoreline change analysis. Journal of Coastal Research, 22(4): 894-905.

Morton, R.A., J.C. Gibeaut and J.G. Paine, 1995. Mesoscale transfer of sand during and after storms - implications for prediction of shoreline movement. Marine Geology, 126(1-4): 161-179.

Morton, R.A., M.P. Leach, J.G. Paine and M.A. Cardoza, 1993. Monitoring beach changes using GPS surveying techniques. Journal of Coastal Research, 9(3): 702720 .

Morton, R.A. and T.L. Miller, 2005. National assessment of shoreline change: part 2. 2055-1401, USGS, St. Petersburg, 35 pp.

Morton, R.A., J.G. Paine and J.C. Gibeaut, 1994. Stages and durations of post-storm beach recovery, southeastern Texas coast, USA. Journal of Coastal Research, 10(4): 884-908.

Nicholls, R.J., W.A. Birkemeier and G.H. Lee, 1998. Evaluation of depth of closure using data from Duck, NC, USA. Marine Geology, 148(3-4): 179-201.

Optech, 2004. Field Test Report for CHARTS. 0020905/Rev A, Optech Inc., Toronto, 76 pp.

Pajak, M.J. and S. Leatherman, 2002. The high water line as shoreline indicator. Journal of Coastal Research, 18(2): 329-337.

Pilkey, O.H., R.S. Young, S.R. Riggs, A.W.S. Smith, H.Y. Wu and W.D. Pilkey, 1993. The concept of shoreface profile of equilibrium - a critical review. Journal of Coastal Research, 9(1): 255-278.

Riggs, S.R., W.J. Cleary and S.W. Snyder, 1995. Influence of inherited geologic framework on barrier shoreface morphology and dynamics. Marine Geology, 126(1-4): 213-234.

Robertson, W., D. Whitman, K.Q. Zhang and S.P. Leatherman, 2004. Mapping shoreline position using airborne laser altimetry. Journal of Coastal Research, 20(3): 884892. 
Robertson, W., K. Zhang and D. Whitman, 2007. Hurricane-induced beach change derived from airborne laser measurements near Panama City, Florida. Marine Geology, 237(3-4): 191-205.

Robertson, W., K. Zhang, D. Whitman and S.P. Leatherman, 2005. Shoreline and beach volume change before and after the 2004 hurricane season, Palm Beach County, Florida. Shore \& Beach, 73(2-3): 79-84.

Rosati, J.D., 2005. Concepts in sediment budgets. Journal of Coastal Research, 21(2): 307-322.

Sallenger, A.H., W.B. Krabill, R.N. Swift, J. Brock, J. List, M. Hansen, R.A. Holman, S. Manizade, J. Sontag, A. Meredith, K. Morgan, J.K. Yunkel, E.B. Frederick and H. Stockdon, 2003. Evaluation of airborne topographic lidar for quantifying beach changes. Journal of Coastal Research, 19(1): 125-133.

Schmidt, W., 1997. Geomorphology and physiography of Florida. In: A.F. Randazzo and D.S. Jones (Editors), The Geology of Florida. University Press of Florida, Miami, $1-12$.

Scott, T.M., 1997. Miocene to Holocene history of Florida. In: A.F. Randazzo and D.S. Jones (Editors), The Geology of Florida. University Press of Florida, Miami, 5767.

Shalowitz, A.L., 1964. Shore and sea boundaries, U.S. Department of Commerce, Washington D.C., 749 pp.

Shepard, F.P., 1950. Beach cycles in southern California, U.S. Army Corps of Engineers, $26 \mathrm{pp}$.

Shrestha, R.L. and W. Carter, 1998. Instant evaluation of beach storm damage. Earth Observation Magazine, March(1): 42-44.

Shrestha, R.L., W.E. Carter, M. Lee, P. Finer and M. Sartori, 1999. Airborne laser swath mapping: accuracy assessment for surveying and mapping applications. Journal of American Congress for Surveying and Mapping, 59(2): 83-94.

Stockdon, H.F., A.H. Sallenger, J.H. List and R.A. Holman, 2002. Estimation of shoreline position and change using airborne topographic lidar data. Journal of Coastal Research, 18(3): 502-513.

Swales, A., 2002. Geostatistical estimation of short-term changes in beach morphology and sand budget. Journal of Coastal Research, 18(2): 338-351.

Teague, W.J., E. Jarosz, T.R. Keen, D.W. Wang and M.S. Hulbert, 2006. Bottom scour observed under Hurricane Ivan. Geophysical Research Letters, 33(7): L07607. 
Thevenot, M.M. and N.C. Kraus, 1995. Longshore sand waves at Southampton Beach, New York: observation and numerical simulation of their movement. Marine Geology, 126(1-4): 249-269.

Thieler, E.R., A.L. Brill, W.J. Cleary, C.H. Hobbs and R.A. Gammisch, 1995. Geology of the Wrightsville Beach, North-Carolina Shoreface - Implications for the Concept of Shoreface Profile of Equilibrium. Marine Geology, 126(1-4): 271-287.

Thom, B.G. and W. Hall, 1991. Behaviour of beach profiles during accretion and erosion dominated periods. Earth Surface Processes and Landforms, 16: 113-127.

Tolman, H.L., 1992. Effects of numerics on the physics in a 3rd-generation wind-wave model. Journal of Physical Oceanography, 22(10): 1095-1111.

White, S.A. and Y. Wang, 2003. Utilizing DEMs derived from LIDAR data to analyze morphologic change in the North Carolina coastline. Remote Sensing of Environment, 85(1): 39-47.

White, W.A., 1970. The geomorphology of the Florida Peninsula. Geological Bulletin No. 51. Designers Press, Orlando, 164 pp.

Whitman, D., K. Zhang, S. Leatherman and W. Robertson, 2003. An airborne laser topographic mapping application to hurricane storm surge hazard. In: G. Heigen, R. Fakundin and J. Sutter (Editors), Earth Science in the City. AGU, Washington, DC, 444.

Winant, C.D., D.L. Inman and C.E. Nordstrom, 1975. Description of seasonal beach changes using empirical eigenfunctions. Journal of Geophysical Research, 80(15): 1979-1986.

Woolard, J.W. and J.D. Colby, 2002. Spatial characterization, resolution, and volumetric change of coastal dunes using airborne LIDAR: Cape Hatteras, North Carolina. Geomorphology, 48(1-3): 269-287.

Wozencraft, J.M. and W.J. Lillycrop, 2003. SHOALS airborne coastal mapping: Past, present, and future. Journal of Coastal Research, Special Issue(38): 207-215.

Zhang, K., W. Huang, B.C. Douglas and S.P. Leatherman, 2002. Shoreline position variability and long-term trend analysis. Shore \& Beach, 70(1): 31-35.

Zhang, K. and D. Whitman, 2005. Comparison of three algorithms for filtering airborne lidar data. Photogrammetric Engineering and Remote Sensing, 71(3): 313-324.

Zhang, K.Q., S.C. Chen, D. Whitman, M.L. Shyu, J.H. Yan and C.C. Zhang, 2003. A progressive morphological filter for removing nonground measurements from airborne LIDAR data. IEEE Transactions on Geoscience and Remote Sensing, 41(4): 872-882. 
Zhang, K.Q., D. Whitman, S. Leatherman and W. Robertson, 2005. Quantification of beach changes caused by Hurricane Floyd along Florida's Atlantic coast using airborne laser surveys. Journal of Coastal Research, 21(1): 123-134. 
VITA

\section{WILLIAM ROBERTSON V}

1995

Guest Student, Woods Hole Oceanographic Institution (WHOI)

Research Assistant, University of Pennsylvania

1996

Geology Field Camp, University of Pennsylvania

Student Internship, WHOI

1997

B.A., Geology: Skidmore College, Saratoga Springs, NY

Research Assistant, WHOI

1999 Graduate Student, Department of Earth Sciences at Florida International University (FIU)

Research Assistant, International Hurricane Research Center (IHRC), FIU

2002

M.S., Geology: FIU, Miami, FL

Research Associate, IHRC, FIU

Ph.D. Candidate, Department of Earth Sciences, FIU

2004 Certificate in Geographic Information Systems: FIU, Miami, FL

\section{PUBLICATIONS AND PRESENTATIONS}

Aubrey, D.G. and W. Robertson (presenter), 1997. Historical analysis of changes in Nauset Inlet, outer Cape Cod. Coastal Landform Management in Massachusetts Meeting, Woods Hole, MA.

Robertson, W. Preparing LIDAR data for analysis in GIS. 2006 Governor's Hurricane Conference, Ft. Lauderdale, FL.

Robertson, W. and D. Aubrey, 1999. Use of vertical aerial photographs to calculate shoreline erosion rates at Nauset Beach, MA: implications for management. Geological Society of America Northeast Regional Meeting, Providence, RI.

Robertson, W., D. Whitman, 2004. Terrain modeling for storm surge prediction using light detection and ranging (LIDAR). $18^{\text {th }}$ Annual Governor's Hurricane Conference, Tampa, FL. 
Robertson, W., D. Whitman, K. Zhang, S. Leatherman, 2002. Comparison of aerial photographic wet-dry line extraction with projection of water levels onto LIDAR data. Seventh International Conference on Remote Sensing for Marine and Coastal Environments, Miami, FL.

Robertson, W., D. Whitman, K. Zhang, S. Leatherman, 2002. The use of airborne laser altimetry to measure shoreline position in North and South Carolina. Seventh International Conference on Remote Sensing for Marine and Coastal Environments, Miami, FL.

Robertson, W., D. Whitman, K. Zhang, and S. Leatherman, 2004. Shoreline position measurement by airborne laser altimetry in North and South Carolina. Journal of Coastal Research, 20(3), 884-892.

Robertson, W., K. Zhang, S. Leatherman, D. Whitman, 2006. Airborne laser derived shoreline and volume changes caused by Hurricane Charley. ICCE 2006, San Diego, CA.

Robertson, W., K. Zhang, and D. Whitman, 2007. Hurricane induced shoreline and beach volume change near Panama City, Florida. Marine Geology, 237(3-4), 191-205.

Robertson, W., K. Zhang, D. Whitman, S. Leatherman, 2005. Beach recovery rates derived from airborne LIDAR following Hurricane Ivan. Fall American Geophysical Union Meeting, San Francisco, CA.

Robertson, W., K. Zhang, D. Whitman, and S. Leatherman, 2005. Shoreline and beach volume change before and after the 2004 hurricane season, Palm Beach County, Florida. Shore \& Beach, 73(2\&3), 79-84.

Whitman, D., K. Zhang, S.P. Leatherman, and W. Robertson, 2003. An airborne laser topographic mapping application to hurricane storm surge hazard. In: Earth Science in the City. G. Heigen, R. Fakundin, and J. Sutter (eds), American Geophysical Union, 363377.

Whitman, D., K. Zhang, W. Robertson (presenter), 2001. Processing and analysis techniques for coastal topographic airborne laser data. Coastal Geotools '01, Charleston, $\mathrm{SC}$.

Zhang, K., D. Whitman, S.P. Leatherman, and W. Robertson, 2005. Quantification of the changes caused by Hurricane Floyd along Florida's Atlantic coast using airborne laser surveys. Journal of Coastal Research, 21(1), 123-134. 